Cochrane Database of Systematic Reviews

\title{
Early versus delayed selective surfactant treatment for neonatal respiratory distress syndrome (Review)
}

Bahadue FL, Soll R

Bahadue FL, Soll R.

Early versus delayed selective surfactant treatment for neonatal respiratory distress syndrome.

Cochrane Database of Systematic Reviews 2012, Issue 11. Art. No.: CD001456.

DOI: 10.1002/14651858.CD001456.pub2.

www.cochranelibrary.com 
TABLE OF CONTENTS

HEADER

ABSTRACT

PLAIN LANGUAGE SUMMARY

BACKGROUND

OBJECTIVES

METHODS

RESULTS

DISCUSSION

AUTHORS' CONCLUSIONS

ACKNOWLEDGEMENTS

\section{REFERENCES}

\section{CHARACTERISTICS OF STUDIES}

\section{DATA AND ANALYSES}

Analysis 1.1. Comparison 1 Early versus delayed selective surfactant treatment, Outcome 1 Neonatal mortality. .....................

Analysis 1.2. Comparison 1 Early versus delayed selective surfactant treatment, Outcome 2 Mortality at discharge. ................

Analysis 1.3. Comparison 1 Early versus delayed selective surfactant treatment, Outcome 3 Bronchopulmonary dysplasia. ....

Analysis 1.4. Comparison 1 Early versus delayed selective surfactant treatment, Outcome 4 BPD or death at 28 to 30 days. ....

Analysis 1.5. Comparison 1 Early versus delayed selective surfactant treatment, Outcome 5 Chronic lung disease. .................

Analysis 1.6. Comparison 1 Early versus delayed selective surfactant treatment, Outcome 6 CLD or death at 36 weeks' PMA. ...

Analysis 1.7. Comparison 1 Early versus delayed selective surfactant treatment, Outcome 7 Any air leak syndrome.

Analysis 1.8. Comparison 1 Early versus delayed selective surfactant treatment, Outcome 8 Pneumothorax.

Analysis 1.9. Comparison 1 Early versus delayed selective surfactant treatment, Outcome 9 Pulmonary interstitial emphysema.

Analysis 1.10. Comparison 1 Early versus delayed selective surfactant treatment, Outcome 10 Pulmonary hemorrhage. ........

Analysis 1.11. Comparison 1 Early versus delayed selective surfactant treatment, Outcome 11 Patent ductus arteriosus. ........

Analysis 1.12. Comparison 1 Early versus delayed selective surfactant treatment, Outcome 12 Confirmed bacterial sepsis. ....

Analysis 1.13. Comparison 1 Early versus delayed selective surfactant treatment, Outcome 13 Necrotizing enterocolitis. ........

Analysis 1.14. Comparison 1 Early versus delayed selective surfactant treatment, Outcome 14 Intraventricular hemorrhage (any).

Analysis 1.15. Comparison 1 Early versus delayed selective surfactant treatment, Outcome 15 Intraventricular hemorrhage (severe).

Analysis 1.16. Comparison 1 Early versus delayed selective surfactant treatment, Outcome 16 Periventricular leukomalacia. ..

Analysis 1.17. Comparison 1 Early versus delayed selective surfactant treatment, Outcome 17 Retinopathy of prematurity (any).

Analysis 1.18. Comparison 1 Early versus delayed selective surfactant treatment, Outcome 18 Retinopathy of prematurity stage 3 or greater.

Analysis 1.19. Comparison 1 Early versus delayed selective surfactant treatment, Outcome 19 Long-term follow-up.

Analysis 2.1. Comparison 2 Early versus delayed selective surfactant treatment in infants less than 30 weeks' gestation, Outcome 1 Neonatal mortality.

Analysis 2.2. Comparison 2 Early versus delayed selective surfactant treatment in infants less than 30 weeks' gestation, Outcome 2 Mortality at discharge.

Analysis 2.3. Comparison 2 Early versus delayed selective surfactant treatment in infants less than 30 weeks' gestation, Outcome 3 Chronic lung disease.

Analysis 2.4. Comparison 2 Early versus delayed selective surfactant treatment in infants less than 30 weeks' gestation, Outcome 4 CLD or death at 36 weeks' PMA.

Analysis 3.1. Comparison 3 Early versus delayed selective surfactant treatment by steroid exposure, Outcome 1 Neonatal mortality.

Analysis 3.2. Comparison 3 Early versus delayed selective surfactant treatment by steroid exposure, Outcome 2 Mortality at discharge.

Analysis 3.3. Comparison 3 Early versus delayed selective surfactant treatment by steroid exposure, Outcome 3 Bronchopulmonary dysplasia.

Analysis 3.4. Comparison 3 Early versus delayed selective surfactant treatment by steroid exposure, Outcome 4 BPD or death at 28 to 30 days. 
Analysis 3.5. Comparison 3 Early versus delayed selective surfactant treatment by steroid exposure, Outcome 5 Chronic lung disease.

Analysis 3.6. Comparison 3 Early versus delayed selective surfactant treatment by steroid exposure, Outcome 6 CLD or death at 36 weeks' PMA.

WHAT'S NEW

HISTORY 
[Intervention Review]

\section{Early versus delayed selective surfactant treatment for neonatal respiratory distress syndrome}

Felicia L Bahadue ${ }^{1}$, Roger Soll2

1University of Vermont, Burlington, Vermont, USA. 2Division of Neonatal-Perinatal Medicine, University of Vermont, Burlington, Vermont, USA

Contact address: Roger Soll, Division of Neonatal-Perinatal Medicine, University of Vermont, Fletcher Allen Health Care, Smith 552A, 111 Colchester Avenue, Burlington, Vermont, 05401, USA. Roger.Soll@vtmednet.org.

Editorial group: Cochrane Neonatal Group

Publication status and date: New search for studies and content updated (no change to conclusions), published in Issue 11, 2012.

Citation: Bahadue FL, Soll R. Early versus delayed selective surfactant treatment for neonatal respiratory distress syndrome. Cochrane Database of Systematic Reviews 2012, Issue 11. Art. No.: CD001456. DOI: 10.1002/14651858.CD001456.pub2.

Copyright @ 2012 The Cochrane Collaboration. Published by John Wiley \& Sons, Ltd.

\section{A B S T R A C T}

\section{Background}

Clinical trials have confirmed that surfactant therapy is effective in improving the immediate need for respiratory support and the clinical outcome of premature newborns. Trials have studied a wide variety of surfactant preparations used either to prevent (prophylactic or delivery room administration) or treat (selective or rescue administration) respiratory distress syndrome (RDS). Using either treatment strategy, significant reductions in the incidence of pneumothorax, as well as significant improvement in survival, have been noted. It is unclear whether there are any advantages to treating infants with respiratory insufficiency earlier in the course of RDS.

\section{Objectives}

To compare the effects of early versus delayed selective surfactant therapy for newborns intubated for respiratory distress within the first two hours of life. Planned subgroup analyses included separate comparisons for studies utilizing natural surfactant extract and synthetic surfactant.

\section{Search methods}

We searched the Oxford Database of Perinatal Trials, MEDLINE (MeSH terms: pulmonary surfactant; text word: early; limits: age, newborn: publication type, clinical trial), PubMed, abstracts, conference and symposia proceedings, expert informants, and journal handsearching in the English language. For the updated search in April 2012 we searched the Cochrane Central Register of Controlled Trials (CENTRAL, The Cochrane Library, 2012, Issue 1) and PubMed (January 1997 to April 2012).

\section{Selection criteria}

Randomized and quasi-randomized controlled clinical trials comparing early selective surfactant administration (surfactant administration via the endotracheal tube in infants intubated for respiratory distress, not specifically for surfactant dosage) within the first two hours of life versus delayed selective surfactant administration to infants with established RDS were considered for review.

\section{Data collection and analysis}

Data regarding clinical outcomes were excerpted from the reports of the clinical trials by the review authors. Subgroup analyses were performed based on type of surfactant preparation, gestational age, and exposure to prenatal steroids. Data analysis was performed in accordance with the standards of the Cochrane Neonatal Review Group. 


\section{Main results}

Six randomized controlled trials met selection criteria. Two of the trials utilized synthetic surfactant (Exosurf Neonatal) and four utilized animal-derived surfactant preparations.

The meta-analyses demonstrate significant reductions in the risk of neonatal mortality (typical risk ratio (RR) 0.84 ; $95 \%$ confidence interval (Cl) 0.74 to 0.95 ; typical risk difference (RD) $-0.04 ; 95 \% \mathrm{Cl}-0.06$ to $-0.01 ; 6$ studies; 3577 infants), chronic lung disease (typical RR $0.69 ; 95 \%$ $\mathrm{Cl} 0.55$ to 0.86 ; typical RD $-0.04 ; 95 \% \mathrm{Cl}-0.06$ to $-0.01 ; 3$ studies; 3041 infants), and chronic lung disease or death at 36 weeks (typical RR $0.83 ; 95 \% \mathrm{Cl} 0.75$ to 0.91 ; typical RD $-0.06 ; 95 \% \mathrm{Cl}-0.09$ to $-0.03 ; 3$ studies; 3050 infants) associated with early treatment of intubated infants with RDS.

Intubated infants randomized to early selective surfactant administration also demonstrated a decreased risk of acute lung injury including a decreased risk of pneumothorax (typical RR $0.69 ; 95 \% \mathrm{Cl} 0.59$ to 0.82 ; typical RD $-0.05 ; 95 \% \mathrm{Cl}-0.08$ to $-0.03 ; 5$ studies; 3545 infants), pulmonary interstitial emphysema (typical RR $0.60 ; 95 \% \mathrm{Cl} 0.41$ to $0.89 ;$ typical RD $-0.06 ; 95 \% \mathrm{Cl}-0.10$ to $-0.02 ; 3$ studies; 780 infants), and overall air leak syndromes (typical RR $0.61 ; 95 \% \mathrm{Cl} 0.48$ to 0.78 ; typical RD $-0.18 ; 95 \% \mathrm{Cl}-0.26$ to $-0.09 ; 2$ studies; 463 infants).

A trend toward risk reduction for bronchopulmonary dysplasia (BPD) or death at 28 days was also evident (typical RR $0.94 ; 95 \% \mathrm{Cl} 0.88$ to 1.00; typical RD $-0.04 ; 95 \% \mathrm{Cl}-0.07$ to $-0.00 ; 3$ studies; 3039 infants). No differences in other complications of RDS or prematurity were noted.

Only two studies reported on infants under 30 weeks' gestation. Decreased risk of neonatal mortality and chronic lung disease or death at 36 weeks' postmenstrual age was noted.

\section{Authors' conclusions}

Early selective surfactant administration given to infants with RDS requiring assisted ventilation leads to a decreased risk of acute pulmonary injury (decreased risk of pneumothorax and pulmonary interstitial emphysema) and a decreased risk of neonatal mortality and chronic lung disease compared to delaying treatment of such infants until they develop worsening RDS.

\section{PLAIN LANGUAGE SUMMARY}

\section{Early versus delayed selective surfactant treatment for neonatal respiratory distress syndrome}

Giving early selective surfactant to newborn babies on assisted ventilation who have early signs of respiratory distress syndrome (RDS) reduces the risk of short-term and longer-term lung injury.

Pulmonary surfactant is a substance that prevents the air sacs of the lungs from collapsing by reducing surface tension. Surfactant is often lacking in the lungs of newborn babies with RDS. The effectiveness of surfactant extracts in increasing their survival rate has been confirmed. The question remains about the best time to start giving surfactant. The review of trials compared early selective treatment of RDS (within the first two hours of life) to late selective treatment and found evidence of the benefit of early therapy. 


\section{B A C K G R O U N D}

\section{Description of the condition}

Respiratory distress syndrome (RDS) is caused by a deficiency or dysfunction of pulmonary surfactant. Surfactant lines the alveolar surface and prevents atelectasis at end expiration. Pulmonary surfactant is predominantly dipalmitoylphosphatidylcholine with lesser amounts of other phospholipids including phosphatidylglycerol (PG), phosphatidylethanolamine, and phosphatidylinositol. In addition, pulmonary surfactant also contains neutral lipids and four distinct surfactant proteins (SP-A, SP-B, SP-C, and SP-D). These proteins may play a role in surfactant secretion, recycling, cooperative functioning with other SPs and phospholipids (Possmayer 1990; Schurch 1992), and innate host defense of the lung (Wright 1997). The physiologic functions of surfactant include the ability to lower surface tension, and the ability to rapidly adsorb, spread, and reform a monolayer in the dynamic conditions associated with the respiratory cycle (Jobe 1993).

\section{Description of the intervention}

Clinical trials have confirmed that surfactant therapy is effective in improving the immediate need for respiratory support and the clinical outcome of premature newborns (Sinclair 1992). Trials have studied a wide variety of surfactant preparations used either prophylactically or in the treatment of established RDS. Using either treatment strategy, significant reductions in the incidence of pneumothorax, as well as significant improvement in survival, has been noted.

\section{How the intervention might work}

Although both prophylactic surfactant administration and surfactant treatment of infants with established RDS are successful treatment strategies, the original trials comparing treatment strategies appeared to demonstrate that prophylactic surfactant had greater clinical benefit. In one systematic overview of trials performed in the 1990s that compared prophylactic surfactant administration to surfactant treatment of established RDS, infants who received prophylactic therapy had a decreased incidence of pneumothorax, pulmonary interstitial emphysema (PIE), and mortality (Soll 2001). Selective treatment in infants with RDS ranged from 90 minutes to eight hours of age. In a more recent systematic review that included trials of prophylactic surfactant compared to early stabilization on nasal continuous positive airway pressure (CPAP), the advantages of prophylactic administration are no longer apparent (Rojas-Reyes 2012).

Earlier treatment of infants with evolving RDS may offer many of the advantages of prophylactic therapy. Early treatment may decrease the need for ventilatory support and avoid barotrauma that results from even short periods of assisted ventilation (Nilsson 1978). However, surfactant treatment reserved for infants with more severe RDS offers the advantage of treating only infants with serious clinical disease, eliminating the potential risks and costs of treating relatively mildly affected infants.

\section{Why it is important to do this review}

\section{Cochrane reviews that address trials of pulmonary surfactant in neonates}

Multiple systematic reviews have addressed the use of animal-derived surfactant preparations or synthetic surfactant preparations in the prevention or treatment of RDS. Meta-analyses of the original randomized controlled trials of surfactant for the treatment and prevention of RDS were first published in Effective Care of the Newborn (Soll 1992). Since then, multiple systematic reviews have been published in The Cochrane Library including reviews of protein-free synthetic surfactant for the prevention and treatment of RDS (Soll 2000; Soll 2010) and reviews of animalderived surfactant for the prevention and treatment of RDS (Soll 1997; Seger 2009).

Reviews that compare different surfactant preparations (Soll 2001; Pfister 2007; Pfister 2009; Singh 2011 (non-Cochrane review)) as well as different treatment strategies (Soll 1999; Stevens 2007; Soll 2009; Rojas-Reyes 2012) have been published.

A companion review to this systematic review addresses the clinical issue of prophylactic surfactant administration (intubation and surfactant administration to infants at high risk of developing RDS) compared to surfactant treatment of RDS (Rojas-Reyes 2012). In recent years, the increased utilization of prenatal steroids and the routine use of early continuous distending pressure may have changed the risk/benefit analysis of aggressive universal prophylactic intubation and treatment of infants at high risk of RDS.

This review evaluates early selective treatment of RDS (within the first two hours of life) compared with late selective treatment in infants with established RDS. The previous published version of this review was last updated in 1999 (Soll 1999).

Other reviews have addressed the method of instillation of surfactant (Abdel-Latif 2010; Abdel-Latif 2011; Abdel-Latif 2011a) as well as the use of surfactant replacement therapy in conditions other than RDS (Dargaville 2002; El Shahed 2007; Tan 2012).

\section{O B J E C T IVES}

To compare the effects of early versus delayed selective surfactant therapy for newborns intubated for respiratory distress within the first three hours of life.

Planned subgroup analyses include separate comparisons for studies that utilized animal-derived surfactant extract versus synthetic surfactant; studies enrolling infants $<30$ weeks' gestation, and studies that utilized prenatal steroids in more than half of the enrolled infants.

\section{METHODS}

\section{Criteria for considering studies for this review}

\section{Types of studies}

Prospective randomized controlled clinical trials or quasirandomized trials comparing early selective surfactant administration (surfactant administration via the endotracheal tube in infants intubated for respiratory distress, not specifically for surfactant dosage) within the first three hours of life with 
delayed selective surfactant administration to such infants when they develop worsening established RDS.

\section{Types of participants}

Preterm infants with RDS requiring intubation and assisted ventilation at less than three hours of life.

\section{Types of interventions}

Early selective surfactant administration (surfactant administration via the endotracheal tube in infants intubated for respiratory distress, not specifically for surfactant dosage), within the first three hours of life versus delayed selective administration to such infants when they develop established RDS.

Any surfactant product was eligible (synthetic surfactant, proteincontaining synthetic surfactant, animal-derived surfactant).

\section{Types of outcome measures}

\section{Primary outcomes}

1. Neonatal mortality (mortality $<28$ days of age) from any cause.

2. Mortality prior to hospital discharge (from any cause).

3. Bronchopulmonary dysplasia (BPD) (oxygen requirement at 28 to 30 days of age).

4. BPD or death prior to 28 to 30 days of age.

5. Chronic lung disease (CLD) (use of supplemental oxygen at 36 weeks' postmenstrual age).

6. CLD (use of supplemental oxygen at 36 weeks' postmenstrual age) or death prior to 36 weeks' postmenstrual age.

\section{Secondary outcomes}

1. Any air leak syndromes (including PIE, pneumothorax, pneumomediastinum).

2. Any pneumothorax.

3. Pulmonary interstitial emphysema.

4. Any pulmonary hemorrhage.

5. Patent ductus arteriosus (PDA) (that has been treated with cyclooxygenase inhibitor or surgery).

6. Any culture confirmed bacterial sepsis.

7. Any culture confirmed fungal sepsis.

8. Necrotizing enterocolitis (NEC) (defined as Bell Stage II or greater).

9. Intraventricular hemorrhage (IVH) (any grade and severe (grade 3 to 4$)$ ).

10.Periventricular leukomalacia (PVL).

11. Retinopathy of prematurity (ROP) (all stages and severe (stage 3 or greater)).

12. Number of doses per infant.

13. Cerebral palsy.

14. Neurodevelopmental outcome at approximately two years' corrected age (acceptable range 18 months to 28 months) including: cerebral palsy, mental retardation (Bayley Scales of Infant Development Mental Developmental Index < 70), legal blindness (<20/200 visual acuity), and hearing deficit (aided or $<60 \mathrm{~dB}$ on audiometric testing). The composite outcome "neurodevelopmental impairment" will be defined as having any one of the aforementioned deficits.
Post hoc outcome measures:

Limited data was available on long-term follow-up. The one study that reported on follow-up included the following clinically important outcomes that were added to our analysis post hoc:

1. visual impairment;

2. auditory impairment;

3. pathologic muscle tone;

4. pathologic walking.

In the 2012 update, the outcome "number of doses per infant" was deleted.

\section{Search methods for identification of studies}

See: Collaborative Review Group search strategy. The standard search method of the Cochrane Neonatal Review Group was used.

\section{Electronic searches}

Original search: searches were made of the Oxford Database of Perinatal Trials, MEDLINE 1985 through 1998 (MeSH terms: pulmonary surfactant; text word: early; limits: age, newborn: publication type, clinical trial), PubMed, abstracts, conference and symposia proceedings, expert informants, and journal handsearching in the English language.

Updated search: published manuscripts: we searched the Cochrane Central Register of Controlled Trials (CENTRAL, The Cochrane Library, 2012, Issue 1) and PubMed (January 1997 to April 2012). We included all languages. Search terms: \{surfactant OR pulmonary surfactant\}, limited to humans and further limited to the age group of newborn infants (infant, newborn) and type of publication (clinical trial). From the resulting studies, we selected randomized or quasi-randomized controlled studies that fulfilled the inclusion criteria. We performed a search using the following keywords: (outcome OR sequelae OR follow-up OR mental retardation OR cerebral palsy OR hearing OR visual OR motor OR mental OR psychological) AND (surfactant OR pulmonary surfactant) not limited to any age group or language to identify long-term neurodevelopmental sequelae. We searched the bibliography cited in each publication obtained in order to identify additional relevant articles.

\section{Searching other resources}

Published abstracts: we searched the abstracts of the Society for Pediatric Research (US) (published in Pediatric Research) for the years 1985 to 1999 by hand. We searched the abstracts from 2000 to 2012 electronically through the PAS website (abstractsonline) using the following key words: \{surfactant OR pulmonary surfactant $\}$ AND \{respiratory distress syndrome\}.

We also searched clinical trials registries for ongoing or recently completed trials (clinicaltrials.gov; controlled-trials.com; and who.int/ictrp).

\section{Data collection and analysis}

We used the standard methods of the Cochrane Neonatal Review Group in creating this update. 


\section{Selection of studies}

We included all randomized and quasi-randomized controlled trials fulfilling the selection criteria described in the previous section. Two review authors (FB and RS) reviewed the results of the search and separately selected the studies for inclusion. The review authors resolved any disagreement by discussion.

\section{Data extraction and management}

Two review authors separately extracted, assessed, and coded all data for each study using a form that was designed specifically for this review. For each included study, information was collected regarding the method of randomization, blinding, drug intervention, stratification, and whether the trial was conducted at a single center or multiple centers. Information regarding inclusion criteria, including gestational age, postnatal age at the time of treatment, and disease severity criteria for the rescue treatment group was noted. Information was collected on clinical outcomes including pneumothorax, PIE, PDA, sepsis, NEC, IVHs (any IVH and severe IVH), PVL, BPD (defined at 28 days), CLD (defined at 36 weeks' postmenstrual age) ROP, neonatal mortality, mortality prior to hospital discharge, and BPD or death. Long-term outcomes were sought, including neurodevelopmental outcome at approximately two years corrected age (acceptable range 18 months to 28 months) including: cerebral palsy, mental retardation (Bayley Scales of Infant Development Mental Developmental Index $<70$ ), legal blindness (<20/200 visual acuity), and hearing deficit (aided or $<60 \mathrm{~dB}$ on audiometric testing). The composite outcome "neurodevelopmental impairment" was defined as having any one of the aforementioned deficits.

Limited data were available on long-term follow-up. The one study that reported on follow-up included the following clinically important outcomes that were added to our analysis post hoc visual impairment, auditory impairment, pathologic muscle tone, and pathologic walking.

Differences in assessment were resolved by discussion. For each study, final data were entered into Review Manager software (RevMan 2011) by one review author and then checked by the second review author. Any disagreements were resolved by discussion.

\section{Assessment of risk of bias in included studies}

The standard methods of the Cochrane Neonatal Review Group were employed. The methodological quality of the studies were assessed using the following key criteria: allocation concealment (blinding of randomization), blinding of intervention, completeness of follow-up, and blinding of outcome measurement/assessment. For each criterion, assessment was yes, no, cannot determine. Two review authors separately assessed each study. Any disagreement was resolved by discussion. This information was added to the Characteristics of included studies table.

In addition, for the update in 2012, the following issues were evaluated and entered into the 'Risk of bias' table.

\section{1) Sequence generation (checking for possible selection bias). Was the allocation sequence adequately generated?}

For each included study, we categorized the method used to generate the allocation sequence as:
- adequate (any truly random process, e.g. random number table; computer random number generator);

- inadequate (any non random process, e.g. odd or even date of birth; hospital or clinic record number);

- unclear.

(2) Allocation concealment (checking for possible selection bias). Was allocation adequately concealed?

For each included study, we categorized the method used to conceal the allocation sequence as:

- adequate (e.g. telephone or central randomization; consecutively numbered sealed opaque envelopes);

- inadequate (open random allocation; unsealed or non-opaque envelopes, alternation, date of birth);

- unclear.

(3) Blinding (checking for possible performance bias). Was knowledge of the allocated intervention adequately prevented during the study? At study entry? At the time of outcome assessment?

For each included study, we categorized the methods used to blind study participants and personnel from knowledge of which intervention a participant received. Blinding was assessed separately for different outcomes or classes of outcomes. We categorized the methods as:

- adequate, inadequate, or unclear for participants;

- adequate, inadequate, or unclear for personnel;

- adequate, inadequate, or unclear for outcome assessors.

In some situations there may be partial blinding (e.g. where outcomes are self-reported by unblinded participants but they are recorded by blinded personnel without knowledge of group assignment). Where needed "partial" was added to the list of options for assessing quality of blinding.

(4) Incomplete outcome data (checking for possible attrition bias through withdrawals, drop-outs, protocol deviations). Were incomplete outcome data adequately addressed?

For each included study and for each outcome, we described the completeness of data including attrition and exclusions from the analysis. We noted whether attrition and exclusions were reported, the numbers included in the analysis at each stage (compared with the total randomized participants), reasons for attrition or exclusion where reported, and whether missing data were balanced across groups or were related to outcomes. Where sufficient information was reported or supplied by the trial authors, we re-included missing data in the analyses. We categorized the methods as:

- adequate (<20\% missing data);

- inadequate ( $\geq 20 \%$ missing data);

- unclear.

(5) Selective reporting bias. Are reports of the study free of suggestion of selective outcome reporting?

For each included study, we described how we investigated the possibility of selective outcome reporting bias and what we found. We assessed the methods as: 
- adequate (where it is clear that all of the study's prespecified outcomes and all expected outcomes of interest to the review have been reported);

- inadequate (where not all the study's prespecified outcomes have been reported; one or more reported primary outcomes were not prespecified; outcomes of interest are reported incompletely and so cannot be used; study fails to include results of a key outcome that would have been expected to have been reported);

- unclear.

(6) Other sources of bias. Was the study apparently free of other problems that could put it at a high risk of bias?

For each included study, we described any important concerns we had about other possible sources of bias (e.g. whether there was a potential source of bias related to the specific study design or whether the trial was stopped early owing to some datadependent process). We assessed whether each study was free of other problems that could put it at risk of bias as:

- yes;

- no;

- unclear.

If needed, we planned to explore the impact of the level of bias through undertaking sensitivity analyses.

\section{Measures of treatment effect}

We used the standard methods of the Cochrane Neonatal Review Group. We performed statistical analyses using Review Manager software (RevMan 2011). We analyzed categorical data using risk ratio (RR), risk difference (RD), the number needed to treat for an additional beneficial effect (NNTB), and the number to treat for an additional harmful effect (NNTH). We analyzed continuous data using weighted mean difference (WMD). We reported the 95\% confidence interval $(\mathrm{Cl})$ on all estimates.

\section{Assessment of heterogeneity}

We estimated the treatment effects of individual trials and examined heterogeneity between trials by inspecting the forest plots and quantifying the impact of heterogeneity using the 12 statistic. We graded the degree of heterogeneity as: $<25 \%$ no heterogeneity; $25 \%$ to $49 \%$ low heterogeneity; $50 \%$ to $75 \%$ moderate heterogeneity; and $>75 \%$; substantial heterogeneity. If we detected substantial statistical heterogeneity, we planned to explore the possible causes (e.g. differences in study quality, participants, intervention regimens, or outcome assessments) using post hoc subgroup analyses.

\section{Data synthesis}

The meta-analysis was performed using Review Manager software (RevMan 2011), supplied by The Cochrane Collaboration. We used the Mantel-Haenszel method for estimates of typical RR and RD. We used the inverse variance method for measured quantities. All meta-analyses were done using a fixed-effect model.

\section{Subgroup analysis and investigation of heterogeneity}

Comparison 1: studies that compared the effect of early selective surfactant administration (surfactant administration via the endotracheal tube in infants intubated for respiratory distress, not specifically for surfactant dosing) within the first three hours of life with delayed selective surfactant administration for worsening RDS in preterm infants

1. Studies that utilized synthetic surfactant (with or without protein).

2. Studies that utilized animal-derived surfactant.

Comparison 2: studies that compared the effect of early selective surfactant administration (surfactant administration via the endotracheal tube in infants intubated for respiratory distress, not specifically for surfactant dosing) within the first three hours of life with delayed selective surfactant administration for worsening RDS in preterm infants less than 30 weeks' gestation

1. Studies that utilized synthetic surfactant preparations (with or without protein).

2. Studies that utilized animal-derived surfactant preparations

Comparison 3: studies that compared the effect of early selective surfactant administration (surfactant administration via the endotracheal tube in infants intubated for respiratory distress, not specifically for surfactant dosing) within the first three hours of life with delayed selective surfactant administration for worsening RDS in preterm infants

1. Studies in which less than $50 \%$ of the enrolled infants received prenatal steroids.

2. Studies in which $50 \%$ or more of the enrolled infants received prenatal steroids.

\section{RESULTS}

\section{Description of studies}

Studies included in this review: European Study 1992; Konishi 1992; OSIRIS 1992; Gortner 1998; Plavka 2002; Lefort 2003.

\section{Results of the search}

Review did not include studies of prophylactic surfactant for infants at high risk of RDS or studies of spontaneously breathing infants who were intubated for the purpose of surfactant administration. These excluded studies were noted in the 'Characteristics of excluded studies' table.

\section{Included studies}

Studies included in this review: European Study 1992; Konishi 1992, OSIRIS 1992, Gortner 1998; Plavka 2002 and Lefort 2003. The details concerning each study are discussed below and included in the table 'Characteristics of included studies' and references. Only the study of Gortner 1998 reported on longer-term follow-up (Hentschel 2009).

\section{Studies with synthetic surfactant}

European study 1992

European Study 1992 was a randomized, double blind, placebocontrolled study that compared a policy of giving surfactant to all intubated babies of gestational age 26 to 29 weeks with a policy of treating only those babies developing RDS. A total of 420 babies were included in the study with 212 given early surfactant treatment and 208 babies given selective surfactant. The study 
involved blinded administration of either surfactant (colfosceril palmitate, Exosurf) or air placebo, within two hours of birth. Babies in either group developing RDS during the following 18 hours received two unblinded doses of surfactant 12 hours apart. Babies without RDS received a second dose of surfactant or air as originally randomized 18 hours after the first dose. The primary outcome of the trial was survival to age 28 days with an intact central nervous system (CNS), specifically without cranial ultrasound evidence of parenchymal cyst formation or post-hemorrhagic hydrocephalus. The secondary outcomes were incidence of RDS requiring rescue treatment, and the duration of intubation, intensive care, and oxygen therapy. In addition, the study measured and reported the following outcomes: any air leak syndrome (including PIE, pneumothorax, and pneumomediastinum), pneumothorax, PIE, PDA, and NEC. The use of prenatal steroids in each group was $24 \%$.

\section{OSIRIS 1992}

The aim of this randomized multicenter trial was to determine the best regimen for the administration of a synthetic surfactant in efforts to prevent and treat RDS (OSIRIS 1992). Of the 6774 babies recruited to the trial, the outcome was known for 6757 (99.7\%) infants. There were 2690 babies judged to be at high risk of RDS at less than two hours of age and these were randomly allocated to either early administration or delayed selective administration. These 2690 infants were further randomized in a factorial design to either two doses of surfactant 12 hours apart or the option of third and fourth doses at 12- to 36-hour intervals if signs of RDS persisted or recurred. There were another 4067 infants who later developed RDS who were also recruited to this comparison, giving a total of 3376 infants allocated up to four doses (of whom, $45 \%$ received more than two) and 3381 allocated two doses. The primary outcomes measured in this study were death or dependence on supplemental oxygen at 28 days of life, death at any time, and prolonged oxygen dependence. The secondary outcomes measured were major cerebral abnormality, pneumothorax, pulmonary hemorrhage, other air leak, treated PDA, recurrent apnoea, NEC, pneumonia diagnosed after 48 hours, neonatal seizures, and cryotherapy for ROP. The use of prenatal steroid was $23.3 \%$ in the early surfactant treatment group and $20.7 \%$ in the delayed surfactant treatment group.

\section{Studies with animal-derived surfactant}

\section{Konishi 1992}

The aim of this prospective, randomized, controlled study was to investigate if a single dose of surfactant given shortly after birth to infants with established surfactant deficiency would prevent progression of RDS and development of BPD (Konishi 1992). Thirtytwo neonates weighing $500 \mathrm{~g}$ to $1500 \mathrm{~g}$ with documented surfactant deficiency and without evidence of severe birth asphyxia, infection, prolonged rupture of membranes of 72 hours or longer, or oligohydramnios were randomly assigned to receive a single intratracheal dose of surfactant-TA $(100 \mathrm{mg} / \mathrm{kg})$ either within 30 minutes of birth ( $\mathrm{N}=16$, early group) or at six hours of age ( $\mathrm{N}$ $=16$, late group). The primary outcomes reported were neonatal mortality, BPD, air leaks, IVH, PDA, and ROP. None of the infants in the early treatment group received steroids. Only one of 16 infants received steroids in the delayed treatment group.

\section{Gortner 1998}

The aim of this randomized controlled multicenter clinical trial was to investigate whether early (< one hour after birth) surfactant administration would be superior to late treatment (two to six hours after birth) in preterm infants 27 to 32 weeks' gestational age (Gortner 1998). Animal-derived surfactant was given to 317 infants randomized to either early surfactant treatment (154 infants) or late surfactant treatment (163 infants).The primary outcome measured was time on mechanical ventilation. The secondary outcomes measured were survival until discharge, survival without BPD (i.e. supplemental oxygen or need for mechanical ventilation at 28 days), oxygen dependency at 36 weeks' postconceptional age, PIE, pneumothorax requiring chest tube drainage, pulmonary hemorrhage, and time on nasal CPAP. Further secondary outcomes included PDA, IVH, PVL, and ROP. The rate of prenatal steroid use was similar in both the early surfactant treatment group (79.9\%) and the late surfactant treatment group $(72.8 \%)$.

\section{Hentschel 2009}

This a follow-up study to the 1998 clinical trial by Gortner 1998 investigating whether neurodevelopmental outcome or pulmonary morbidity at two years of age might be different after early versus late surfactant treatment in intubated preterm infants with severe RDS. Of the original 317 infants, 185 ex-preterm infants of 27 to 32 completed weeks of gestation who were enrolled in a controlled trial of early versus late surfactant treatment were represented in this study for follow-up. This included a standardized follow-up of medical history, pulmonary morbidity, and neurodevelopmental outcome using the Griffiths scales. The outcomes measured included, but were not limited to auditory impairment, visual impairment, pathologic walking, and pathologic muscular tone. The rate of prenatal steroid use was similar in both the early surfactant treatment group (79.9\%) and the late surfactant treatment group (72.8\%) (Gortner 1998).

\section{Plavka 2002}

The aim of this randomized clinical trial was to determine whether early surfactant administration is superior to selective delayed treatment in terms of improving survival or reducing CLD, or both in extremely premature neonates with RDS treated by highfrequency oscillatory ventilation (HFOV) (Plavka 2002). The study included 43 extremely premature infants who needed artificial ventilation within three hours after delivery who were randomly assigned to either early $(\mathrm{N}=21)$ or delayed $(\mathrm{N}=22)$ administration of animal-derived surfactant. The secondary outcomes reported were: duration of mechanical ventilation, incidence of air leaks, pneumothorax, PIE, radiographic score according to the Toce scale at age 28 to 30 days, and the incidence of other complications of prematurity such as IVH, PVL, ROP, and NEC. The rate of prenatal steroid use was $48 \%$ in the early treatment group and $40 \%$ in the late treatment group.

\section{Lefort 2003}

The aim of the study was to perform a comparative analysis of the clinical outcome and study the effects of exogenous surfactant of premature infants born at a gestational age of 34 weeks or less (Lefort 2003). The 75 infants included in this study were intubated in the delivery room owing to respiratory insufficiency and were randomized into two groups: group A, comprising 35 neonates who were submitted to surfactant within the first hour of life and group $\mathrm{B}$, comprising 40 neonates who were not submitted to surfactant within the first hour of life. The surfactant used in this study was animal-derived surfactant. The outcomes measured and reported were pneumothorax, intracranial hemorrhage, PDA, pulmonary 
hemorrhage, NEC and sepsis, ROP, BPD (oxygen requirement at 28 days or requirement for supplemental oxygen at 36 weeks adjusted age) and further need for oxygen therapy, and neonatal survival. The use of prenatal steroid use was unable to be determined in this study.

\section{Overview}

\section{Timing of surfactant}

While each of the studies sought to compare early versus delayed surfactant administration, significant differences were noted in the timing of the first dose. Konishi 1992 administered the early dose of surfactant within the first 30 minutes of life with a mean time of 18 minutes to surfactant administration in the early group. The European Exosurf Trial (European Study 1992) and the OSIRIS Trial (OSIRIS 1992) both defined early treatment as prior to two hours of life. The median time to surfactant administration in the early group in the OSIRIS trial (OSIRIS 1992) was 118 minutes in the early group. Gortner 1998 and Lefort 2003 used one hour of life as the cut-off for early treatment. The average time to surfactant administration in the early group in the study by Gortner 1998 was 31 minutes. The study by Plavka 2002 considered early treatment as surfactant administration given immediately after intubation, with an eligibility criteria for the study as intubation and assisted ventilation needed within three hours after delivery for significant RDS with a mean time of five minutes to surfactant administration in the early group.

\section{Study population}

All studies attempted to evaluate a population at high risk for RDS, but differed slightly in their inclusion criteria. Konishi 1992 included babies of $500 \mathrm{~g}$ to $1500 \mathrm{~g}$ whose weight was appropriate for gestational age and whose surfactant deficiency had to be documented by analysis of the gastric aspirate. The European Exosurf Trial (European Study 1992) included infants between 26 and 29 weeks' gestational age. Gortner 1998 included neonates between 27 and 32 weeks' gestational age. The OSIRIS trial (OSIRIS 1992) did not specify specific inclusion criteria for gestational age or weight. Plavka 2002 included newborns with a gestational age of less than 30 weeks. Lefort 2003 studied infants less than 34 weeks' gestational age. All studies excluded infants with pre- or postnatal congenital anomalies, as well as infants with oligohydramnios or prolonged rupture of membranes > 72 hours; all studies required informed consent.

\section{Surfactant preparation}

The surfactant preparations differed between studies. Konishi 1992 and Gortner 1998 used natural bovine surfactant extract, Surfactant TA and Alveofact, respectively. Plavka 2002 and Lefort 2003 used Curosurf, an animal-derived exogenous surfactant. The European Exosurf Trial (European Study 1992) and the OSIRIS trial (OSIRIS 1992) treated infants with Exosurf Neonatal, a synthetic surfactant containing dipalmitoylphosphatidylcholine choline, tyloxapol, and hexadecanol. This review includes subgroup analyses by surfactant type.

\section{Reported outcome}

Primary outcomes were survival and survival without BPD in both the OSIRIS (OSIRIS 1992) and European Exosurf trials (European Study 1992). In the studies utilizing a natural surfactant extract, Konishi 1992 measured ventilatory requirements in the first seven days of life. Gortner 1998 measured length of mechanical ventilation as primary outcomes. Plavka 2002 measured CLD or death at 36 weeks' postconceptional age as the primary outcome. Lefort 2003 did not differentiate primary from secondary outcomes but did measure pneumothorax, intracranial hemorrhage, PDA, pulmonary hemorrhage, NEC and sepsis, ROP, BPD (oxygen requirement at 28 days or requirement for supplemental oxygen at 36 weeks' adjusted age) and further need for oxygen therapy, and neonatal survival. Secondary outcomes in six of the seven studies included complications of prematurity. Hentschel 2009 reported on follow-up outcomes which included auditory impairment, visual impairment, pathologic walking, and pathologic muscular tone (Gortner 1998).

\section{Prenatal steroid exposure}

Five of the six original studies reported the incidence of prenatal steroid use. Konishi 1992, the OSIRIS trial (OSIRIS 1992), the European Exosurf trial (European Study 1992), and Plavka 2002 all reported less than $50 \%$ prenatal steroid exposure in mothers. Gortner 1998 was the only included study carried out in a population where the majority of infants' mothers had received a complete course of prenatal steroids $(79.9 \%$ in the early treatment group and $72.8 \%$ in the late treatment group). Lefort 2003 did not report the use of prenatal steroids.

\section{Long-term follow-up}

Only one study included in this review assessed long-term followup of the study population. Hentschel 2009 was a follow-up study to Gortner 1998.

\section{Excluded studies}

Details of excluded studies are noted in the 'Characteristics of excluded studies' table.

The following types of studies were excluded from this review:

\section{Studies comparing the use of prophylactic surfactant versus rescue surfactant therapy}

Dunn 1991; Kendig 1991; Merritt 1991; Egberts 1993; Kattwinkel 1993; Walti 1995; Bevilacqua 1996; Bevilacqua 1997; Iarŭkova 1999; SUPPORT 2010; Dunn 2011

Systematic review of these studies is addressed in the Cochrane review: Prophylactic versus selective use of surfactant in preventing morbidity and mortality in preterm infants (Rojas-Reyes 2012).

\section{Studies of intubation (with or without endotracheal tube) and early surfactant compared to $n C P A P$}

Morley 2008; Rojas 2009; Sandri 2010; Göpel 2011

\section{Studies of intubation/surfactant administration/extubation}

Verder 1999; Escobedo 2004; Reininger 2005; Dunn 2011

Systematic review of these studies is addressed in the Cochrane review: Early surfactant administration with brief ventilation versus selective surfactant and continued mechanical ventilation for preterm infants with or at risk for respiratory distress syndrome (Stevens 2007). 


\section{Studies of re-treatment}

Kattwinkel 2000; Figueras-Aloy 2001; Köksal 2009

\section{Uncertain status}

\section{Osborn 2000}

Study of prophylactic surfactant versus early selective surfactant with the use of the "click test" to determine need for therapy for respiratory distress syndrome (Osborn 2000).

\section{Risk of bias in included studies}

Details of risk of bias are given in the 'Risk of bias' tables.

Only randomized controlled studies comparing the effects of early selective surfactant administration (intratracheal surfactant at less than three hours of life in infants intubated for early respiratory distress) versus delayed selective surfactant administration for the treatment of established RDS were included in the analysis. The OSIRIS study (OSIRIS 1992), the European Exosurf study (European Study 1992), and the study by Gortner 1998 were multicenter studies. Konishi 1992; Plavka 2002; and Lefort 2003 were single center studies.

\section{Randomization}

Methods varied between studies. Konishi 1992 did not describe any blinding of randomization, stating only that the 32 included infants were randomized after meeting inclusion criteria. Gortner 1998 provided randomization lists to the six participating centers from a central statistical center for medical informatics. The European Exosurf trial (European Study 1992) generated a unique trial number corresponding to an opaque sealed envelope located at the various trial centers. The OSIRIS trial (OSIRIS 1992) randomized trial entrants by telephone from a central location after entry criteria were met and prognostic variables recorded. Plavka 2002 randomized infants according to a table with random numbers. Lefort 2003 did not specify any randomization generation but did report their subjects were randomized into two groups (early and delayed treatment) with a total of 75 infants enrolled.

\section{Blinding of treatment}

Only the European Exosurf trial (European Study 1992) maintained full blinding of treatment. Konishi 1992; Gortner 1998; Plavka 2002; and Lefort 2003 did not comment on any blinding of treatment, and the OSIRIS trial (OSIRIS 1992) was unblinded to treatment by design.

\section{Blinding of outcome assessment}

The European Exosurf trial (European Study 1992) demonstrated full blinding of outcome assessment. The sequential design of the trial allowed for assessment of the data by an independent, non-clinical analysis team after every 20th baby. Results that might warrant termination of the trial were to be submitted to an independent advisory board with authority to terminate the trial. The other trials did not comment on blinding at the outcome assessment level.

\section{Exclusion after randomization}

All data were analyzed from an intent-to-treat perspective after initial randomization. The European Exosurf Trial (European Study 1992); OSIRIS 1992; Gortner 1998; Plavka 2002; and Lefort 2003 excluded no patients after the initial randomization. Konishi 1992 excluded eight of 40 infants initially randomized, because they did not meet the prospective inclusion criteria.

The combined sample sizes of the trials using synthetic surfactant was seven times the size of the trials using animal-derived surfactant (467 infants enrolled in trials utilizing natural surfactant compared to 3110 infants enrolled in trials utilizing synthetic surfactant).

\section{Effects of interventions}

\section{Comparison 1: studies that compared the effect of early selective surfactant administration (surfactant administration via the endotracheal tube in infants intubated for respiratory distress, not specifically for surfactant dosage) within the first two hours of life with delayed selective surfactant administration when they develop established RDS in preterm infants}

1. Studies that utilized synthetic surfactant (with or without protein)

2. Studies that utilized animal-derived surfactant.

3. Overall estimate.

\section{Primary outcomes}

\section{Neonatal mortality (Outcome 1.1)}

Six studies reported on the effect of early selective surfactant administration on neonatal mortality (European Study 1992; Konishi 1992; OSIRIS 1992; Gortner 1998; Plavka 2002; Lefort 2003) (Analysis 1.1).

Studies that utilized synthetic surfactant: both the European Exosurf Study (European Study 1992) and the OSIRIS Study (OSIRIS 1992) of early selective synthetic surfactant administration reported a decrease in the risk of mortality. When these two studies are included in the subgroup analysis, the typical estimate suggested a decrease in the risk of neonatal mortality with early selective surfactant therapy (typical RR $0.85 ; 95 \% \mathrm{Cl} 0.75$ to 0.96 ; typical RD $-0.04 ; 95 \% \mathrm{Cl}-0.07$ to $-0.01 ; 2$ trials; 3110 subjects).

Studies that utilized animal-derived surfactant: four studies of animal-derived surfactant preparations reported on neonatal mortality (Konishi 1992; Gortner 1998; Plavka 2002; Lefort 2003). None of the four studies of early selective administration of animalderived surfactant demonstrated an effect on neonatal mortality. The meta-analysis of these trials did not suggest an impact on neonatal mortality (typical RR $0.69 ; 95 \% \mathrm{Cl} 0.44$ to 1.09 ; typical RD $-0.04 ; 95 \% \mathrm{Cl}-0.09$ to $0.01 ; 4$ trials; 467 subjects).

Overall estimate: the meta-analysis of all six studies estimated a significant reduction in neonatal mortality with early selective surfactant therapy (typical RR $0.84 ; 95 \% \mathrm{Cl} 0.74$ to 0.95 ; typical RD $-0.04 ; 95 \% \mathrm{Cl}-0.06$ to $-0.01 ; 6$ trials; 3577 subjects). The NNTB to reduce neonatal mortality was 25 .

\section{Mortality prior to discharge (Outcome 1.2)}

Five studies reported on the effect of early selective surfactant administration on mortality prior to discharge (Konishi 1992, OSIRIS 1992, Gortner 1998; Plavka 2002; Lefort 2003) (Analysis 1.2).

Studies that utilized synthetic surfactant: the only study that utilized synthetic surfactant that reported on mortality prior to 
discharge was the OSIRIS trial (OSIRIS 1992). This study showed no effect on mortality prior to discharge (RR $0.89 ; 95 \% \mathrm{Cl} 0.79$ to 1.01 ; RD - $0.03 ; 95 \% \mathrm{Cl}-0.07$ to 0.00 ).

Studies that utilized animal-derived surfactant: the four studies of animal-derived surfactant that reported on mortality prior to discharge (Konishi 1992; Gortner 1998; Plavka 2002; Lefort 2003) demonstrated no significant effect on mortality prior to discharge (typical RR 0.74; 95\% Cl 0.47 to 1.15; typical RD $-0.04 ; 95 \% \mathrm{Cl}-0.09$ to $-0.01 ; 4$ trials; 467 subjects).

Overall estimate: the meta-analysis of all six studies estimated a similar trend on mortality prior to discharge (typical RR $0.88 ; 95 \%$ $\mathrm{Cl} 0.78$ to 0.99 ; typical RD $-0.03 ; 95 \% \mathrm{Cl}-0.06$ to $0.00 ; 5$ trials; 3157 subjects).

\section{Bronchopulmonary dysplasia (Outcome 1.3)}

Four studies reported on the effect of early selective surfactant administration on BPD (Konishi 1992; OSIRIS 1992; Gortner 1998; Lefort 2003) (Analysis 1.3). The stated definition of BPD in all studies but Konishi 1992 was any oxygen supplementation at 28 days of life. Konishi 1992 defined BPD as an $\mathrm{FiO}_{2}$ of 0.3 or greater at 28 days of life. Using data provided by the study by Konishi 1992 study, the more liberal and standard definition of BPD was applied to their results and included in this review.

Studies that utilized synthetic surfactant: the only study that utilized synthetic surfactant that reported on BPD was the OSIRIS trial (OSIRIS 1992). This study showed no effect on BPD (RR 0.97; $95 \% \mathrm{Cl} 0.88$ to 1.08 ; RD $-0.01 ; 95 \% \mathrm{Cl}-0.05$ to 0.03 ).

Studies that utilized animal-derived surfactant: of the four studies that utilized animal-derived surfactant, three reported on BPD (Konishi 1992; Gortner 1998; Lefort 2003). None of these studies demonstrated a significant reduction in BPD with early selective surfactant treatment (typical RR 0.94; $95 \% \mathrm{Cl} 0.67$ to 1.31 ; typical RD $-0.01 ; 95 \% \mathrm{Cl}-0.09$ to $-0.06 ; 3$ trials; 424 subjects).

Overall estimate: the meta-analysis found no evidence of a significant reduction in the risk of BPD with early selective surfactant (typical RR $0.97 ; 95 \% \mathrm{Cl} 0.88$ to 1.07 ; typical RD: -0.01 ; $95 \% \mathrm{Cl}-0.04$ to $0.02 ; 4$ trials; 3114 subjects).

\section{Bronchopulmonary dysplasia or death at 28 to 30 days (Outcome 1.4)}

Three studies reported on the effect of early selective surfactant administration on BPD or death at 28 to 30 days of life (Konishi 1992; OSIRIS 1992; Gortner 1998) (Analysis 1.4). The European Exosurf Trial (European Study 1992), Plavka 2002, and Lefort 2003 did not comment on the effect of early selective surfactant on BPD or death at 28 to 30 days of life.

Studies that utilized synthetic surfactant: the only study that utilized synthetic surfactant that reported on BPD or death at 28 to 30 days of life was the OSIRIS trial (OSIRIS 1992). This study did not show an effect of early selective surfactant on BPD or death at 28 to 30 days of life (RR 0.94; $95 \% \mathrm{Cl} 0.88$ to 1.00 ; RD $-0.04 ; 95 \% \mathrm{Cl}-0.08$ to -0.00$)$.

Studies that utilized animal-derived surfactant: Konishi 1992 and Gortner 1998 reported on the effect of early selective surfactant on BPD or death at 28 to 30 days of life. Gortner 1998 showed no reduction of BPD or death at 28 to 30 days of life with the use of early selective surfactant (RR 1.09; $95 \%$ Cl 0.74 to 1.59; RD 0.02; 95\%
$\mathrm{Cl}-0.07$ to 0.12). Konishi 1992 demonstrated a reduction in BPD or death at 28 to 30 days of life with early selective surfactant therapy (RR $0.54 ; 95 \% \mathrm{Cl} 0.29$ to 0.98 ; RD $-0.38 ; 95 \% \mathrm{Cl}-0.68$ to -0.07 ). When the two studies were combined, there was no significant reduction in BPD or death at 28 to 30 days of life with the use of early selective surfactant (typical RR $0.95 ; 95 \% \mathrm{Cl} 0.68$ to 1.31 ; typical RD $-0.02 ; 95 \%$ $\mathrm{Cl}-0.11$ to $0.08 ; 2$ trials; 349 subjects).

Overall estimate: the meta-analysis estimated that there was no significant reduction on BPD or death at 28 to 30 days of life with the use of early selective surfactant therapy (typical RR 0.94; 95\% $\mathrm{Cl} 0.88$ to 1.00 ; typical RD $-0.04 ; 95 \% \mathrm{Cl}-0.07$ to $-0.00 ; 3$ trials; 3039 subjects).

\section{Chronic lung disease (Outcome 1.5)}

Three studies reported on the effect of early selective surfactant administration on CLD (OSIRIS 1992; Gortner 1998; Plavka 2002) (Analysis 1.5).

Studies that utilized synthetic surfactant: the study that utilized synthetic surfactant that reported on CLD was the OSIRIS trial (OSIRIS 1992), which defined CLD as a supplemental oxygen requirement at the "expected delivery date". This study demonstrated a significant reduction on the risk of CLD with the use of early selective surfactant (RR $0.70 ; 95 \% \mathrm{Cl} 0.55$ to 0.89 ; RD -0.03 ; $95 \% \mathrm{Cl}-0.06$ to -0.01$)$.

Studies that utilized animal-derived surfactant: Gortner 1998 reported the effect of early selective surfactant administration on CLD. Gortner defined CLD as a requirement for supplemental oxygen at 36 weeks' adjusted age. There was no significant effect of early surfactant treatment on CLD (RR $0.62 ; 95 \% \mathrm{Cl} 0.25$ to 1.53; RD $-0.03 ; 95 \% \mathrm{Cl}-0.08$ to 0.02 ). Plavka 2002 defined CLD by radiographic score at 28 to 30 days of life or oxygen use at 36 weeks, or both. Plavka showed some difference (RR $0.60 ; 95 \% \mathrm{Cl} 0.20$ to 1.75; RD $-0.13 ; 95 \% \mathrm{Cl}-0.38$ to 0.13 ) but this did not individually reach statistical significance in this sample size. When combined, these two studies show no significant reduction on the risk of CLD with the use of early selective surfactant treatment (typical RR 0.61; $95 \% \mathrm{Cl} 0.30$ to 1.22 ; typical RD $-0.04 ; 95 \% \mathrm{Cl}-0.10$ to $0.01 ; 2$ trials; 360 subjects).

Overall estimate: the meta-analysis estimated a significant reduction in CLD with early selective surfactant treatment (typical RR $0.69 ; 95 \% \mathrm{Cl} 0.55$ to 0.87 ; typical RD $-0.03 ; 95 \% \mathrm{Cl}-0.05$ to -0.01 ; 3 trials; 3050 subjects).

\section{Chronic lung disease or death (Outcome 1.6)}

Three studies reported on the effect of early selective surfactant administration on CLD (OSIRIS 1992; Gortner 1998; Plavka 2002) (Analysis 1.6).

Studies that utilized synthetic surfactant: the study that utilized synthetic surfactant that reported on CLD or death was the OSIRIS trial (OSIRIS 1992), which defined CLD as a supplemental oxygen requirement at the "expected delivery date". This study demonstrated a reduction on the risk of CLD with the use of early selective surfactant (RR 0.84; $95 \% \mathrm{Cl} 0.75$ to 0.93 ; RD $-0.06 ; 95 \% \mathrm{Cl}$ -0.10 to -0.03$)$.

Studies that utilized animal-derived surfactant: Gortner 1998 defined CLD as a requirement for supplemental oxygen at 36 weeks' adjusted age. No significant effect of early surfactant treatment on 
CLD or death was noted (RR $0.85 ; 95 \% \mathrm{Cl} 0.41$ to 1.75 ; RD -0.01 ; $95 \% \mathrm{Cl}-0.08$ to 0.05$)$. Plavka 2002 defined CLD by radiographic score at 28 to 30 days of life or oxygen use at 36 weeks, or both. Plavka 2002 demonstrated a significant reduction on CLD or death (RR $0.65 ; 95 \% \mathrm{Cl} 0.21$ to 0.95 ; RD $-0.35 ; 95 \% \mathrm{Cl}-0.63$ to -0.07 ) but this did not individually reach statistical significance in the small sample size. When combined, these two studies showed no significant reduction on the risk of CLD with the use of early selective surfactant treatment (typical RR $0.65 ; 95 \% \mathrm{Cl} 0.39$ to 1.10 ; typical RD $-0.05 ; 95 \% \mathrm{Cl}-0.12$ to $0.01 ; 2$ trials; 360 subjects).

Overall estimate: the meta-analysis supported a significant reduction in CLD or death at 36 weeks with early selective surfactant therapy (typical RR $0.83 ; 95 \% \mathrm{Cl} 0.75$ to 0.91 ; typical RD $-0.06 ; 95 \%$ $\mathrm{Cl}-0.09$ to $-0.03 ; 3$ trials; 3050 subjects).

\section{Secondary outcomes}

\section{Any air leak syndrome (Outcome 1.7)}

Two studies reported on the effect of early selective surfactant administration on the incidence of any air leak syndrome (European Study 1992; Plavka 2002) (Analysis 1.7).

Studies that utilized synthetic surfactant: the European Exosurf trial (European Study 1992) demonstrated a significant reduction in air leak syndromes in infants treated with early surfactant therapy (RR $0.63 ; 95 \% \mathrm{Cl} 0.49$ to 0.80 ; RD $-0.18 ; 95 \% \mathrm{Cl}-0.28$ to -0.09 ).

Studies that utilized animal-derived surfactant: Plavka 2002 demonstrated a reduction in air leak syndromes but this result did not reach statistical significance (RR $0.15 ; 95 \% \mathrm{Cl} 0.01$ to 2.73 ; RD $-0.14 ; 95 \% \mathrm{Cl}-0.30$ to 0.02 ).

Overall estimate: the meta-analysis supports a decrease in any air leak syndrome in infants treated with early selective surfactant therapy (typical RR $0.61 ; 95 \% \mathrm{Cl} 0.48$ to 0.78 ; typical RD $-0.18 ; 95 \%$ $\mathrm{Cl}-0.26$ to $-0.09 ; 2$ trials; 463 subjects).

\section{Pneumothorax (Outcome 1.8)}

Five studies reported on the effect of early selective surfactant administration on pneumothorax (European Study 1992; OSIRIS 1992; Gortner 1998; Plavka 2002; Lefort 2003) (Analysis 1.8).

Studies that utilized synthetic surfactant: both trials of early selective synthetic surfactant treatment (European Study 1992; OSIRIS 1992) reported on the risk of pneumothorax. The European Exosurf Trial (European Study 1992) demonstrated a decrease on the risk of pneumothorax with early surfactant treatment (RR $0.68 ; 95 \% \mathrm{Cl} 0.47$ to 0.98 ; RD $-0.09 ; 95 \% \mathrm{Cl}-0.16$ to -0.01 ). OSIRIS (OSIRIS 1992) also demonstrated a significant decrease on the risk of pneumothorax with early surfactant administration (RR $0.69 ; 95 \% \mathrm{Cl} 0.57$ to 0.83 ; RD $-0.05 ; 95 \% \mathrm{Cl}-0.08$ to -0.03 ). When combined, these studies show a significant reduction on the risk of pneumothorax with early selective surfactant treatment (typical RR $0.69 ; 95 \% \mathrm{Cl} 0.58$ to 0.81 ; typical RD $-0.06 ; 95 \% \mathrm{Cl}-0.08$ to $-0.03: 2$ trials; 3110 subjects)

Studies that utilized animal-derived surfactant: Gortner 1998 did not demonstrate any effect of early animal-derived surfactant extract administration on the risk of pneumothorax. Plavka 2002 and Lefort 2003 both demonstrated an increase in the incidence of pneumothorax in the delayed surfactant treatment groups, but neither reached statistical significance (typical RR 0.78; 95\% Cl 0.42 to 1.45 ; typical RD $-0.02 ; 95 \% \mathrm{Cl}-0.07$ to $-0.03 ; 3$ trials; 435 subjects).

Overall estimate: the meta-analysis of all trials supported a decrease in risk of pneumothorax with early selective surfactant treatment (typical RR $0.69 ; 95 \% \mathrm{Cl} 0.59$ to 0.82 ; typical RD $-0.05 ; 95 \%$ $\mathrm{Cl}-0.08$ to $-0.03 ; 5$ trials; 3545 subjects).

\section{Pulmonary interstitial emphysema (Outcome 1.9)}

Three studies reported on the effect of early selective surfactant administration on PIE (European Study 1992; Gortner 1998; Plavka 2002)

Studies that utilized synthetic surfactant: the European Exosurf Trial (European Study 1992) showed a significant decrease in the risk of PIE with early surfactant treatment (RR $0.62 ; 95 \% \mathrm{Cl} 0.40$ to 0.94; RD -0.08; $95 \% \mathrm{Cl}-0.16$ to -0.01 ).

Studies that utilized animal-derived surfactant: Gortner 1998 found no significant decrease in the risk of PIE with early surfactant treatment (RR $0.71 ; 95 \% \mathrm{Cl} 0.26$ to $1.94 ; \mathrm{RD}-0.16 ; 95 \% \mathrm{Cl}-0.06$ to 0.03). Plavka 2002 found an increase in PIE in patients who received delayed surfactant treatment, but this was not of statistical significance (RR $0.15 ; 95 \% \mathrm{Cl} 0.01$ to 2.73 ; RD $-0.14 ; 95 \% \mathrm{Cl}-0.30$ to 0.02 ). When these studies are combined, there was no effect on the risk of PIE with early selective surfactant (typical RR 0.55; 95\% $\mathrm{Cl} 0.22$ to 1.39 ; typical RD $-0.03 ; 95 \% \mathrm{Cl}-0.08$ to $-0.01 ; 2$ trials; 360 subjects).

Overall estimate: the meta-analysis supported a reduction on the risk of PIE associated with early selective surfactant administration (typical RR 0.60; 95\% Cl 0.41 to 0.89; typical RD -0.06 ; 95\% Cl -0.10 to $-0.02 ; 3$ trials; 780 subjects).

\section{Pulmonary hemorrhage (Outcome 1.10)}

Three studies reported on the effect of early selective surfactant administration on pulmonary hemorrhage (OSIRIS 1992; Gortner 1998; Lefort 2003) (Analysis 1.10).

Studies that utilized synthetic surfactant: the OSIRIS trial (OSIRIS 1992) showed no significant reduction on the risk of pulmonary hemorrhage with early surfactant administration (RR 1.01; $95 \% \mathrm{Cl}$ 0.75 to $1.37 ; \mathrm{RD} 0.00 ; 95 \% \mathrm{Cl}-0.02$ to 0.02 ).

Studies that utilized animal-derived surfactant: Gortner 1998 reported on the risk of pulmonary hemorrhage associated with early selective surfactant treatment and found no significant effect on pulmonary hemorrhage ( $\mathrm{RR} 0.21 ; 95 \% \mathrm{Cl} 0.01$ to 4.37 ; RD $-0.01 ; 95 \% \mathrm{Cl}-0.03$ to 0.01 ). Lefort 2003 reported on pulmonary hemorrhage and showed no significant difference with early selective surfactant treatment (RR $0.86 ; 95 \% \mathrm{Cl} 0.21$ to 3.57 ; RD $-0.01 ; 95 \% \mathrm{Cl}-0.15$ to 0.12 ). When these studies were combined, there was no effect on the risk of pulmonary hemorrhage with early selective surfactant (typical RR $0.60 ; 95 \% \mathrm{Cl} 0.17$ to 2.10 ; typical RD $-0.01 ; 95 \% \mathrm{Cl}-0.04$ to $0.02 ; 2$ trials; 392 subjects).

Overall estimate: the meta-analysis found no evidence of effect on the risk of pulmonary hemorrhage with early selective surfactant treatment (typical RR $0.98 ; 95 \%$ Cl 0.73 to 1.32 ; typical RD $-0.00 ; 95 \%$ $\mathrm{Cl}-0.02$ to $0.02 ; 3$ trials; 3082 subjects). 


\section{Patent ductus arteriosis (Outcome 1.11)}

Six studies reported on the effect of early selective surfactant administration on PDA (European Study 1992; Konishi 1992; OSIRIS 1992; Gortner 1998; Plavka 2002; Lefort 2003) (Analysis 1.11).

Studies that utilized synthetic surfactant: both trials of synthetic surfactant, the OSIRIS trial (OSIRIS 1992) and the European Exosurf trial (European Study 1992), did not demonstrate a decrease on the risk of PDA with the use of early selective surfactant (typical RR 1.02; $95 \% \mathrm{Cl} 0.91$ to 1.14 ; typical RD $-0.00 ; 95 \% \mathrm{Cl}-0.02$ to $0.04 ; 2$ trials; 3110 subjects).

Studies that utilized animal-derived surfactant: none of the four studies of early selective administration of animal-derived surfactant (Konishi 1992; Gortner 1998; Plavka 2002; Lefort 2003) reported an effect on PDA (typical RR $1.09 ; 95 \% \mathrm{Cl} 0.77$ to 1.55 ; typical RD $0.02 ; 95 \% \mathrm{Cl}-0.05$ to $0.08 ; 4$ trials; 467 subjects).

Overall estimate: the meta-analysis demonstrated no evidence of effect on the risk of PDA with early selective surfactant treatment (typical RR $1.02 ; 95 \% \mathrm{Cl} 0.92$ to 1.14 ; typical RD $0.01 ; 95 \% \mathrm{Cl}-0.02$ to 0.03; 6 trials; 3577 subjects).

\section{Confirmed bacterial sepsis (Outcome 1.12)}

Only Lefort 2003 reported on confirmed bacterial sepsis in the context of early selective treatment with surfactant (Analysis 1.12). There was no significant effect between the early treatment group and the delayed treatment group (RR 1.14; $95 \% \mathrm{Cl} 0.81$ to 1.60 ; RD $0.09 ; 95 \% \mathrm{Cl}-0.13$ to $0.30 ; 1$ trial; 75 subjects).

\section{Nerotizing enterocolitis (Outcome 1.13)}

Five studies reported on the effect of early selective surfactant administration on NEC (European Study 1992; OSIRIS 1992; Gortner 1998; Plavka 2002; Lefort 2003).

Studies that utilized synthetic surfactant: neither trial of synthetic surfactant, the OSIRIS trial (OSIRIS 1992) and the European Exosurf trial (European Study 1992) demonstrated a decreased risk of NEC with the use of early selective surfactant (typical RR $1.07 ; 95 \% \mathrm{CI}$ 0.75 to 1.51 ; typical RD $0.00 ; 95 \% \mathrm{Cl}-0.01$ to $0.02 ; 2$ trials; 3110 subjects).

Studies that utilized animal-derived surfactant: none of the three studies of early selective administration of animal-derived surfactant (Konishi 1992, Gortner 1998; Plavka 2002; Lefort 2003) reported an effect on NEC (typical RR $0.72 ; 95 \% \mathrm{Cl} 0.32$ to 1.62 ; typical RD $-0.02 ; 95 \% \mathrm{Cl}-0.05$ to $-0.01 ; 3$ trials; 435 subjects).

Overall estimate: the meta-analysis demonstrated no evidence of effect on the risk of NEC with early selective surfactant treatment (typical RR $1.01 ; 95 \% \mathrm{Cl} 0.73$ to 1.38 ; typical RD $0.00 ; 95 \% \mathrm{Cl}-0.01$ to 0.02; 5 trials; 3545 subjects).

\section{Intraventricular hemorrhage (all grades) (Outcome 1.14)}

Three studies reported on the effect of early selective surfactant administration on IVH (all grades) (Konishi 1992; Plavka 2002; Lefort 2003) (Analysis 1.14).

Studies that utilized animal-derived surfactant: two of the three animal-derived studies (Konishi 1992; Lefort 2003) showed no reduction in the risk of IVH (any grade) with early selective surfactant treatment. Plavka 2002 reported a significant reduction in the risk of IVH (any grade) (RR $0.50 ; 95 \% \mathrm{Cl} 0.29$ to 0.84 ; RD -0.44; $95 \% \mathrm{Cl}-0.69$ to -0.18$)$. When combined, these studies showed no reduction in the risk of IVH (any grade) with the use of early selective surfactant use (typical RR $0.69 ; 95 \% \mathrm{Cl} 0.43$ to 1.10 ; typical RD -0.10; $95 \% \mathrm{Cl}-0.20$ to $0.01 ; 3$ trials; 150 subjects).

Overall estimate: the meta-analysis demonstrated no evidence of effect on the risk of IVH (any grade) with early selective surfactant treatment (typical RR $0.69 ; 95 \% \mathrm{Cl} 0.43$ to 1.10 ; typical RD $-0.10 ; 95 \%$ Cl -0.20 to $0.01 ; 3$ trials; 150 subjects).

\section{Intraventricular hemorrhage (severe) (Outcome 1.15)}

Three studies reported on the effect of early selective surfactant administration on IVH (severe) (OSIRIS 1992; Gortner 1998; Plavka 2002) (Analysis 1.15).

Studies that utilized synthetic surfactant: the only study that utilized synthetic surfactant that reported on IVH (severe) was the OSIRIS trial (OSIRIS 1992). This study showed no effect on severe IVH (RR 0.95; $95 \% \mathrm{Cl} 0.81$ to $1.12 ; \mathrm{RD}-0.01 ; 95 \% \mathrm{Cl}-0.04$ to 0.02 ).

Studies that utilized animal-derived surfactant: two studies of animal-derived surfactant (Gortner 1998; Plavka 2002) reported on severe IVH. Neither of these two studies showed an effect of early selective surfactant on severe IVH (typical RR 1.06; $95 \% \mathrm{Cl} 0.47$ to 2.38); typical RD $0.00 ; 95 \% \mathrm{Cl}-0.05$ to $0.05 ; 2$ trials; 360 subjects).

Overall estimate: the meta-analysis did not support a significant effect on the risk of severe IVH associated with early selective surfactant administration (typical RR $0.96 ; 95 \% \mathrm{Cl} 0.82$ to 1.12 ; typical RD $-0.01 ; 95 \% \mathrm{Cl}-0.03$ to $0.02 ; 3$ trials; 3050 subjects).

\section{Periventricular leukomalacia (Outcome 1.16)}

Only Plavka 2002 reported on PVL in the context of early selective treatment with surfactant (Analysis 1.16). There was no significant effect between the early treatment group and the delayed treatment group (RR $0.15 ; 95 \% \mathrm{Cl} 0.01$ to 2.73 ; RD $-0.14 ; 95 \% \mathrm{Cl}-0.30$ to $0.02 ; 1$ trial; 43 subjects).

\section{Retinopathy of prematurity (all stages) (Outcome 1.17)}

Only Lefort 2003 reported on the ROP (all stages) in the context of early selective treatment with surfactant (Analysis 1.17). There was no significant effect between the early treatment group and the delayed treatment group (RR 3.43; 95\% Cl 0.37 to 31.48; RD 0.06; $95 \% \mathrm{Cl}-0.04$ to $0.17 ; 1$ trial; 75 subjects).

\section{Retinopathy of prematurity (stage 3 or greater) (Outcome 1.18)}

Three studies reported on the effect of early selective surfactant administration on ROP (stage 3 or greater) (OSIRIS 1992; Gortner 1998; Plavka 2002) (Analysis 1.18).

Studies that utilized synthetic surfactant: the only study that utilized synthetic surfactant that reported on ROP (stage 3 or greater) was the OSIRIS trial (OSIRIS 1992). This study showed no effect on ROP (stage 3 or greater) (RR $1.11 ; 95 \% \mathrm{Cl} 0.59$ to 2.09; RD $0.00 ; 95 \% \mathrm{Cl}-0.01$ to 0.01 ).

Studies that utilized animal-derived surfactant: two studies of animal-derived surfactant (Gortner 1998; Plavka 2002) reported on ROP (stage 3 or greater). Neither of these two studies showed an effect of early selective surfactant on ROP (stage 3 or greater) (typical RR 0.92; $95 \% \mathrm{Cl} 0.36$ to 2.33; typical RD $0.00 ; 95 \% \mathrm{Cl}-0.04$ to $0.04 ; 2$ trials; 360 subjects) 
Overall estimate: the meta-analysis demonstrated no evidence of effect on the risk of ROP (stage 3 or greater) with early surfactant therapy (typical RR $1.05 ; 95 \% \mathrm{Cl} 0.62$ to 1.78 ; typical RD $0.00 ; 95 \% \mathrm{Cl}$ -0.01 to $0.01 ; 3$ trials; 3050 subjects).

\section{Long-term follow-up (Outcome 1.19)}

Only the study by Hentschel 2009 (Gortner 1998) reported on long-term follow-up (Analysis 1.19). There were four significant parameters included in the study: visual impairment, auditory impairment, pathological muscle tone, and pathological walking.

There was no significant reduction in risk in long-term visual impairment associated with the use of early versus later selective surfactant administration (RR $0.91 ; 95 \% \mathrm{Cl} 0.48$ to 1.70 ; RD -0.02; $95 \% \mathrm{Cl}-0.14$ to 0.10 ).

There was no significant reduction in risk in long-term auditory impairment associated with the use of early versus later selective surfactant administration (RR $0.58 ; 95 \% \mathrm{Cl} 0.05$ to 6.32 ; RD -0.01 ; $95 \% \mathrm{Cl}-0.05$ to 0.03 ).

There was no significant reduction in risk in long-term pathologic muscle tone associated with the use of early versus later selective surfactant administration (RR 2.14; $95 \% \mathrm{Cl} 1.14$ to 4.04 ; RD $0.15 ; 95 \%$ $\mathrm{Cl} 0.03$ to 0.28 ).

There was no significant reduction in risk in long-term pathologic walking associated with the use of early versus later selective surfactant administration (RR $0.97 ; 95 \% \mathrm{Cl} 0.31$ to $3.07 ; \mathrm{RD} 0.00 ; 95 \%$ $\mathrm{Cl}-0.08$ to 0.07$)$.

\section{Comparison 2: studies that compared the effect of early} selective surfactant administration (surfactant administration via the endotracheal tube in infants intubated for respiratory distress, not specifically for surfactant dosage) within the first two hours of life with delayed selective surfactant administration when they develop established RDS in preterm infants less than 30 weeks' gestation

1. Studies that utilized synthetic surfactant preparations (with or without protein).

2. Studies that utilized animal-derived surfactant preparations.

3. Overall estimate.

Only two studies reported on infants < 30 weeks' gestation; one utilized synthetic surfactant (European Study 1992) and one utilized animal-derived surfactant (Plavka 2002).

\section{Neonatal mortality (Outcome 2.1)}

Two included studies reported on the effect of early selective surfactant administration on neonatal mortality in infants born at less than 30 weeks' gestational age (European Study 1992; Plavka 2002) (Analysis 2.1).

Studies that utilized synthetic surfactant: the European Exosurf trial (European Study 1992) reported a significant decrease on neonatal mortality in infants less than 30 weeks' gestation with the use of early surfactant administration (RR $0.66 ; 95 \% \mathrm{Cl} 0.46$ to 0.96 ; RD $-0.09 ; 95 \% \mathrm{Cl}-0.17$ to -0.01$)$.

Studies that utilized animal-derived surfactant: Plavka 2002 reported no significant difference in neonatal mortality in infants less than 30 weeks' gestation with early selective surfactant (RR $0.30 ; 95 \% \mathrm{Cl} 0.07$ to 1.28 ; RD $-0.22 ; 95 \% \mathrm{Cl}-0.45$ to -0.01 ).

Overall estimate: the meta-analysis estimated a significant reduction in neonatal mortality with early selective surfactant therapy in infants born at less than 30 weeks' gestation (typical RR $0.62 ; 95 \% \mathrm{Cl} 0.43$ to 0.89 ; typical RD $-0.10 ; 95 \% \mathrm{Cl}-0.18$ to $-0.03 ; 2$ trials; 463 subjects).

\section{Mortality prior to discharge (Outcome 2.2)}

Only one included study reported on mortality prior to discharge in infants born at less than 30 weeks' gestational age (Plavka 2002) (Analysis 2.2).

Studies that utilized animal-derived surfactant: Plavka 2002 demonstrated that early surfactant treatment in neonates born at less than 30 weeks' gestational age tended to have lower mortality prior to discharge. However, this result did not reach statistical significance owing to the small sample size (RR 0.30; $95 \% \mathrm{Cl} 0.07$ to 1.28; RD $-0.22 ; 95 \% \mathrm{Cl}-0.45$ to 0.01 ).

\section{Bronchopulmonary dysplasia}

None of the included study reported on BPD in infants born at less than 30 weeks' gestational age.

\section{Bronchopulmonary dysplasia or death at 28 to 30 days}

None of the included studies reported on BPD or death at 28 to 30 days of life in infants born at less than 30 weeks' gestational age.

\section{Chronic lung disease (Outcome 2.3)}

Only the study by Plavka 2002 reported on CLD in infants born at less than 30 weeks' gestational age (Analysis 2.3).

Studies that utilized animal-derived surfactant: Plavka 2002 defined CLD by radiographic score at 28 to 30 days of life or oxygen use at 36 weeks, or both. Plavka 2002 demonstrated a reduction in the risk of CLD (RR 0.60; 95\% Cl 0.20 to 1.75 ; RD -0.13 ; $95 \% \mathrm{Cl}-0.38$ to 0.13 ) but this did not individually reach statistical significance in this sample size.

\section{Chronic lung disease or death (Outcome 2.4)}

Only the study by Plavka 2002 reported on CLD or death at 36 weeks in infants born at less than 30 weeks' gestational age (Analysis 2.4).

Studies that utilized animal-derived surfactant: Plavka 2002 showed a significant reduction with early surfactant administration on the risk of oxygen use or death at 36 weeks (RR $0.45 ; 95 \% \mathrm{Cl} 0.21$ to 0.95 ; RD $-0.35 ; 95 \% \mathrm{Cl}-0.63$ to -0.07 ).

\section{Comparison 3: studies that compared the effect of early} selective surfactant administration (surfactant administration via the endotracheal tube in infants intubated for respiratory distress, not specifically for surfactant dosage) within the first two hours of life with delayed selective surfactant administration when they develop established RDS in preterm infants

1. Studies in which less than $50 \%$ of the enrolled infants received prenatal steroids.

2. Studies in which $50 \%$ or more of the enrolled infants received prenatal steroids. 
Only one study (Gortner 1998) reported steroid exposure of greater than $50 \%$ in early selective surfactant treated infants.

\section{Neonatal mortality (Outcome 3.1)}

Gortner 1998 showed no decreased risk on neonatal mortality in infants treated with early selective surfactant (RR 1.59; 95\% Cl 0.27 to 9.37 ; RD $0.01 ; 95 \% \mathrm{Cl}-0.02$ to 0.03 ) (Analysis 3.1).

\section{Mortality prior to discharge (Outcome 3.2)}

Gortner 1998 showed no decreased risk on mortality prior to discharge in infants treated with early selective surfactant (RR 1.76; $95 \% \mathrm{Cl} 0.43$ to $7.26 ; \mathrm{RD} 0.01 ; 95 \% \mathrm{Cl}-0.02$ to 0.05 ) (Analysis 3.2 ).

\section{Bronchopulmonary dysplasia (Outcome 3.3)}

Gortner 1998 showed no decreased risk on BPD in infants treated with early selective surfactant (RR 1.00; $95 \% \mathrm{Cl} 0.67$ to 1.49; RD 0.00; $95 \% \mathrm{Cl}-0.09$ to 0.09 ) (Analysis 3.3).

\section{Bronchopulmonary dysplasia or death at 28 to 30 days (Outcome 3.4)}

Gortner 1998 showed no reduction of BPD or death at 28 to 30 days of life with the use of early selective surfactant (RR 1.09; 95\% Cl 0.74 to $1.59 ; \mathrm{RD} 0.02 ; 95 \% \mathrm{Cl}-0.07$ to 0.12 ) (Analysis 3.4).

\section{Chronic lung disease (Outcome 3.5)}

Gortner 1998 reported the effect of early selective surfactant administration on CLD. Gortner defined CLD as a requirement for supplemental oxygen at 36 weeks' adjusted age (Analysis 3.5). There was no significant effect of early surfactant treatment demonstrated on CLD (RR 0.62; 95\% Cl 0.25 to 1.53; RD -0.03; 95\% $\mathrm{Cl}-0.08$ to 0.02$)$.

\section{Chronic lung disease or death (Outcome 3.6)}

Gortner 1998 defined CLD as a requirement for supplemental oxygen at 36 weeks' adjusted age (Analysis 3.6). No significant effect of early surfactant treatment on CLD or death was demonstrated (RR $0.85 ; 95 \% \mathrm{Cl} 0.41$ to 1.75 ; RD $-0.01 ; 95 \% \mathrm{Cl}-0.08$ to 0.05 ).

\section{DISCUSSION}

Surfactant replacement therapy has been shown to improve clinical outcome, whether given prophylactically to infants at high risk of developing RDS, or when given to infants with established RDS (Soll 1992). A broad range of criteria for both timing of treatment and disease severity (two related but clearly distinct clinical issues) has been successfully utilized. This leaves clinicians with uncertainty regarding the optimal timing of surfactant treatment.

In this review, we evaluated the merits of early selective surfactant treatment compared to delayed selective surfactant treatment in intubated infants with RDS. Six studies were identified. Of the six studies, the OSIRIS trial (OSIRIS 1992), which utilized synthetic surfactant, is by far the largest study, and dominated the estimates of the effect of these treatment strategies. Given the relatively small number of infants studied in the trials of animal-derived surfactant extracts, it is hard to draw conclusions regarding any differences in the effects of animal-derived versus synthetic surfactant when used early in the treatment of respiratory distress. Overall, early selective surfactant administration decreased the risk of acute pulmonary injury (decreased risk of pneumothorax, PIE, and overall air leak syndromes) and decreased the risk of neonatal mortality and CLD compared to delayed selective treatment of infants with established RDS. There was also a trend toward a reduction in the risk of BPD or death at 28 to 30 days of life with the use of early selective surfactant. Based on these data, recommendations favoring earlier treatment seem reasonable.

Early surfactant treatment is distinct from true 'prophylactic' surfactant administration. In this review, early treatment was given to infants already intubated for respiratory support; in trials of prophylactic surfactant administration, infants at high risk of developing RDS are intubated for the purpose of giving surfactant therapy. It is hard to judge the relative value of early surfactant treatment compared to true prophylactic use of surfactant in the absence of any randomized trials that have directly compared these policies.

The evidence supporting prophylactic surfactant treatment has changed in recent years. The original studies comparing prophylactic to selective treatment were conducted in a clinical setting where there was little prenatal use of corticosteroids to promote lung maturation. In addition, infants were not stabilized in the delivery room on CPAP in order to help establish an adequate functional residual capacity. Analysis of these studies from the 1990s suggests that prophylactic rather than delayed administration of surfactant to all infants deemed at high risk for RDS reduces the risk of pneumothorax, PIE, BPD or death, as well as mortality. More recent trials suggest the opposite effect; the Vermont Oxford Delivery Room Trial (Dunn 2011) and the NICHD SUPPORT trial (SUPPORT 2010) suggest improved outcome in infants who are stabilized on nasal CPAP and only receive surfactant if intubated for respiratory insufficiency. Meta-analysis of these trials clearly demonstrates the differences in these studies and those conducted in the 1990s (Rojas-Reyes 2012).

This apparent tension can be resolved if the following is considered; in current practice, it may be best to stabilize infants on nasal CPAP and treat only if they have signs and symptoms of worsening RDS. However, once intubated, it is probably of some value to administer surfactant very shortly thereafter. The potential benefit of earlier treatment is consistent with evidence of lung injury from animal studies that demonstrate leakage of proteins into the alveolar spaces of the surfactant-deficient lung that act as surfactant inhibitors (Jobe 1993). Exogenous surfactant has reduced the leakage of such surfactant-inhibiting proteins in animal models (Ikegami 1983; Jobe 1993). In the original trials of prophylaxis, even small delays in treating infants with established RDS appear to be clinically important. Kattwinkel 1993 conducted a study comparing prophylactic versus early surfactant therapy in the 29 to 32 week' gestational age population of premature neonates. Criteria for intubation and early selective surfactant treatment were liberal; an $\mathrm{FiO}_{2}$ requirement of 0.30 with radiographic findings not consistent with another respiratory process prompted intubation for surfactant therapy. In the studies of early treatment, criteria for the early selective treatment group were frequently more stringent than in the selective treatment group of Kattwinkel 1993. The OSIRIS trial (OSIRIS 1992) required intubation for respiratory distress prior to surfactant dosing; however, no child was intubated for the sole purpose of surfactant administration. The European Exosurf trial (European Study 1992) enrolled only infants at high risk for RDS and intubated for respiratory distress before two hours of life. Gortner 1998 administered the first dose of surfactant within 
the first hour of life if respiratory distress required intubation. Plavka 2002 included infants that required intubation within the first three hours of life, with immediate administration of surfactant and subsequent initiation of HFOV. Lefort 2003 administered surfactant to infants if they clinically presented with RDS and they required mechanical ventilation, with an $\mathrm{FiO}_{2}$ of $>0.04$ and $\mathrm{PaO}_{2} /$ $\mathrm{FiO}_{2}$ ratio of $175 \mathrm{mmHg}$ or less. Clearly, Kattwinkel 1993 had a lower threshold for selective surfactant treatment, and surfactant was given earlier than in most of the included studies in this review. The selective treatment group of Kattwinkel 1993 had a median time to first surfactant dose of 90 minutes versus the 118 minutes noted in the OSIRIS study (OSIRIS 1992) trial for early selective treatment.

Estimates show that not all infants judged to be at high risk for RDS are surfactant deficient. Of the trials included in this metaanalysis, only Konishi 1992 estimated surfactant deficiency prior to surfactant administration. He found only $66 \%$ of those judged at risk for RDS based on a birthweight criterion of 500 to $1500 \mathrm{~g}$ to have surfactant deficiency at birth. Kattwinkel 1993 noted that of those randomized to early selective surfactant treatment only $43 \%$ of 621 infants required surfactant as indicated by their admittedly liberal criteria. Clearly prophylaxis with surfactant would over treat a large number of infants judged at risk for RDS, and this over treatment may be justified to save the life of every 20th child. However, it appears that treatment with surfactant within the first three hours of life in those infants intubated for respiratory distress confers the benefits of reduced mortality and pneumothorax while treating a substantially smaller portion of those infants judged at risk prenatally.

Prenatal steroids improve the outcome of premature infants at risk for RDS (Crowley 2006). Gortner 1998 provided the only included study carried out in a population where the majority of infants' mothers had received a complete course of prenatal steroids. He did not document a significant reduction in rates of pneumothorax or neonatal mortality. The review of studies comparing prophylactic versus delayed selective surfactant administration was also carried out in populations not fully benefiting from the documented effects of prenatal steroids. Gortner 1998 questions the impact of prophylactic or early treatment in the population of steroid-treated infants, who are at less risk of RDS. However, most other studies of surfactant replacement have suggested a synergistic effect of these two therapies (Jobe 1993).

\section{AUTHORS' CONCLUSIONS}

\section{Implications for practice}

Early surfactant administration to intubated infants significantly reduces the risk of key clinical outcomes including pneumothorax, PIE, CLD, and neonatal mortality. The difficulty of judging which infant is at risk for surfactant deficiency continues. The meta-analysis would suggest that intubated neonates with early respiratory distress should be given surfactant as early as possible.

\section{Implications for research}

Improved identification of infants at risk for RDS will improve the selection criteria for prophylactic or early selective surfactant therapy. Newer less invasive techniques of surfactant administration should be tested in both an at-risk population (prophylactic treatment) and in infants with early signs of respiratory distress (early selective surfactant treatment).

\section{ACKNOWLEDGEMENTS}

We would like to thank Ms. Diane Haughton and Yolanda Brosseau for their help in creating the searches, obtaining original studies, and copyediting the manuscript. 


\section{R E F E R E N C E S}

\section{References to studies included in this review}

\section{European Study 1992 \{published data only\}}

European Exosurf Study Group. Early or selective surfactant (Colfosceril Palmitate, Exosurf) for intubated babies at 26 to 29 weeks gestation: a European double-blind trial with sequential analysis. Online Journal of Current Clinical Trials 1992:Doc. No. 28.

\section{Gortner 1998 \{published data only\}}

* Gortner L, Wauer RR, Hammer H, Stock GJ, Heitmann F, Reiter $\mathrm{HL}$, et al. Early versus late surfactant treatment in preterm infants of 27 to 32 weeks' gestational age: a multicenter controlled clinical trial. Pediatrics 1998;102(5):1153-60.

Hentschel R, Dittrich F, Hilgendorff A, Wauer R, Westmeier M, Gortner L. Neurodevelopmental outcome and pulmonary morbidity two years after early versus late surfactant treatment: does it really differ?. Acta Paediatroca 2009;98(4):654-9.

\section{Konishi 1992 \{published data only\}}

Konishi M, Fujiwara T, Chida S, Maeta H, Shimada S, Kasai T, et al. A prospective randomized trial of early versus late administration of a single dose of surfactant-TA. Early Human Development 1992;29(1-3):275-82.

\section{Lefort 2003 \{published and unpublished data\}}

Lefort S, Diniz EM, Vaz FA. Clinical course of premature infants intubated in the delivery room, submitted or not to porcine-derived lung surfactant therapy within the first hour of life. Journal of Maternal-Fetal \& Neonatal Medicine 2003;14(3):187-96

\section{OSIRIS 1992 \{published data only\}}

The OSIRIS Collaborative Group. Early versus delayed neonatal administration of a synthetic surfactant - the judgement of OSIRIS. The OSIRIS Collaborative Group (open study of infants at high risk of or with respiratory insufficiency - the role of surfactant. Lancet 1992;340(8832):1363-9.

\section{Plavka 2002 \{published and unpublished data\}}

Plavka R, Kopecký P, Sebron V, Leiská A, Svihovec P, Ruffer J, et al. Early versus delayed surfactant administration in extremely premature neonates with respiratory distress syndrome ventilated by high-frequency oscillatory ventilation. Intensive Care Medicine 2002;28(10):1483-90.

\section{References to studies excluded from this review}

\section{Bevilacqua 1996 \{published data only\}}

Bevilacqua G, Parmigiani S, Robertson B. Prophylaxis of respiratory distress syndrome by treatment with modified porcine surfactant at birth: a multicentre prospective randomized trial. Journal of Perinatal Medicine 1996;24(6):609-20.

\section{Bevilacqua 1997 \{published data only\}}

Bevilacqua G, Chernev T, Parmigiani S, Iarakova N, Gaioni L, Volante $\mathrm{E}$, et al. Use of surfactant for prophylaxis versus rescue treatment of respiratory distress syndrome: experience from an Italian-Bulgarian trial. Acta Bio-Medica de L'Ateneo parmense 1997;68(Suppl 1):47-54.

Dunn 1991 \{published data only\}

Dunn MS, Shennan AT, Zayack D, Possmayer F. Bovine surfactant replacement therapy in neonates of less than 30 weeks' gestation: a randomized controlled trial of prophylaxis vs treatment. Pediatrics 1991;87(3):377-86.

Dunn 2011 \{published data only\}

Dunn MS, Kaempf J, de Klerk A, de Klerk R, Reilly M, Howard D, et al. Randomized trial comparing 3 approaches to the initial respiratory management of preterm neonates. Pediatrics 2011;128(5):e1069-76.

Egberts 1993 \{published data only\}

Egberts J, de Winter JP, Sedin G, de Kleine MJ, Broberger U, van Bel F, et al. Comparison of prophylaxis and rescue treatment with Curosurf in neonates less than 30 weeks gestation: a randomized trial. Pediatrics 1993;92(6):768-74.

Escobedo 2004 \{published data only\}

Escobedo MB, Gunkel JH, Kennedy KA, Shattuck KE, Sánchez PJ, Seidner S, et al. Early surfactant for neonates with mild to moderate respiratory distress syndrome: a multicenter, randomized trial. Journal of Pediatrics 2004;144(6):804-8.

Figueras-Aloy 2001 \{published data only\}

Figueras-Aloy J, Quero J, Carbonell-Estrany X, Ginovart G, PérezRodríguez J, Raspall F, et al. Early administration of the second dose of surfactant (beractant) in the treatment of severe hyaline membrane disease. Acta Pediatrica 2001;90(3):296-301.

\section{Göpel 2011 \{published data only\}}

Göpel W, Kribs A, Ziegler A, Laux R, Hoehn T, Wieg C, et al. Avoidance of mechanical ventilation by surfactant treatment of spontaneously breathing preterm infants (AMV): an open-label, randomised, controlled trial. Lancet 2011;378(9803):1627-34.

\section{Iarŭkova 1999 \{published data only\}}

larŭkova N, Vakrilova L, Slŭncheva B, Dancheva S, Popivanova A, Emilova Z, et al. Administration of exogenous surfactant in very low birth weight infants with RDS. Akuserstvo $i$ Ginekologija 1999;38(1):23-6.

\section{Kattwinkel 1993 \{published data only\}}

Kattwinkel J, Bloom BT, Delmore P, Davis CL, Farrell E, Friss H, et al. Prophylactic administration of calf lung surfactant extract is more effective than early treatment of respiratory distress syndrome in neonates of 29 through 32 weeks' gestation. Pediatrics 1993;92(1):90-8.

\section{Kattwinkel 2000 \{published data only\}}

Kattwinkel J, Bloom BT, Delmore P, Glick C, Brown D, Lopez S, et al. High-versus low-threshold surfactant retreatment for neonatal respiratory distress syndrome. Pediatrics 2000;106(2 Pt 1):282-8 
Kendig 1991 \{published data only\}

Kendig JW, Notter RH, Cox C, Reubens LJ, Davis JM, Maniscalco WM, et al. A comparison of surfactant as immediate prophylaxis and as rescue therapy in newborns of less than 30 weeks' gestation. New England Journal of Medicine 1991;324(13):865-71.

\section{Köksal 2009 \{published data only\}}

Köksal N, Akpinar R, Cetinkaya M. Early administration of the second surfactant dose in preterm infants with severe respiratory distress syndrome. Turkis Journal of Pediatrics 2009;51(6):556-64.

\section{Merritt 1991 \{published data only\}}

Merritt TA, Hallman M, Berry C, Pohjavuori M, Edwards DK, Jaaskelainen J, et al. Randomized, placebo-controlled trial of human surfactant given at birth vs rescue administration in very low birthweight infants with lung immaturity. Journal of Pediatrics 1991;118(4 Pt 1):581-94.

\section{Morley 2008 \{published data only\}}

Morley CJ, Davis PG, Doyle LW, Brion LP, Hascoet JM, Carlin JB, COIN Trial Investigators. Nasal CPAP or intubation at birth for very preterm infants. New England Journal of Medicine 2008;358(7):700-8.

\section{Osborn 2000 \{published data only\}}

Osborn DA, Jeffery HE, Bredemeyer SL, Polverino JM, Reid S. Targeted early rescue surfactant in ventilated preterm infants using the click test. Pediatrics 2000;106(3):E30.

\section{Reininger 2005 \{published data only\}}

Reininger A, Khalak R, Kendig JW, Ryan RM, Stevens TP, Reubens $L$, et al. Surfactant administration by transient intubation in infants 29 to 35 weeks' gestation with respiratory distress syndrome decreases the likelihood of later mechanical ventilation: a randomized controlled trial. Journal of Perinatology 2005;25(11):703-8.

\section{Rojas 2009 \{published data only\}}

Rojas MA, Lozano JM, Rojas MX, Laughon M, Bose CL, Rondon MA, et al. Very early surfactant without mandatory ventilation in premature infants treated with early continuous positive airway pressure: a randomized, controlled trial. Pediatrics 2009;123(1):137-42.

\section{Sandri 2010 \{published data only\}}

Sandri F, Plavka R, Ancora G, Simeoni U, Stranak Z, Martinelli S, et al. Prophylactic or early selective surfactant combined with nCPAP in very preterm infants. Pediatrics 2010;125(6):e1402-9.

\section{SUPPORT 2010 \{published data only\}}

SUPPORT Study Group of the Eunice Kennedy Shriver NICHD Neonatal Research Network, Finer NN, Carlo WA, Walsh MC, Rich W, Gantz MG, Laptook AR, et al. Early CPAP versus surfactant in extremely preterm infants. New England Journal of Medicine 2010;362(21):1970-9.

\section{Verder 1999 \{published data only\}}

Verder H, Albertsen P, Ebbesen F, Greisen G, Robertson B, Bertelsen $A$, et al. Nasal continuous positive airway pressure and early surfactant therapy for respiratory distress syndrome in newborns of less than 30 weeks' gestation. Pediatrics 1999;103(2):E24.

\section{Walti 1995 \{published data only\}}

Walti H, Paris-Llado J, Breart G, Couchard M, and the French Collaborative Multicentre Study Group. Porcine surfactant replacement therapy in newborns of 25-31 weeks' gestation: a randomized multicentre trial of prophylaxis versus rescue with multiple low doses. Acta Paediatrica 1995;84(8):913-21.

\section{Additional references}

\section{Abdel-Latif 2010}

Abdel-Latif ME, Osborn DA. Nebulised surfactant for prevention of morbidity and mortality in preterm infants with or at risk of respiratory distress syndrome. Cochrane Database of Systematic Reviews 2010, Issue 10. [DOI: 10.1002/14651858.CD008310.pub2]

\section{Abdel-Latif 2011}

Abdel-Latif ME, Osborn DA. Laryngeal mask airway surfactant administration for prevention of morbidity and mortality in preterm infants with or at risk of respiratory distress syndrome. Cochrane Database of Systematic Reviews 2011, Issue 7. [DOI: 10.1002/14651858.CD008309.pub2]

\section{Abdel-Latif 2011a}

Abdel-Latif ME, Osborn DA. Pharyngeal instillation of surfactant before the first breath for prevention of morbidity and mortality in preterm infants at risk of respiratory distress syndrome. Cochrane Database of Systematic Reviews 2011, Issue 3. [DOI: 10.1002/14651858.CD008311.pub2]

\section{Crowley 2006}

Crowley P. Prophylactic corticosteroids for preterm delivery. Cochrane Database of Systematic Reviews 2006, Issue 3. [DOI: 10.1002/14651858.CD000065.pub2]

\section{Dargaville 2002}

Dargaville PA, Mills JF, Soll R. Therapeutic lung lavage for meconium aspiration syndrome in newborn infants (Protocol). Cochrane Database of Systematic Reviews 2002, Issue 1. [DOI: 10.1002/14651858.CD003486]

\section{El Shahed 2007}

El Shahed Al, Dargaville P, Ohlsson A, Soll RF. Surfactant for meconium aspiration syndrome in full term/near term infants. Cochrane Database of Systematic Reviews 2007, Issue 3. [DOI: 10.1002/14651858.CD002054.pub2]

\section{Ikegami 1983}

Ikegami M, Jacobs $\mathrm{H}$, Jobe A. Surfactant function in respiratory distress syndrome. Journal of Pediatrics 1983;102(3):443-7.

\section{Jobe 1993}

Jobe AH, Mitchell BR, Gunkel JH. Beneficial effects of the combined use of prenatal corticosteroids and postnatal surfactant in preterm infants. American Journal of Obstetrics and Gynecology 1993;168(2):508-13. 


\section{Nilsson 1978}

Nilsson R, Grossman G, Robertson B. Lung surfactant and the pathogenesis of neonatal bronchiolar lesions induced by artificial ventilation. Pediatric Research 1978;12(4 Pt 1):249-55.

\section{Pfister 2007}

Pfister RH, Soll RF, Wiswell T. Protein containing synthetic surfactant versus animal derived surfactant extract for the prevention and treatment of respiratory distress syndrome. Cochrane Database of Systematic Reviews 2007, Issue 4. [DOI: 10.1002/14651858.CD006069.pub3]

\section{Pfister 2009}

Pfister RH, Soll R, Wiswell TE. Protein-containing synthetic surfactant versus protein-free synthetic surfactant for the prevention and treatment of respiratory distress syndrome. Cochrane Database of Systematic Reviews 2009, Issue 4. [DOI: 10.1002/14651858.CD006180.pub2]

\section{Possmayer 1990}

Possmayer F. The role of surfactant-associated proteins. American Review of Respiratory Disease 1990;142(4):749-52.

\section{RevMan 2011 [Computer program]}

The Nordic Cochrane Centre, The Cochrane Collaboration. Review Manager (RevMan). Version 5.1. Copenhagen: The Nordic Cochrane Centre, The Cochrane Collaboration, 2011.

\section{Rojas-Reyes 2012}

Rojas-Reyes MX, Morley CJ, Soll R. Prophylactic versus selective use of surfactant in preventing morbidity and mortality in preterm infants. Cochrane Database of Systematic Reviews 2012, Issue 3. [DOI: 10.1002/14651858.CD000510.pub2]

\section{Schurch 1992}

Schürch S, Possmayer F, Cheng S, Cockshutt AM. Pulmonary SPA enhances adsorption and appears to induce surface sorting of lipid extract surfactant. American Journal of Physiology 1992;263(2 Pt 1):L210-8.

\section{Seger 2009}

Seger N, Soll R. Animal derived surfactant extract for treatment of respiratory distress syndrome. Cochrane Database of Systematic Reviews 2009, Issue 2. [DOI: 10.1002/14651858.CD007836]

\section{Sinclair 1992}

Sinclair JC, Bracken M (Editors). Effective Care of the Newborn Infant. Oxford: Oxford University Press, 1992.

\section{Singh 2011}

Singh N, Hawley KL, Viswanathan K. Efficacy of porcine versus bovine surfactants for preterm newborns with respiratory distress syndrome: systematic review and meta-analysis. Pediatrics 2011; Vol. 128, issue 6:e1588-95.

\section{Soll 1992}

Soll RF, McQueen MC. Respiratory distress syndrome. In: Sinclair JC, Bracken MB editor(s). Effective Care of the Newborn Infant. Oxford: Oxford University Press, 1992:325-358.

\section{Soll 1997}

Soll RF, Ozek E. Prophylactic animal derived surfactant extract for preventing morbidity and mortality in preterm infants. Cochrane Database of Systematic Reviews 1997, Issue 4. [DOI: 10.1002/14651858.CD000511]

\section{Soll 2000}

Soll RF. Synthetic surfactant for respiratory distress syndrome in preterm infants. Cochrane Database of Systematic Reviews 2000, Issue 2. [DOI: 10.1002/14651858.CD001149]

\section{Soll 2001}

Soll RF, Blanco F. Natural surfactant extract versus synthetic surfactant for neonatal respiratory distress syndrome. Cochrane Database of Systematic Reviews 2001, Issue 2. [DOI: 10.1002/14651858.CD000144]

\section{Soll 2009}

Soll R, Ozek E. Multiple versus single doses of exogenous surfactant for the prevention or treatment of neonatal respiratory distress syndrome. Cochrane Database of Systematic Reviews 2009, Issue 1. [DOI: 10.1002/14651858.CD000141.pub2]

\section{Soll 2010}

Soll R, Ozek E. Prophylactic protein free synthetic surfactant for preventing morbidity and mortality in preterm infants. Cochrane Database of Systematic Reviews 2010, Issue 1. [DOI: 10.1002/14651858.CD001079.pub2]

\section{Stevens 2007}

Stevens TP, Harrington EW, Blennow M, Soll RF. Early surfactant administration with brief ventilation vs. selective surfactant and continued mechanical ventilation for preterm infants with or at risk for respiratory distress syndrome. Cochrane Database of Systematic Reviews 2007, Issue 4. [DOI: 10.1002/14651858.CD003063.pub3]

\section{Tan 2012}

Tan K, Lai NM, Sharma A. Surfactant for bacterial pneumonia in late preterm and term infants. Cochrane Database of Systematic Reviews 2012, Issue 2. [DOI: 10.1002/14651858.CD008155.pub2]

\section{Wright 1997}

Wright JR. Immunomodulatory functions of surfactant. Physiological Reviews 1997;77(4):931-62.

\section{References to other published versions of this review \\ Soll 1999}

Soll R. Early versus delayed selective surfactant treatment for neonatal respiratory distress syndrome. Cochrane Database of Systematic Reviews 1999, Issue 4. [DOI: 10.1002/14651858.CD001456]

* Indicates the major publication for the study 
CHARACTERISTICS OF STUDIES

Characteristics of included studies [ordered by study ID]

European Study 1992

$\begin{array}{ll}\text { Methods } & \text { Randomized multicenter trial+ } \\ & \text { Blinding of randomization: yes (sealed envelope) } \\ \text { Complete follow-up: yes (follow-up scheduled to extend through the first } 2 \text { years of life, but only data } \\ \text { through } 36 \text { weeks' gestational age reported) } \\ \text { Blinding of outcome measurement: yes (full blinding of the interventions achieved with single drug ad- } \\ \text { ministrator delivering air placebo or surfactant. Drug administrator then without clinical responsibili- } \\ \text { ty for ensuing course. Clinical study administrators blinded to results of trial. All data submitted in a se- } \\ \text { quential analysis design for statistical analysis after each } 20 \text { babies. An independent advisory board no- } \\ \text { tified of results possibly warranting termination of the trial) } \\ \text { Stratification: gestational age and gender }\end{array}$

Participants

Early selective treatment: 212 randomized

Delayed selective treatment: 208 randomized

Inclusion criteria:

1. 26 to 29 weeks' gestation by reliable dates or ultrasound examination performed prior to 20 weeks' estimated gestational age

2. intubation and mechanical ventilation required prior to 2 hours of life

3. no stillbirths or major fetal anomalies noted at or prior to delivery

4. no hydrops fetalis, documented intrauterine infection, or confirmed chromosomal anomaly

5. informed consent obtained prior to delivery

Demographics of participants not statically different with respect to sex, gestational age (25 to 32 weeks), and prenatal steroid administration ( $24 \%$ in both early and delayed treatment arms)

Interventions

Early treatment: blinded air placebo versus surfactant (Exosurf $5 \mathrm{~mL} / \mathrm{kg} \times 2$ doses at $<2$ hours and 18 hours of life if no unblinded surfactant rescue treatment needed between 2 and 18 hours of life). Surfactant administered without positional manipulation and delivered via special ETT adaptation without interruption of mechanical ventilation. Surfactant rescue treatment given for $>0.22$ arterial/aveolar ratio

\section{Outcomes}

Primary outcome: survival to 28 days of life with intact CNS survival

Secondary outcomes: incidence of RDS requiring rescue treatment, requirements for ventilatory support, and complications of prematurity

\section{Notes}

\section{Risk of bias}

\begin{tabular}{lll}
\hline Bias & Authors' judgement & Support for judgement \\
\hline $\begin{array}{l}\text { Random sequence genera- } \\
\text { tion (selection bias) }\end{array}$ & Unclear risk & $\begin{array}{l}\text { Randomized multicenter trial } \\
\text { Randomized by means of computer allocation of a unique trial number } \\
\text { Stratification: gestational age and gender }\end{array}$ \\
\hline $\begin{array}{l}\text { Allocation concealment } \\
\text { (selection bias) }\end{array}$ & Low risk & Sealed, opaque envelope containing a card with dosing instructions \\
\hline $\begin{array}{l}\text { Blinding of participants } \\
\text { and personnel (perfor- } \\
\text { mance bias) }\end{array}$ & Low risk & \\
\hline
\end{tabular}


European Study 1992 (Continued)

All outcomes

\section{Blinding of outcome as- Low risk} sessment (detection bias)

Short term outcomes
Outcome assessment blinded (full blinding of the interventions achieved with single drug administrator delivering air placebo or surfactant. Drug administrator then without clinical responsibility for ensuing course. Clinical study administrators blinded to results of trial. All data submitted in a sequential analysis design for statistical analysis after each 20 babies. An independent advisory board notified of results possibly warranting termination of the trial)

Blinding of outcome as- Low risk No long-term developmental outcome reported

sessment (detection bias)

Neurodevelopmental fol-

low up

\begin{tabular}{ll}
\hline $\begin{array}{l}\text { Incomplete outcome data } \\
\text { (attrition bias) }\end{array}$ & Low risk \\
$\begin{array}{l}\text { All outcomes } \\
\text { Noxtend through the first } 2 \text { years of life, but only data through } 36 \text { weeks' gesta- } \\
\text { tional age reported) }\end{array}$
\end{tabular}

\begin{tabular}{lll}
\hline $\begin{array}{l}\text { Selective reporting (re- } \\
\text { porting bias) }\end{array}$ & Low risk & $\begin{array}{l}\text { The study protocol was not available but it is clear that the published reports } \\
\text { included all expected outcomes, including those that were prespecified }\end{array}$ \\
\hline Other bias & Unclear risk & The study appeared to be free of other sources of bias \\
\hline
\end{tabular}

\section{Gortner 1998}

\begin{tabular}{|c|c|}
\hline Methods & $\begin{array}{l}\text { Randomized multicenter trial } \\
\text { Blinding of randomization: yes } \\
\text { Blinding of Intervention: cannot determine } \\
\text { Complete follow-up: yes } \\
\text { Blinding of outcome measurements: cannot determine } \\
\text { Stratification: none }\end{array}$ \\
\hline Participants & $\begin{array}{l}\text { Early selective treatment: } 154 \text { randomized } \\
\text { Delayed selective treatment: } 163 \text { randomized } \\
\text { Inclusion criteria: } \\
\text { 1. prenatal informed consent obtained } \\
\text { 2. gestational age between } 27 \text { and } 32 \text { weeks } \\
\text { 3. no congenital anomalies leading to cardiorespiratory compromise detected at or before deliver } \\
\text { 4. no rupture of membranes with oligo- or polyhydramnios }>3 \text { weeks prior to delivery }\end{array}$ \\
\hline
\end{tabular}

$\begin{array}{ll}\text { Interventions } & \text { Early treatment: intratracheal bovine surfactant }(100 \mathrm{mg} / \mathrm{kg}) \text { during first hour of life if intubation and } \\ \text { mechanical ventilation required }\left(\mathrm{FiO}_{2}>0.5, \mathrm{PaCO}_{2}>60, \mathrm{pH}<7.25 \text { during spontaneous respiration }\right. \\ \text { Delayed treatment: intratracheal bovine surfactant }(100 \mathrm{mg} / \mathrm{kg}) \text { at } 2 \text { to } 6 \text { hours of life if intubated and } \\ \text { requiring } \mathrm{FiO}_{2}>0.4 \text { to adequately oxygenate. Repeat surfactant administrations given as needed with } \\ \text { cumulative dose ceiling of } 200 \mathrm{mg} / \mathrm{kg} \text { with } 50 \mathrm{mg} / \mathrm{kg} \text { repeat doses given no more frequently than every } \\ 8 \text { hours }\end{array}$

Outcomes

Primary outcome: duration of mechanical ventilation

Secondary outcomes: survival, survival without BPD, and complications of prematurity 
Gortner 1998 (Continued)

Risk of bias

\begin{tabular}{|c|c|c|}
\hline Bias & Authors' judgement & Support for judgement \\
\hline $\begin{array}{l}\text { Random sequence genera- } \\
\text { tion (selection bias) }\end{array}$ & Unclear risk & $\begin{array}{l}\text { Randomized multicenter trial } \\
\text { Unknown method of randomization }\end{array}$ \\
\hline $\begin{array}{l}\text { Allocation concealment } \\
\text { (selection bias) }\end{array}$ & Unclear risk & Randomization lists provided by university \\
\hline $\begin{array}{l}\text { Blinding of participants } \\
\text { and personnel (perfor- } \\
\text { mance bias) } \\
\text { All outcomes }\end{array}$ & Unclear risk & Cannot determine blinding of participants, personnel, and outcome assessors \\
\hline $\begin{array}{l}\text { Blinding of outcome as- } \\
\text { sessment (detection bias) } \\
\text { Short term outcomes }\end{array}$ & Unclear risk & Cannot determine blinding of outcome measurements \\
\hline $\begin{array}{l}\text { Blinding of outcome as- } \\
\text { sessment (detection bias) } \\
\text { Neurodevelopmental fol- } \\
\text { low up }\end{array}$ & Unclear risk & Follow-up of a subset of infants reported by Hentschel (2009) \\
\hline $\begin{array}{l}\text { Incomplete outcome data } \\
\text { (attrition bias) } \\
\text { All outcomes }\end{array}$ & Low risk & No missing outcome data \\
\hline $\begin{array}{l}\text { Selective reporting (re- } \\
\text { porting bias) }\end{array}$ & Unclear risk & $\begin{array}{l}\text { The study protocol was not available but it is clear that the published reports } \\
\text { include all expected outcomes, including those that were prespecified }\end{array}$ \\
\hline Other bias & Unclear risk & The study appears to be free of other sources of bias \\
\hline
\end{tabular}

Konishi 1992

\begin{tabular}{ll}
\hline Methods & $\begin{array}{l}\text { Randomized single-center trial } \\
\text { Blinding of randomization: cannot determine } \\
\text { Blinding of intervention: cannot determine } \\
\text { Complete follow-up: yes } \\
\text { Blinding of outcome measurement: cannot determine } \\
\text { Stratification: none }\end{array}$ \\
Early selective treatment: 16 randomized \\
Delayed selective treatment: 16 randomized \\
Inclusion criteria: \\
$\begin{array}{l}\text { 1. AGA } 500 \text { to } 1500 \text { g infants } \\
\text { 2. intubated for early respiratory distress } \\
\text { 3. immature surfactant assay of gastric aspirates } \\
\text { 4. no PROM }>72 \text { hours, maternal fever prenatally, 5-minute Apgar score of } 4 \text { or less, oligo- or polyhy- } \\
\text { dramnios, congenital malformations, WBC }>10 \text { per HPF in gastric contents } \\
\text { 5. informed consent obtained }\end{array}$ \\
\hline
\end{tabular}


Konishi 1992 (Continued)

Interventions $\quad$ Early treatment: surfactant TA $(3 \mathrm{~mL} / \mathrm{kg})$ per ETT in 5 aliquots over 5 minutes given within the first 30 minutes of life. Average age of administration $=18$ minutes Delayed treatment: surfactant TA $(3 \mathrm{~mL} / \mathrm{kg})$ as above given around 6 hours of life. Average age of administration $=6$ hours

Primary outcomes: a/A PO2 gradient and MAP over first 72 hours of life; Ventilatory Index (FiO $2 \times M A P /$

$\left.\mathrm{PaO}_{2}\right) ; 5$ clinical outcomes at 7 and 28 days of life (no support, $\mathrm{O}_{2}, \mathrm{IMV}$ with $\mathrm{O}_{2}<0.3, \mathrm{IMV}_{\text {with } \mathrm{O}_{2}>0.3}$
death)
Secondary outcome: complications of prematurity

Notes

\section{Risk of bias}

\begin{tabular}{lll}
\hline Bias & Authors' judgement & Support for judgement \\
\hline $\begin{array}{l}\text { Random sequence genera- } \\
\text { tion (selection bias) }\end{array}$ & Unclear risk & Randomized single-center trial \\
& & $\begin{array}{l}\text { Unknown method of randomization } \\
\text { Stratification: none }\end{array}$ \\
\hline $\begin{array}{l}\text { Allocation concealment } \\
\text { (selection bias) }\end{array}$ & Unclear risk & Cannot determine blinding of randomization \\
\hline $\begin{array}{l}\text { Blinding of participants } \\
\text { and personnel (perfor- } \\
\text { mance bias) } \\
\begin{array}{l}\text { All outcomes } \\
\text { S }\end{array}\end{array}$ & Unclear risk & Cannot determine blinding of participants, personnel, and outcome assessors \\
\hline
\end{tabular}

\begin{tabular}{lll}
\hline $\begin{array}{l}\text { Blinding of outcome as- } \\
\text { sessment (detection bias) } \\
\text { Short term outcomes }\end{array}$ & Unclear risk & Cannot determine blinding of outcome measurement \\
\hline $\begin{array}{l}\text { Blinding of outcome as- } \\
\text { sessment (detection bias) } \\
\text { Neurodevelopmental fol- } \\
\text { low up }\end{array}$ & Unclear risk & No follow-up reported \\
\hline $\begin{array}{l}\text { Incomplete outcome data } \\
\text { (attrition bias) }\end{array}$ & Low risk & No missing outcome data \\
\hline $\begin{array}{l}\text { All outcomes } \\
\text { pelective reporting (re- }\end{array}$ & Unclear risk & $\begin{array}{l}\text { The study protocol was available and all of the study's prespecified (primary } \\
\text { and secondary) outcomes that are of interest in the review have been reported } \\
\text { in the prespecified way }\end{array}$ \\
\hline \begin{tabular}{l} 
Other bias \\
\hline
\end{tabular} & Unclear risk & \begin{tabular}{l} 
The study appears to be free of other sources of bias \\
\hline
\end{tabular}
\end{tabular}

Lefort 2003

$\begin{array}{ll}\text { Methods } & \text { Randomized single-center trial } \\ & \text { Blinding of randomization: cannot determine } \\ & \text { Blinding of intervention: cannot determine } \\ \text { Complete follow-up: yes } & \text { Blinding of outcome measurement: cannot determine } \\ \text { Stratification: none }\end{array}$


Lefort 2003 (Continued)
Participants
Early selective treatment: 35 randomized
Delayed selective treatment: 40 randomized
Inclusion criteria:
1. informed consent
2. premature infants with high risk of RDS
3. intubation for ventilatory assistance in the delivery room. Criteria for intubation was need for neona- tal resuscitation owing to perinatal asphyxia or when they developed respiratory insufficiency, char- acterized by apnoea and respiratory pauses, or both
4. no major congenital malformations
5. no complications in the prenatal period, such as infection

Interventions

Early treatment: orotracheal intubation and administration of porcine-derived exogenous surfactant, as a bolus, in a single dose of $100 \mathrm{mg} / \mathrm{kg}$, within the first hour of life. Surfactant TA ( $3 \mathrm{~mL} / \mathrm{kg}$ ) per ETT in 5 aliquots over 5 minutes given within the first 30 minutes of life.

Delayed treatment: received porcine-derived surfactant if the following criteria were met: (1) RDS established, diagnosed according to the clinical course and standard radiology; and (2) need for mechanical ventilation, with $\mathrm{FiO}_{2}$ of $>40 \%$ and $\mathrm{PaO}_{2} / \mathrm{FiO}_{2}$ ratio of $\leq 175 \mathrm{mmHg}$

Outcomes

Primary outcomes: pneumothorax, intracranial hemorrhage, patent ductus arteriosus, pulmonary hemorrhage, necrotizing enterocolitis and sepsis, retinopathy of prematurity, BPD (oxygen requirement at 28 days or requirement for supplemental oxygen at 36 weeks' adjusted age) and further need for oxygen therapy, and neonatal survival

Notes -

\section{Risk of bias}

\begin{tabular}{lll}
\hline Bias & Authors' judgement & Support for judgement \\
\hline $\begin{array}{l}\text { Random sequence genera- } \\
\text { tion (selection bias) }\end{array}$ & Unclear risk & Randomized, unknown method of randomization \\
\hline $\begin{array}{l}\text { Allocation concealment } \\
\text { (selection bias) }\end{array}$ & Low risk & Sealed envelopes were used \\
\hline $\begin{array}{l}\text { Blinding of participants } \\
\text { and personnel (perfor- } \\
\text { mance bias) } \\
\text { All outcomes }\end{array}$ & Unclear risk & Cannot determine blinding of participants, personnel, and outcome assessors \\
\hline
\end{tabular}

Blinding of outcome as-
sessment (detection bias) $\quad$ Unclear risk Cannot determine blinding of outcome assessment

Short term outcomes

\begin{tabular}{ll}
\hline Blinding of outcome as- & Unclear risk \\
sessment (detection bias) & \\
Neurodevelopmental fol- & \\
low up & \\
\hline
\end{tabular}

Incomplete outcome data Low risk No missing outcome data
(attrition bias)

All outcomes 
Lefort 2003 (Continued)

$\begin{array}{ll}\begin{array}{l}\text { Selective reporting (re- } \quad \text { Low risk } \\ \text { porting bias) }\end{array} & \begin{array}{l}\text { The study protocol was not available but it is clear that the published reports } \\ \text { include all expected outcomes, including those that were prespecified }\end{array}\end{array}$

Other bias Low risk The study appears to be free of other sources of bias

\section{OSIRIS 1992}

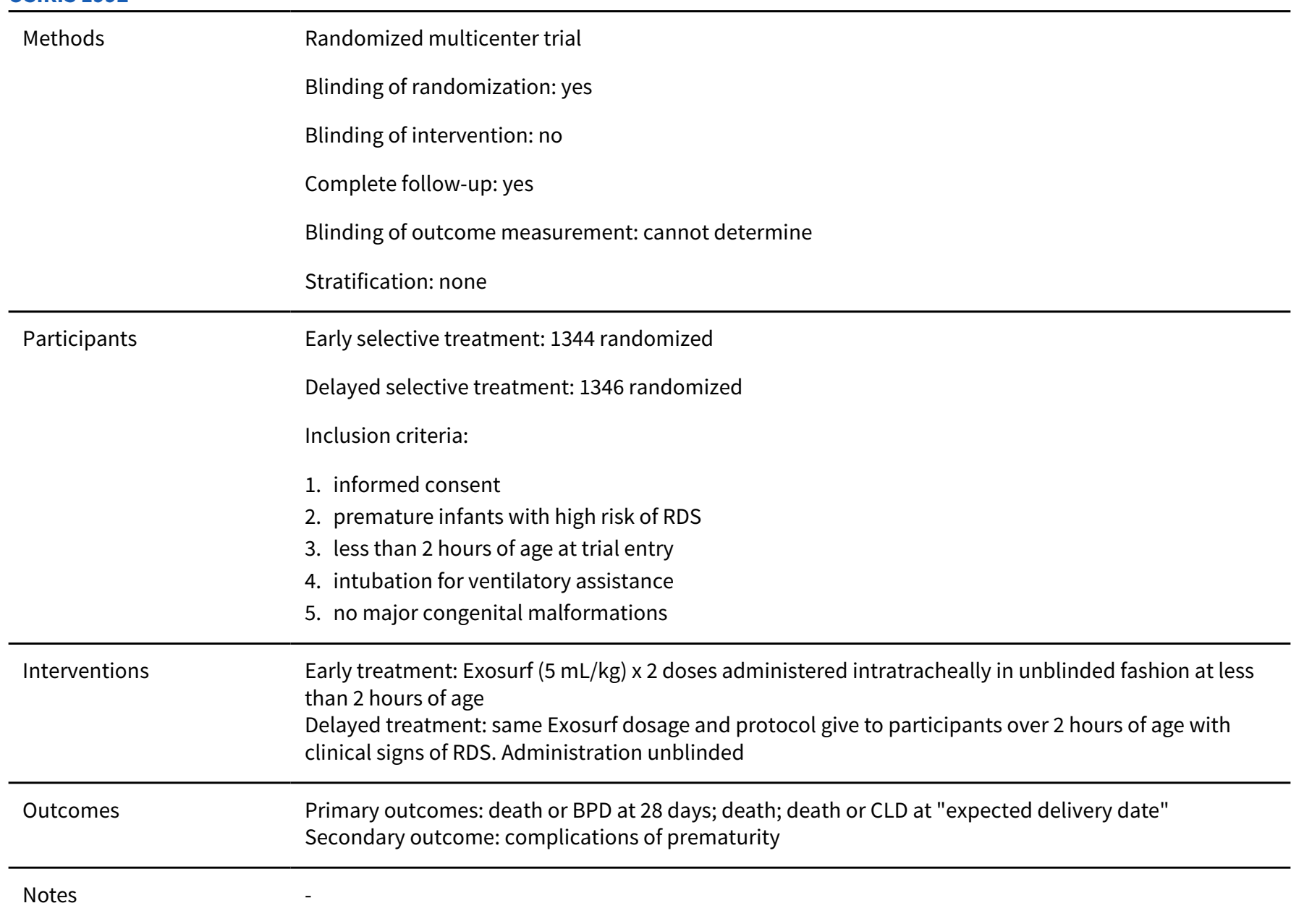

\section{Risk of bias}

\begin{tabular}{|c|c|c|}
\hline Bias & Authors' judgement & Support for judgement \\
\hline \multirow{3}{*}{$\begin{array}{l}\text { Random sequence genera- } \\
\text { tion (selection bias) }\end{array}$} & Low risk & Randomized multicenter trial \\
\hline & & Unknown method of randomization \\
\hline & & Stratification: none \\
\hline \multirow{2}{*}{$\begin{array}{l}\text { Allocation concealment } \\
\text { (selection bias) }\end{array}$} & Low risk & There is blinding of randomization \\
\hline & & Central allocation with telephone calls \\
\hline $\begin{array}{l}\text { Blinding of participants } \\
\text { and personnel (perfor- } \\
\text { mance bias) }\end{array}$ & Unclear risk & $\begin{array}{l}\text { All treatment was open without blinding, but the review authors judge that the } \\
\text { outcome and the outcome measurement were not likely to be influenced by } \\
\text { lack of blinding }\end{array}$ \\
\hline
\end{tabular}


OSIRIS 1992 (Continued)

All outcomes

Blinding of outcome as-
sessment (detection bias) $\quad$ Unclear risk Cannot determine blinding of outcome measurement

sessment (detection bias)

Short term outcomes

Blinding of outcome as- Unclear risk No follow-up reported

sessment (detection bias)

Neurodevelopmental fol-

low up

Incomplete outcome data Low risk No missing outcome data
(attrition bias)
All outcomes

\begin{tabular}{ll}
\hline $\begin{array}{l}\text { Selective reporting (re- } \\
\begin{array}{l}\text { porting bias) } \\
\text { Low risk }\end{array}\end{array}$ & $\begin{array}{l}\text { The study protocol was available and all of the study's prespecified (primary } \\
\text { and secondary) outcomes that were of interest in the review have been report- } \\
\text { ed in the prespecified way }\end{array}$
\end{tabular}

\begin{tabular}{ll}
\hline Other bias $\quad$ Low risk $\quad$ The study appeared to be free of other sources of bias \\
\hline
\end{tabular}

\section{Plavka 2002}

Methods $\quad$ Randomized multicenter trial
Blinding of randomization: yes
Blinding of intervention: no
Complete follow-up: yes
Blinding of outcome measurement: cannot determine
Stratification: none

\section{Participants}

The study included 43 extremely premature infants who needed artificial ventilation within 3 hours after delivery who were randomly assigned to either early $(\mathrm{N}=21)$ or delayed $(\mathrm{N}=22)$ administration of animal-derived surfactant

Early selective treatment: 21 randomized

Delayed selective treatment: 22 randomized

Inclusion criteria:

1. gestational age below 30 weeks of gestation

2. intubation and assisted ventilation needed within 3 hours after delivery for significant RDS

3. written parental informed consent

4. no major congenital malformations

Interventions

Early treatment: natural porcine surfactant Curosurf given at a dose of $100 \mathrm{mg} / \mathrm{kg}$ was given as a single bolus via the ETT within 1 minute after intubation followed by 3 to 5 manual breaths. High-frequency oscillatory ventilation was then initiated as soon as possible

Delayed treatment: Curosurf given at same dosage as stated above administered during high-frequency oscillatory ventilation once the following criteria were reached: (1) $\mathrm{FiO}_{2} \geq 0.35$ or (2) MAP> $10 \mathrm{cmH}_{2} \mathrm{O}$

Outcomes

Primary outcome: CLD or death at 36 weeks' postconceptual age

Secondary outcome: 
Plavka 2002 (Continued)

\author{
duration of mechanical ventilation; \\ incidence of air leaks; \\ pneumothorax; \\ pulmonary interstitial emphysema; \\ radiographic score according to the Toce scale at age 28 to 30 days;
}

incidence of other complications of prematurity such as IVH, periventricular leukomalacia, retinopathy of prematurity, and necrotizing enterocolitis

\begin{tabular}{|c|c|c|}
\hline Notes & - & \\
\hline \multicolumn{3}{|l|}{ Risk of bias } \\
\hline Bias & Authors' judgement & Support for judgement \\
\hline $\begin{array}{l}\text { Random sequence genera- } \\
\text { tion (selection bias) }\end{array}$ & Unclear risk & Randomized, treatment assignment based on table with random numbers \\
\hline $\begin{array}{l}\text { Allocation concealment } \\
\text { (selection bias) }\end{array}$ & Low risk & Sealed envelopes \\
\hline $\begin{array}{l}\text { Blinding of participants } \\
\text { and personnel (perfor- } \\
\text { mance bias) } \\
\text { All outcomes }\end{array}$ & Unclear risk & Cannot determine blinding of participants, personnel, and outcome assessors \\
\hline $\begin{array}{l}\text { Blinding of outcome as- } \\
\text { sessment (detection bias) } \\
\text { Short term outcomes }\end{array}$ & Unclear risk & Cannot determine blinding of outcome assessment \\
\hline $\begin{array}{l}\text { Blinding of outcome as- } \\
\text { sessment (detection bias) } \\
\text { Neurodevelopmental fol- } \\
\text { low up }\end{array}$ & Unclear risk & No follow-up reported \\
\hline $\begin{array}{l}\text { Incomplete outcome data } \\
\text { (attrition bias) } \\
\text { All outcomes }\end{array}$ & Low risk & No missing outcome data \\
\hline $\begin{array}{l}\text { Selective reporting (re- } \\
\text { porting bias) }\end{array}$ & Low risk & $\begin{array}{l}\text { The study protocol was not available but it is clear that the published reports } \\
\text { include all expected outcomes, including those that were prespecified }\end{array}$ \\
\hline Other bias & Low risk & The study appears to be free of other sources of bias \\
\hline
\end{tabular}

AGA: appropriate for gestational age; BPD: bronchopulmonary dysplasia; CLD: chronic lung disease; CNS: central nervous system; ETT: endotracheal tube; HPF: high power field; IMV: intermittent mandatory ventilation; IVH: intraventricular hemorrhage; MAP: mean airway pressure; PROM: premature rupture of membranes; RDS: respiratory distress syndrome; WBC: white blood cell count.

\title{
Characteristics of excluded studies [ordered by study ID]
}

\begin{tabular}{ll}
\hline Study & Reason for exclusion \\
\hline Bevilacqua 1996 & Study of prophylactic surfactant in RDS \\
\hline
\end{tabular}




\begin{tabular}{|c|c|}
\hline Study & Reason for exclusion \\
\hline Bevilacqua 1997 & Study comparing use of prophylactic surfactant versus rescue therapy \\
\hline Dunn 1991 & Study comparing use of prophylactic surfactant versus rescue therapy \\
\hline Dunn 2011 & $\begin{array}{l}\text { Study comparing } 3 \text { initial approaches to RDS: prophylactic surfactant; prophylactic surfactant with } \\
\text { rapid extubation to bubble nCPAP; and selective surfactant treatment }\end{array}$ \\
\hline Egberts 1993 & Study comparing use of prophylactic surfactant versus rescue therapy \\
\hline Escobedo 2004 & Study of intubation, surfactant treatment, extubation \\
\hline Figueras-Aloy 2001 & Study of surfactant retreatment after initial dose of surfactant \\
\hline Göpel 2011 & Study of administering surfactant to infants on nCPAP in order to avoid mechanical ventilation \\
\hline larŭkova 1999 & Study of prophylactic surfactant in RDS \\
\hline Kattwinkel 1993 & Study comparing use of prophylactic surfactant versus rescue therapy \\
\hline Kattwinkel 2000 & Study of surfactant retreatment after initial dose of surfactant \\
\hline Kendig 1991 & Study comparing use of prophylactic surfactant versus rescue therapy \\
\hline Köksal 2009 & Study of surfactant retreatment after initial dose of surfactant \\
\hline Merritt 1991 & Study comparing use of prophylactic surfactant versus rescue therapy \\
\hline Morley 2008 & $\begin{array}{l}\text { Study comparing infants on mechanical ventilation versus nCPAP after administration of surfac- } \\
\text { tant therapy }\end{array}$ \\
\hline Osborn 2000 & Study of prophylactic surfactant administration determined by use with the click test \\
\hline Reininger 2005 & Study of intubation, surfactant treatment, extubation \\
\hline Rojas 2009 & Study of surfactant therapy in infants on nCPAP rather than mechanical ventilation \\
\hline Sandri 2010 & Study comparing prophylactic surfactant versus early selective surfactant combined with nCPAP \\
\hline SUPPORT 2010 & Study comparing prophylactic surfactant to early stabilization on nCPAP \\
\hline Verder 1999 & Study of intubation, surfactant treatment, extubation \\
\hline Walti 1995 & Study comparing use of prophylactic surfactant versus rescue therapy \\
\hline
\end{tabular}

nCPAP: nasal continuous positive airway pressure; RDS: respiratory distress syndrome.

\section{DATA AND ANALYSES}


Comparison 1. Early versus delayed selective surfactant treatment

\begin{tabular}{|c|c|c|c|c|}
\hline Outcome or subgroup title & $\begin{array}{l}\text { No. of } \\
\text { studies }\end{array}$ & $\begin{array}{l}\text { No. of } \\
\text { partici- } \\
\text { pants }\end{array}$ & Statistical method & Effect size \\
\hline 1 Neonatal mortality & 6 & 3577 & Risk Ratio (M-H, Fixed, 95\% Cl) & $0.84[0.74,0.95]$ \\
\hline 1.1 Synthetic surfactant & 2 & 3110 & Risk Ratio (M-H, Fixed, 95\% Cl) & $0.85[0.75,0.96]$ \\
\hline 1.2 Animal-derived surfactant & 4 & 467 & Risk Ratio (M-H, Fixed, 95\% Cl) & $0.69[0.44,1.09]$ \\
\hline 2 Mortality at discharge & 5 & 3157 & Risk Ratio (M-H, Fixed, 95\% Cl) & $0.88[0.78,0.99]$ \\
\hline 2.1 Synthetic surfactant & 1 & 2690 & Risk Ratio (M-H, Fixed, 95\% Cl) & $0.89[0.79,1.01]$ \\
\hline 2.2 Animal-derived surfactant & 4 & 467 & Risk Ratio (M-H, Fixed, 95\% Cl) & $0.74[0.47,1.15]$ \\
\hline 3 Bronchopulmonary dysplasia & 4 & 3114 & Risk Ratio (M-H, Fixed, 95\% Cl) & $0.97[0.88,1.07]$ \\
\hline 3.1 Synthetic surfactant & 1 & 2690 & Risk Ratio (M-H, Fixed, 95\% Cl) & $0.97[0.88,1.08]$ \\
\hline 3.2 Animal-derived surfactant & 3 & 424 & Risk Ratio (M-H, Fixed, 95\% Cl) & $0.94[0.67,1.31]$ \\
\hline 4 BPD or death at 28 to 30 days & 3 & 3039 & Risk Ratio (M-H, Fixed, 95\% Cl) & $0.94[0.88,1.00]$ \\
\hline 4.1 Synthetic surfactant & 1 & 2690 & Risk Ratio (M-H, Fixed, 95\% Cl) & $0.94[0.88,1.00]$ \\
\hline 4.2 Animal-derived surfactant & 2 & 349 & Risk Ratio (M-H, Fixed, 95\% Cl) & $0.95[0.68,1.31]$ \\
\hline 5 Chronic lung disease & 3 & 3050 & Risk Ratio (M-H, Fixed, 95\% Cl) & $0.69[0.55,0.87]$ \\
\hline 5.1 Synthetic surfactant & 1 & 2690 & Risk Ratio (M-H, Fixed, 95\% Cl) & $0.70[0.55,0.89]$ \\
\hline 5.2 Animal-derived surfactant & 2 & 360 & Risk Ratio (M-H, Fixed, 95\% Cl) & $0.61[0.30,1.22]$ \\
\hline 6 CLD or death at 36 weeks' PMA & 3 & 3050 & Risk Ratio (M-H, Fixed, 95\% Cl) & $0.83[0.75,0.91]$ \\
\hline 6.1 Synthetic surfactant & 1 & 2690 & Risk Ratio (M-H, Fixed, 95\% Cl) & $0.84[0.75,0.93]$ \\
\hline 6.2 Animal-derived surfactant & 2 & 360 & Risk Ratio (M-H, Fixed, 95\% Cl) & $0.65[0.39,1.10]$ \\
\hline 7 Any air leak syndrome & 2 & 463 & Risk Ratio (M-H, Fixed, 95\% Cl) & $0.61[0.48,0.78]$ \\
\hline 7.1 Synthetic Surfactant & 1 & 420 & Risk Ratio (M-H, Fixed, 95\% Cl) & $0.63[0.49,0.80]$ \\
\hline 7.2 Animal-derived surfactant & 1 & 43 & Risk Ratio (M-H, Fixed, 95\% Cl) & $0.15[0.01,2.73]$ \\
\hline 8 Pneumothorax & 5 & 3545 & Risk Ratio (M-H, Fixed, 95\% Cl) & $0.69[0.59,0.82]$ \\
\hline 8.1 Synthetic surfactant & 2 & 3110 & Risk Ratio (M-H, Fixed, 95\% Cl) & $0.69[0.58,0.81]$ \\
\hline 8.2 Animal-derived surfactant & 3 & 435 & Risk Ratio (M-H, Fixed, 95\% Cl) & $0.78[0.42,1.45]$ \\
\hline 9 Pulmonary interstitial emphysema & 3 & 780 & Risk Ratio (M-H, Fixed, 95\% Cl) & $0.60[0.41,0.89]$ \\
\hline 9.1 Synthetic surfactant & 1 & 420 & Risk Ratio (M-H, Fixed, 95\% Cl) & $0.62[0.40,0.94]$ \\
\hline
\end{tabular}




\begin{tabular}{|c|c|c|c|c|}
\hline Outcome or subgroup title & $\begin{array}{l}\text { No. of } \\
\text { studies }\end{array}$ & $\begin{array}{l}\text { No. of } \\
\text { partici- } \\
\text { pants }\end{array}$ & Statistical method & Effect size \\
\hline 9.2 Animal-derived surfactant & 2 & 360 & Risk Ratio (M-H, Fixed, 95\% Cl) & $0.55[0.22,1.39]$ \\
\hline 10 Pulmonary hemorrhage & 3 & 3082 & Risk Ratio (M-H, Fixed, 95\% Cl) & $0.98[0.73,1.32]$ \\
\hline 10.1 Synthetic surfactant & 1 & 2690 & Risk Ratio (M-H, Fixed, 95\% Cl) & $1.01[0.75,1.37]$ \\
\hline 10.2 Animal-derived surfactant & 2 & 392 & Risk Ratio (M-H, Fixed, 95\% Cl) & $0.60[0.17,2.10]$ \\
\hline 11 Patent ductus arteriosus & 6 & 3577 & Risk Ratio (M-H, Fixed, 95\% Cl) & $1.02[0.92,1.14]$ \\
\hline 11.2 Animal-derived surfactant & 4 & 467 & Risk Ratio (M-H, Fixed, 95\% Cl) & $1.09[0.77,1.55]$ \\
\hline 12 Confirmed bacterial sepsis & 1 & 75 & Risk Ratio (M-H, Fixed, 95\% Cl) & $1.14[0.81,1.60]$ \\
\hline 12.1 Synthetic surfactant & 0 & 0 & Risk Ratio (M-H, Fixed, 95\% Cl) & $0.0[0.0,0.0]$ \\
\hline 12.2 Animal-derived surfactant & 1 & 75 & Risk Ratio (M-H, Fixed, 95\% Cl) & $1.14[0.81,1.60]$ \\
\hline 13 Necrotizing enterocolitis & 5 & 3545 & Risk Ratio (M-H, Fixed, 95\% Cl) & $1.01[0.73,1.38]$ \\
\hline 13.1 Synthetic surfactant & 2 & 3110 & Risk Ratio (M-H, Fixed, 95\% Cl) & $1.07[0.75,1.51]$ \\
\hline 13.2 Animal-derived surfactant & 3 & 435 & Risk Ratio (M-H, Fixed, 95\% Cl) & $0.72[0.32,1.62]$ \\
\hline 14.1 Synthetic surfactant & 0 & 0 & Risk Ratio (M-H, Fixed, 95\% Cl) & $0.0[0.0,0.0]$ \\
\hline 14.2 Animal-derived surfactant & 3 & 150 & Risk Ratio (M-H, Fixed, 95\% Cl) & $0.69[0.43,1.10]$ \\
\hline 15 Intraventricular hemorrhage (severe) & 3 & 3050 & Risk Ratio (M-H, Fixed, 95\% Cl) & $0.96[0.82,1.12]$ \\
\hline 15.1 Synthetic surfactant & 1 & 2690 & Risk Ratio (M-H, Fixed, 95\% Cl) & $0.95[0.81,1.12]$ \\
\hline 15.2 Animal-derived surfactant & 2 & 360 & Risk Ratio (M-H, Fixed, 95\% Cl) & $1.06[0.47,2.38]$ \\
\hline 16 Periventricular leukomalacia & 1 & 43 & Risk Ratio (M-H, Fixed, 95\% Cl) & $0.15[0.01,2.73]$ \\
\hline 16.1 Synthetic surfactant & 0 & 0 & Risk Ratio (M-H, Fixed, 95\% Cl) & $0.0[0.0,0.0]$ \\
\hline 16.2 Animal-derived surfactant & 1 & 43 & Risk Ratio (M-H, Fixed, 95\% Cl) & $0.15[0.01,2.73]$ \\
\hline 17 Retinopathy of prematurity (any) & 1 & 75 & Risk Ratio (M-H, Fixed, 95\% Cl) & $3.43[0.37,31.48]$ \\
\hline 17.1 Synthetic surfactant & 0 & 0 & Risk Ratio (M-H, Fixed, 95\% Cl) & $0.0[0.0,0.0]$ \\
\hline 17.2 Animal-derived surfactant & 1 & 75 & Risk Ratio (M-H, Fixed, 95\% Cl) & $3.43[0.37,31.48]$ \\
\hline $\begin{array}{l}18 \text { Retinopathy of prematurity stage } 3 \text { or } \\
\text { greater }\end{array}$ & 3 & 3050 & Risk Ratio (M-H, Fixed, 95\% Cl) & $1.05[0.62,1.78]$ \\
\hline
\end{tabular}




\begin{tabular}{lllll}
\hline Outcome or subgroup title & $\begin{array}{l}\text { No. of } \\
\text { studies }\end{array}$ & $\begin{array}{l}\text { No. of } \\
\text { partici- } \\
\text { pants }\end{array}$ & Statistical method & Effect size \\
\hline 18.1 Synthetic surfactant & 1 & 2690 & Risk Ratio (M-H, Fixed, 95\% Cl) & $1.11[0.59,2.09]$ \\
\hline 18.2 Animal-derived surfactant & 2 & 360 & Risk Ratio (M-H, Fixed, 95\% Cl) & $0.92[0.36,2.33]$ \\
\hline 19 Long-term follow-up & 1 & & Risk Ratio (M-H, Fixed, 95\% Cl) & Subtotals only \\
\hline 19.1 Visual impairment & 1 & 167 & Risk Ratio (M-H, Fixed, 95\% Cl) & $0.91[0.48,1.70]$ \\
\hline 19.2 Auditory impairment & 1 & 167 & Risk Ratio (M-H, Fixed, 95\% Cl) & $0.58[0.05,6.32]$ \\
\hline 19.3 Pathologic muscular tone & 1 & 167 & Risk Ratio (M-H, Fixed, 95\% Cl) & $2.14[1.14,4.04]$ \\
\hline 19.4 Pathologic walking & 1 & 167 & Risk Ratio (M-H, Fixed, 95\% Cl) & $0.97[0.31,3.07]$ \\
\hline
\end{tabular}

Analysis 1.1. Comparison 1 Early versus delayed selective surfactant treatment, Outcome 1 Neonatal mortality.

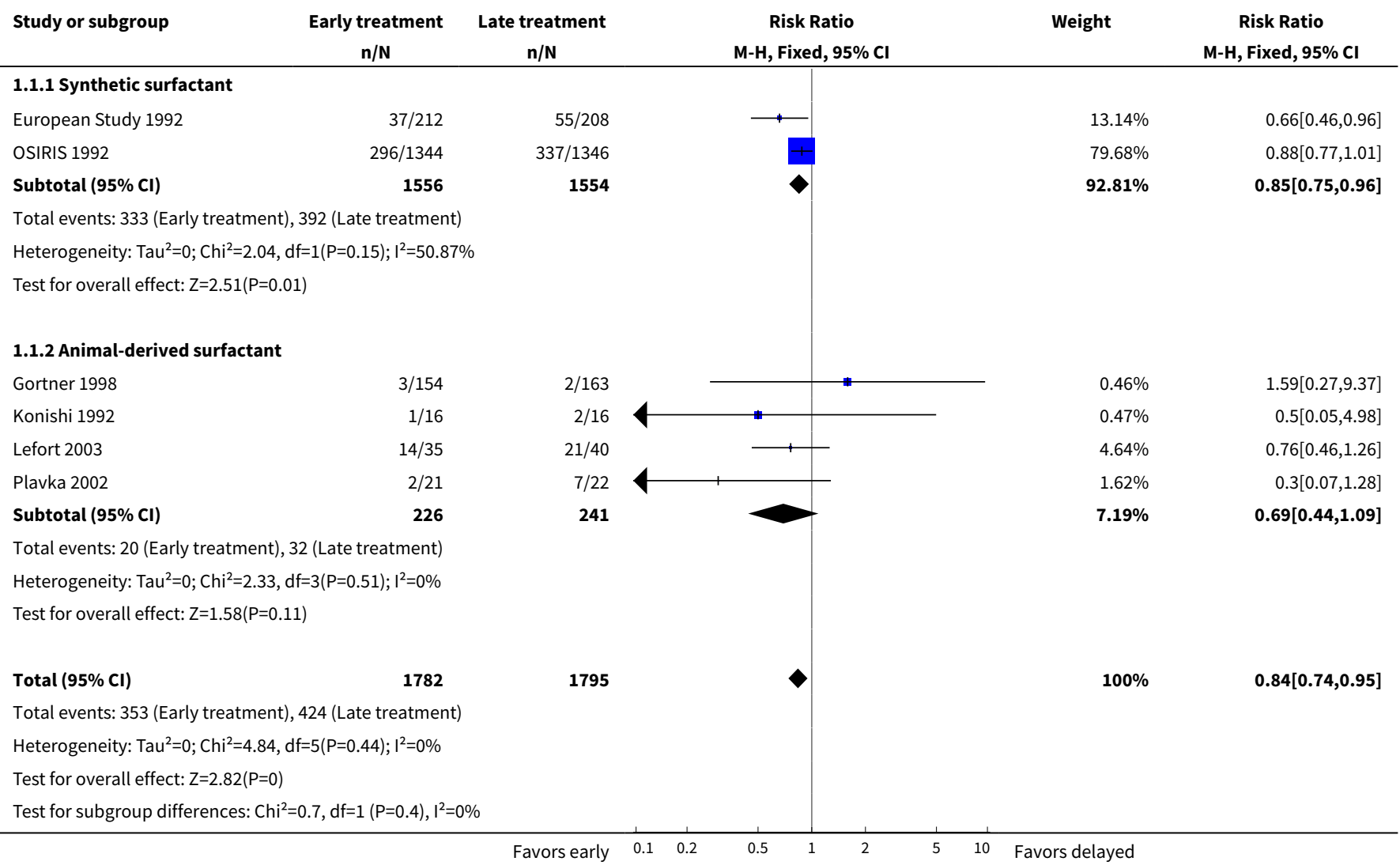


Analysis 1.2. Comparison 1 Early versus delayed selective surfactant treatment, Outcome 2 Mortality at discharge.

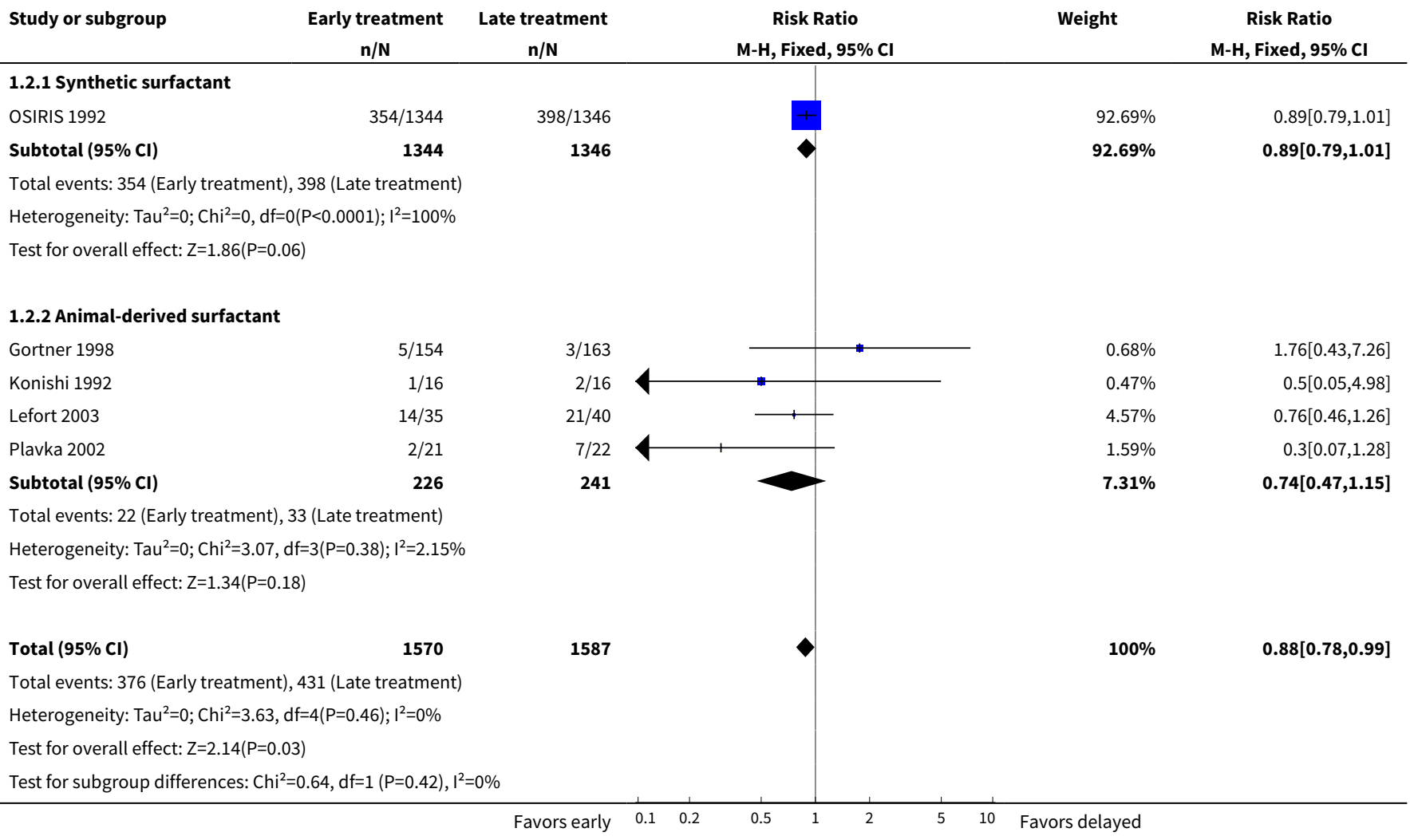

Analysis 1.3. Comparison 1 Early versus delayed selective surfactant treatment, Outcome 3 Bronchopulmonary dysplasia.

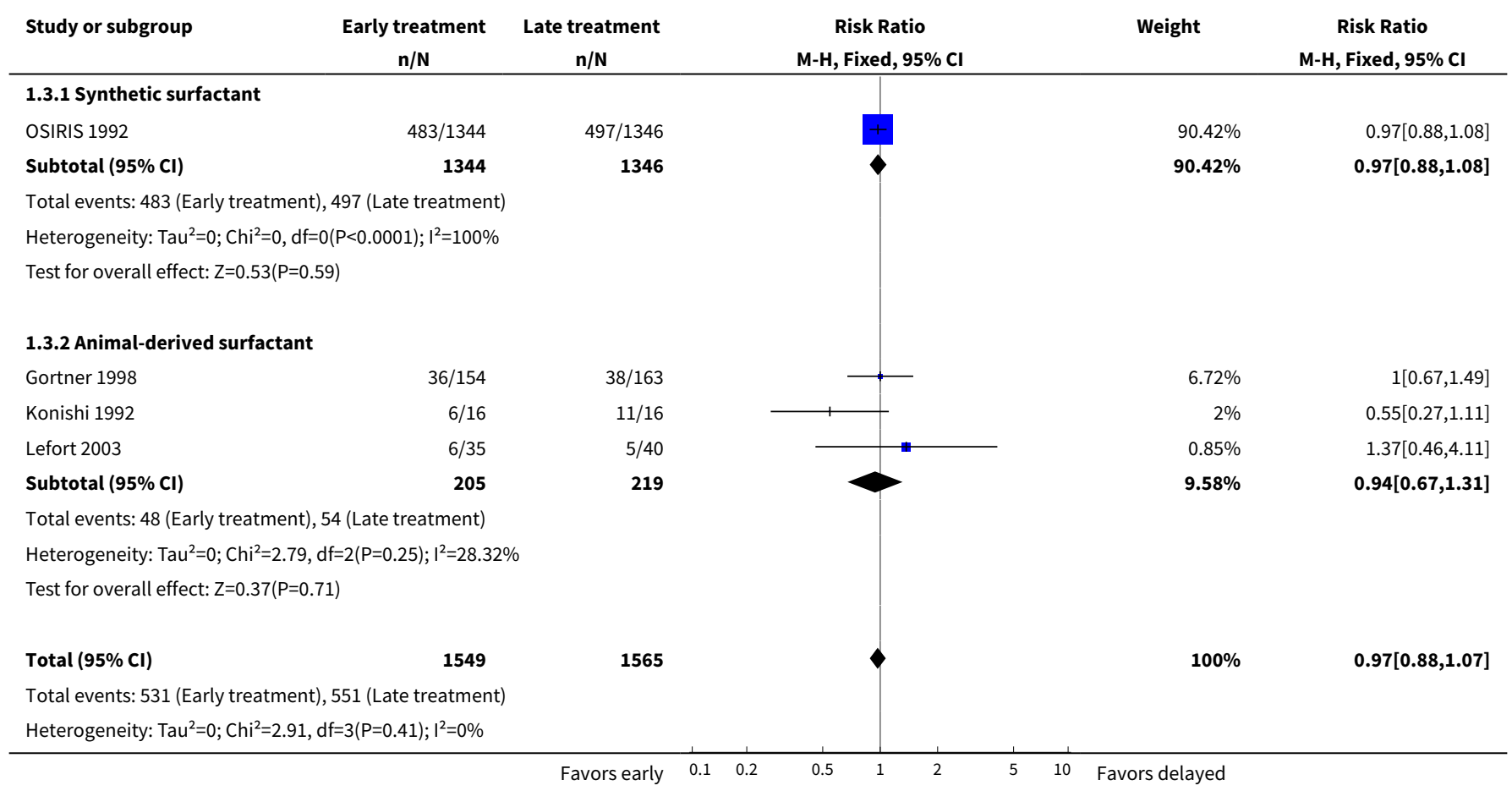




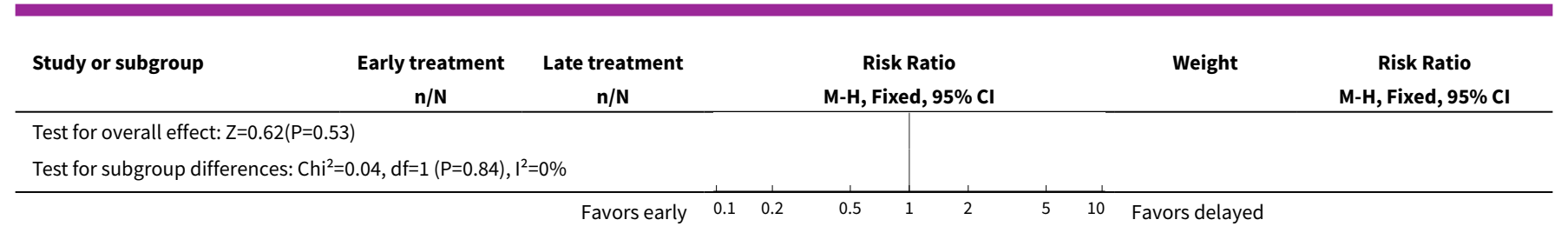

Analysis 1.4. Comparison 1 Early versus delayed selective surfactant treatment, Outcome 4 BPD or death at 28 to 30 days.

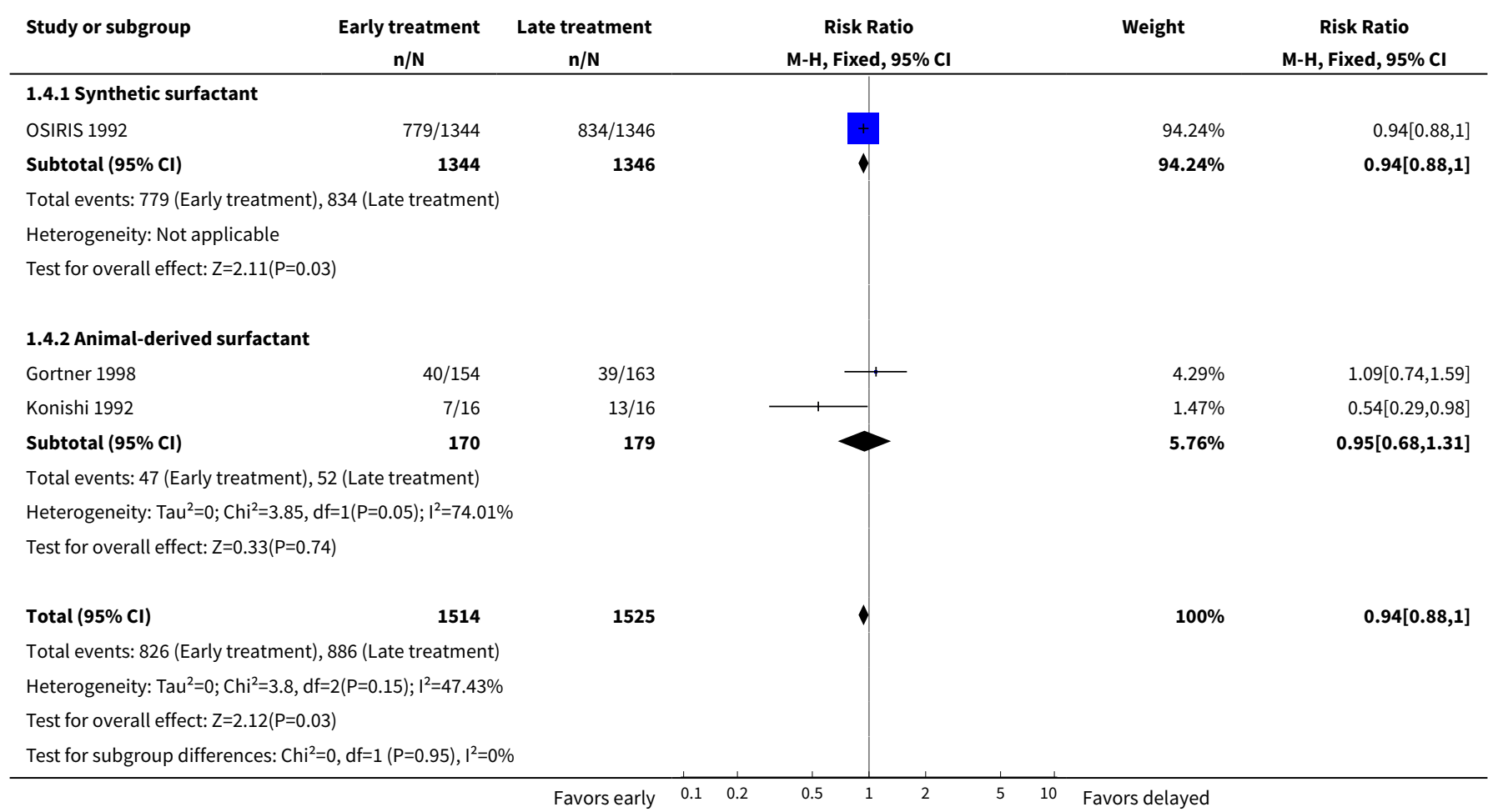

\section{Analysis 1.5. Comparison 1 Early versus delayed selective surfactant treatment, Outcome 5 Chronic lung disease.}

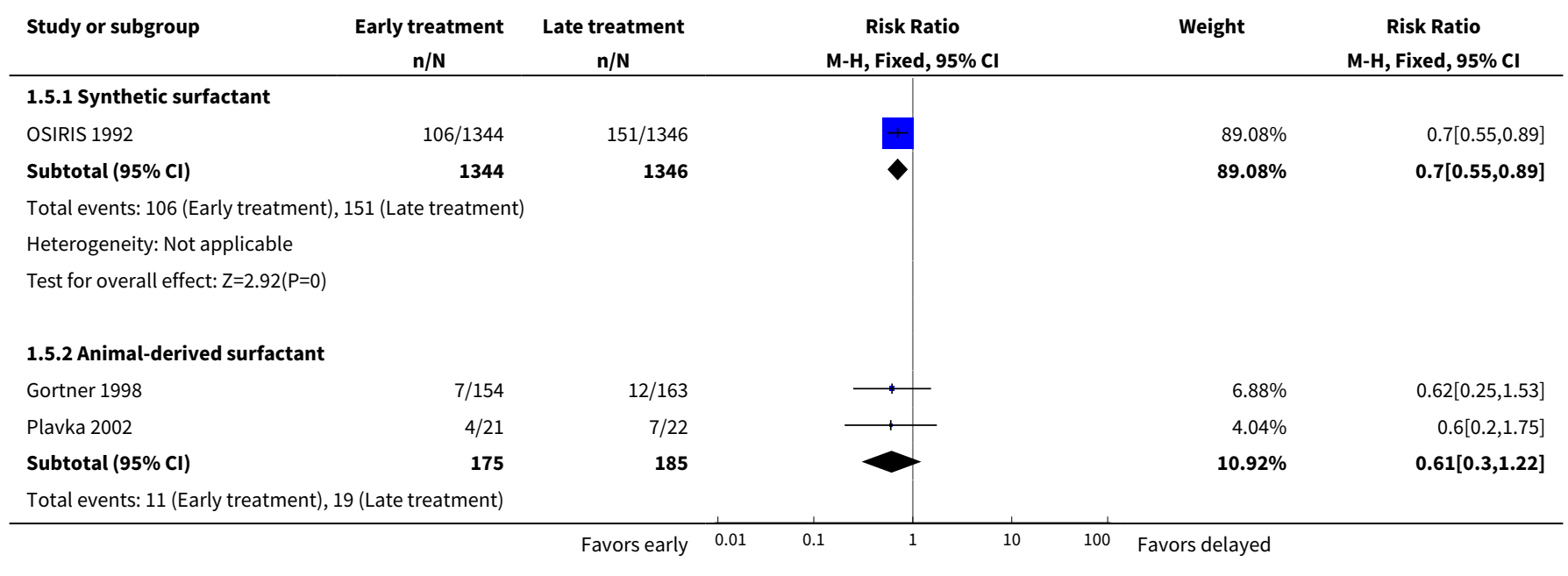




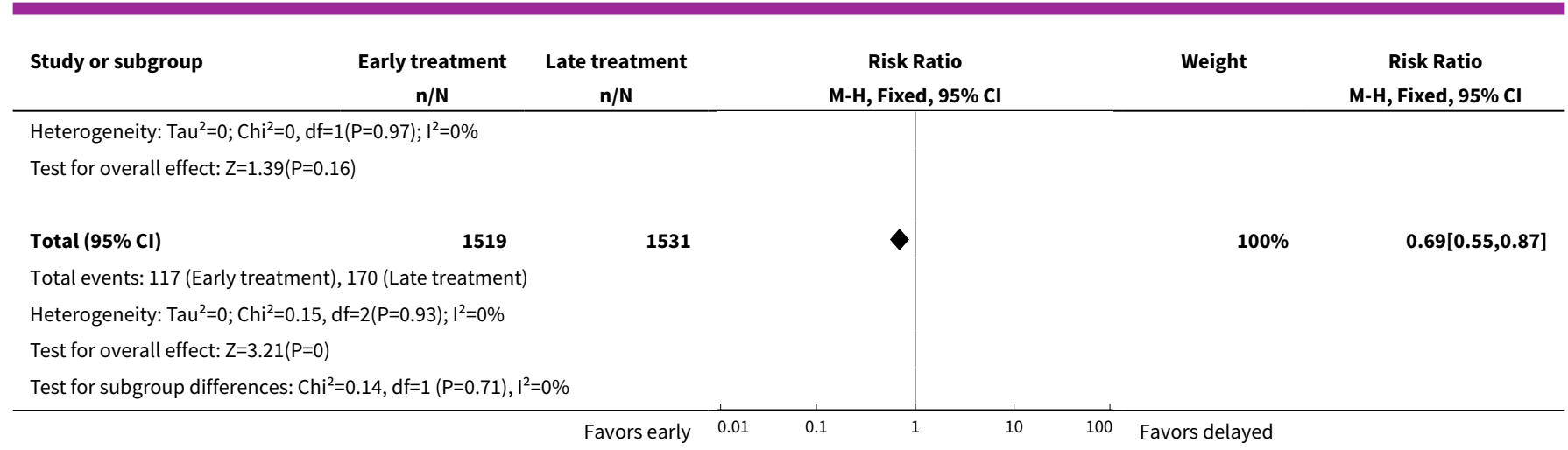

Analysis 1.6. Comparison 1 Early versus delayed selective surfactant treatment, Outcome 6 CLD or death at 36 weeks' PMA.

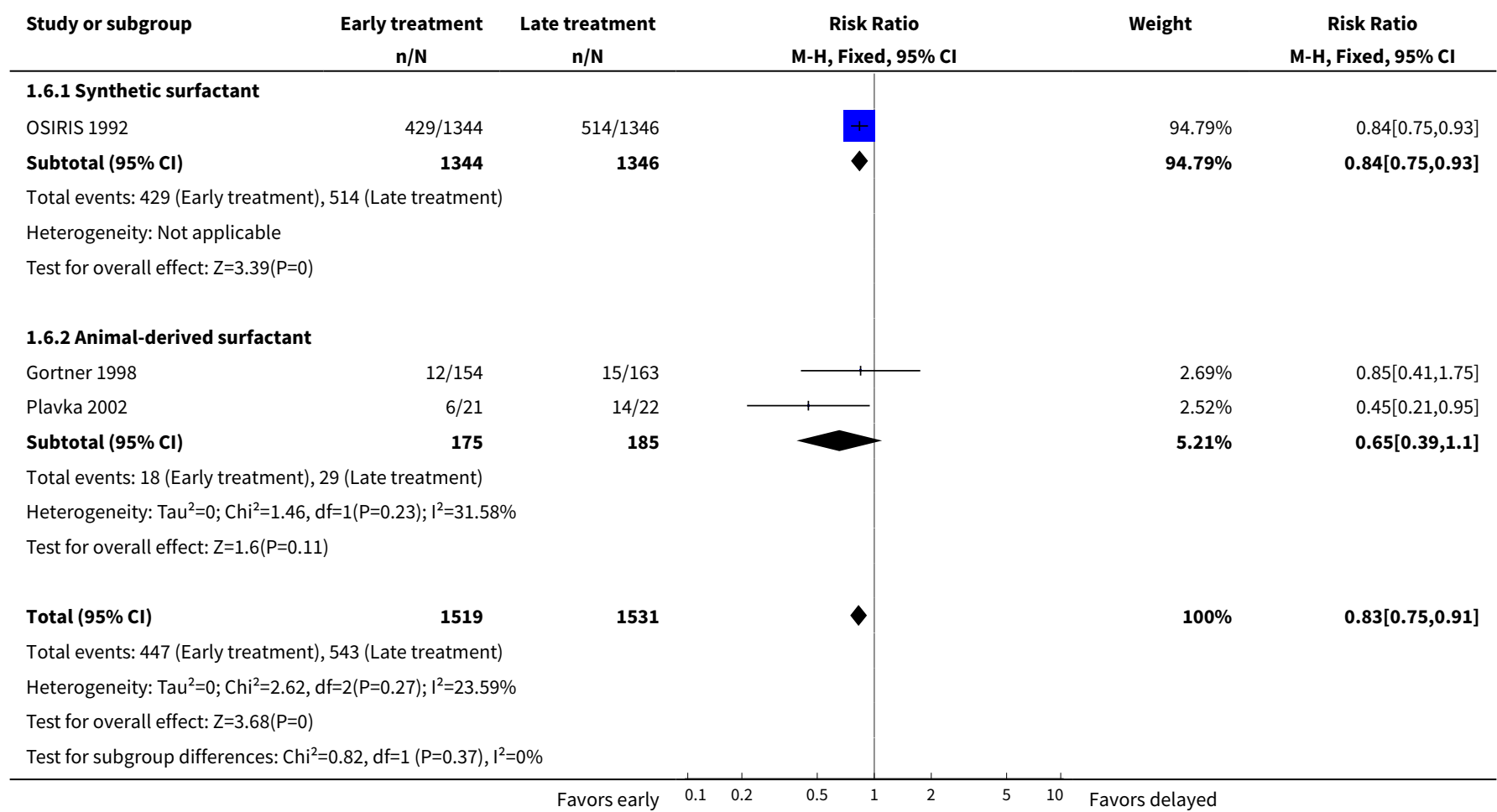

Analysis 1.7. Comparison 1 Early versus delayed selective surfactant treatment, Outcome 7 Any air leak syndrome.

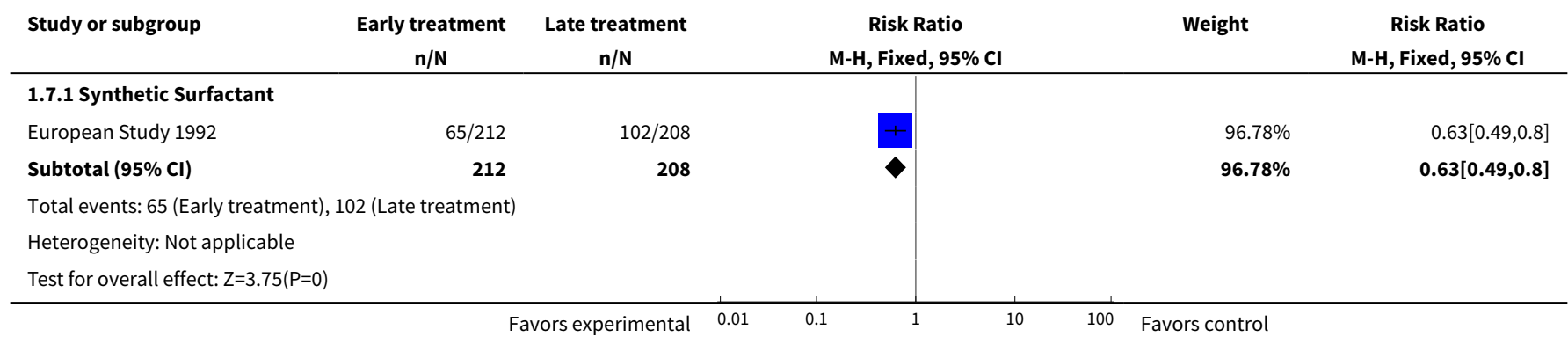




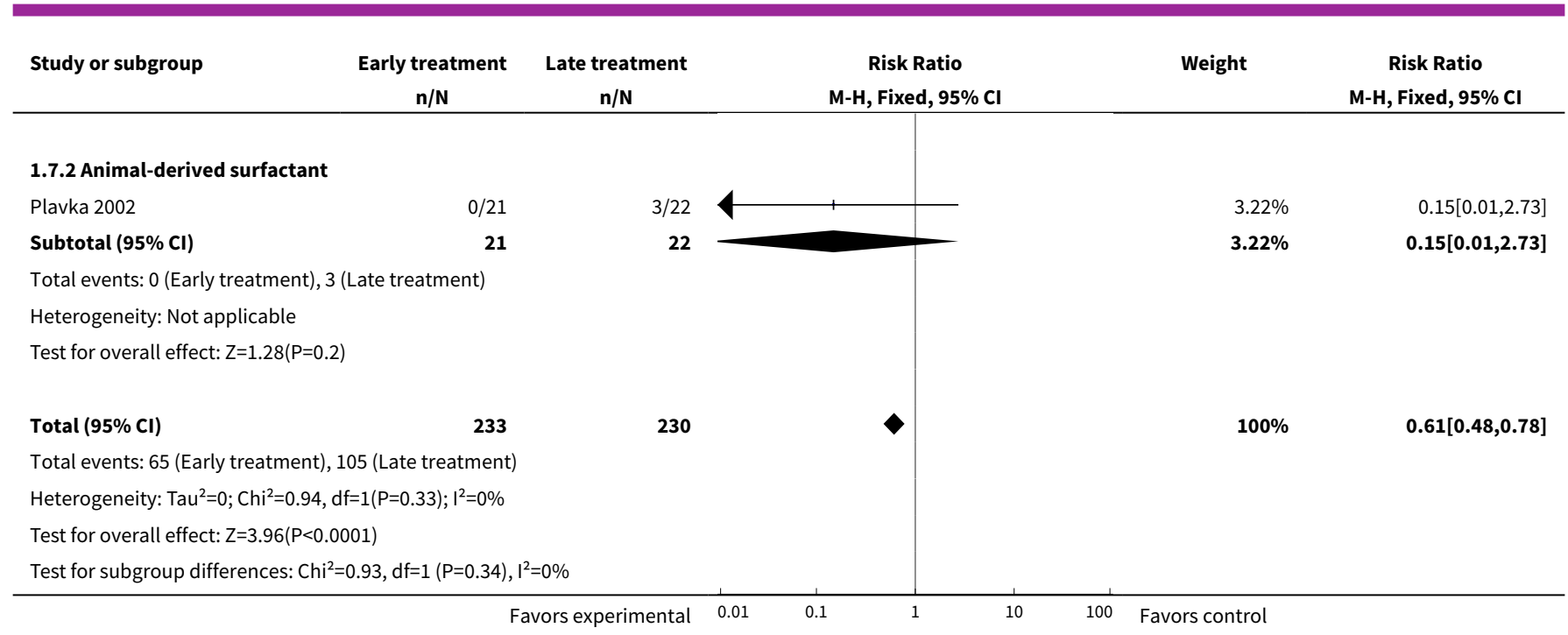

\section{Analysis 1.8. Comparison 1 Early versus delayed selective surfactant treatment, Outcome 8 Pneumothorax.}

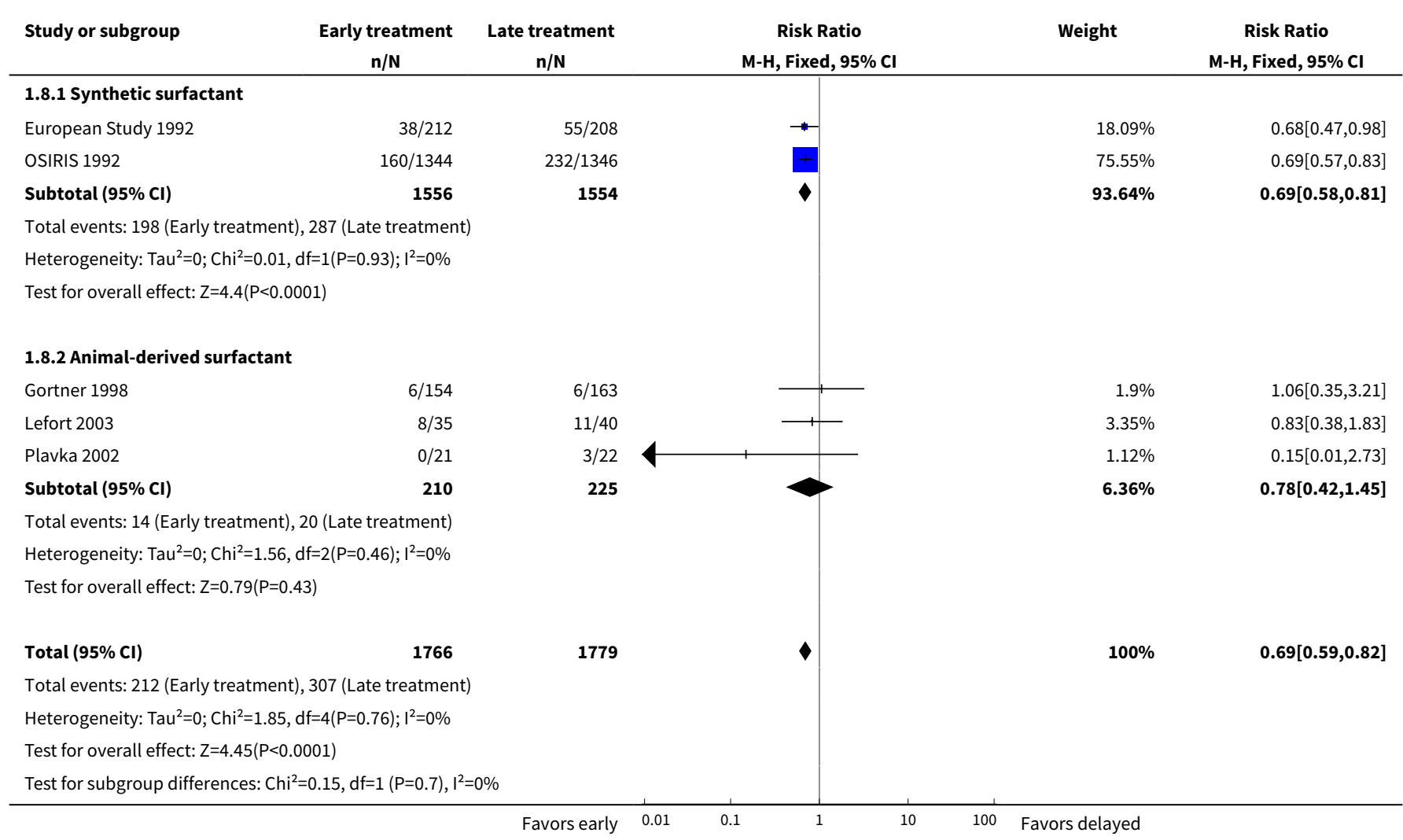




\section{Analysis 1.9. Comparison 1 Early versus delayed selective surfactant} treatment, Outcome 9 Pulmonary interstitial emphysema.

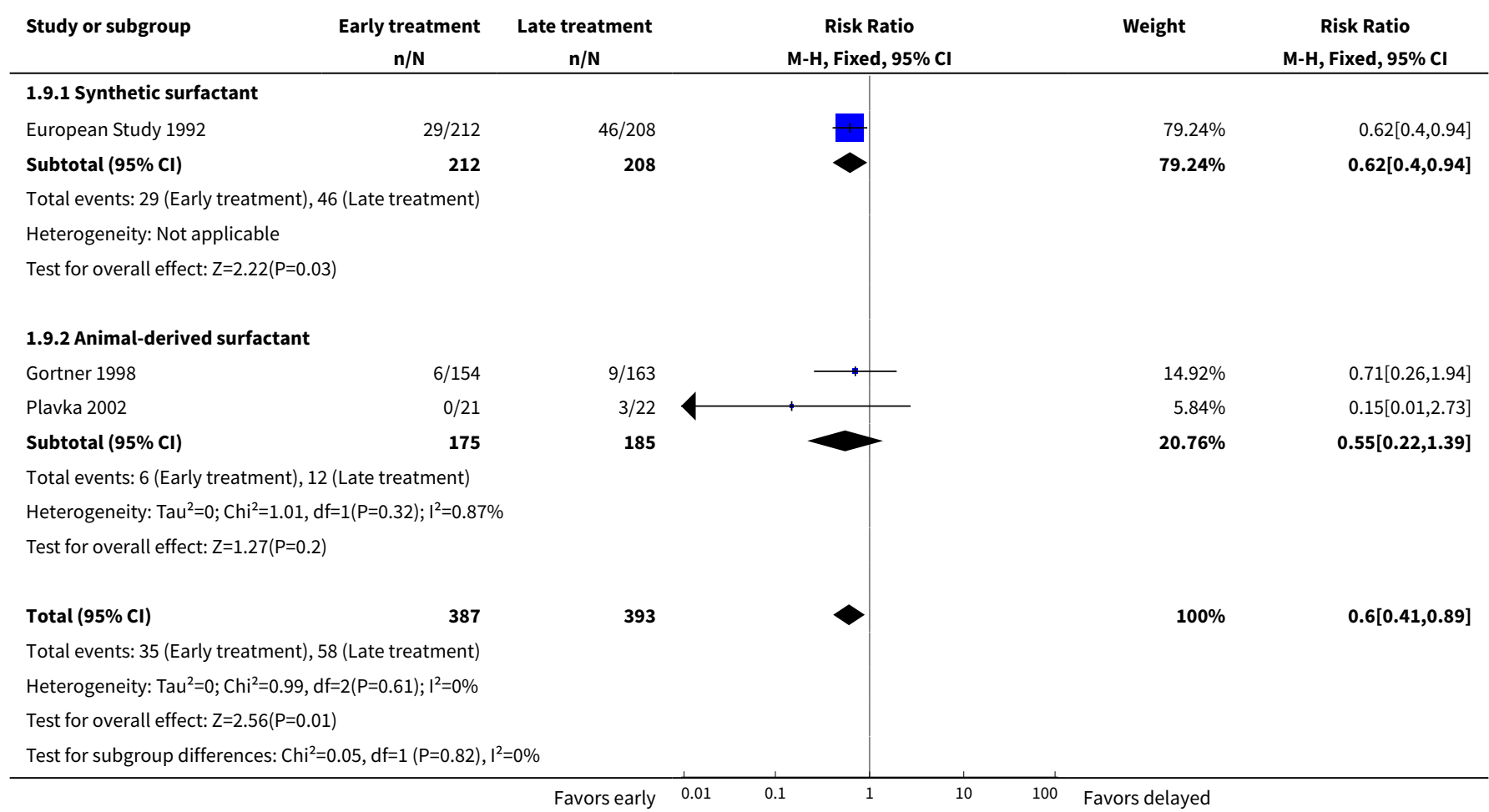

Analysis 1.10. Comparison 1 Early versus delayed selective

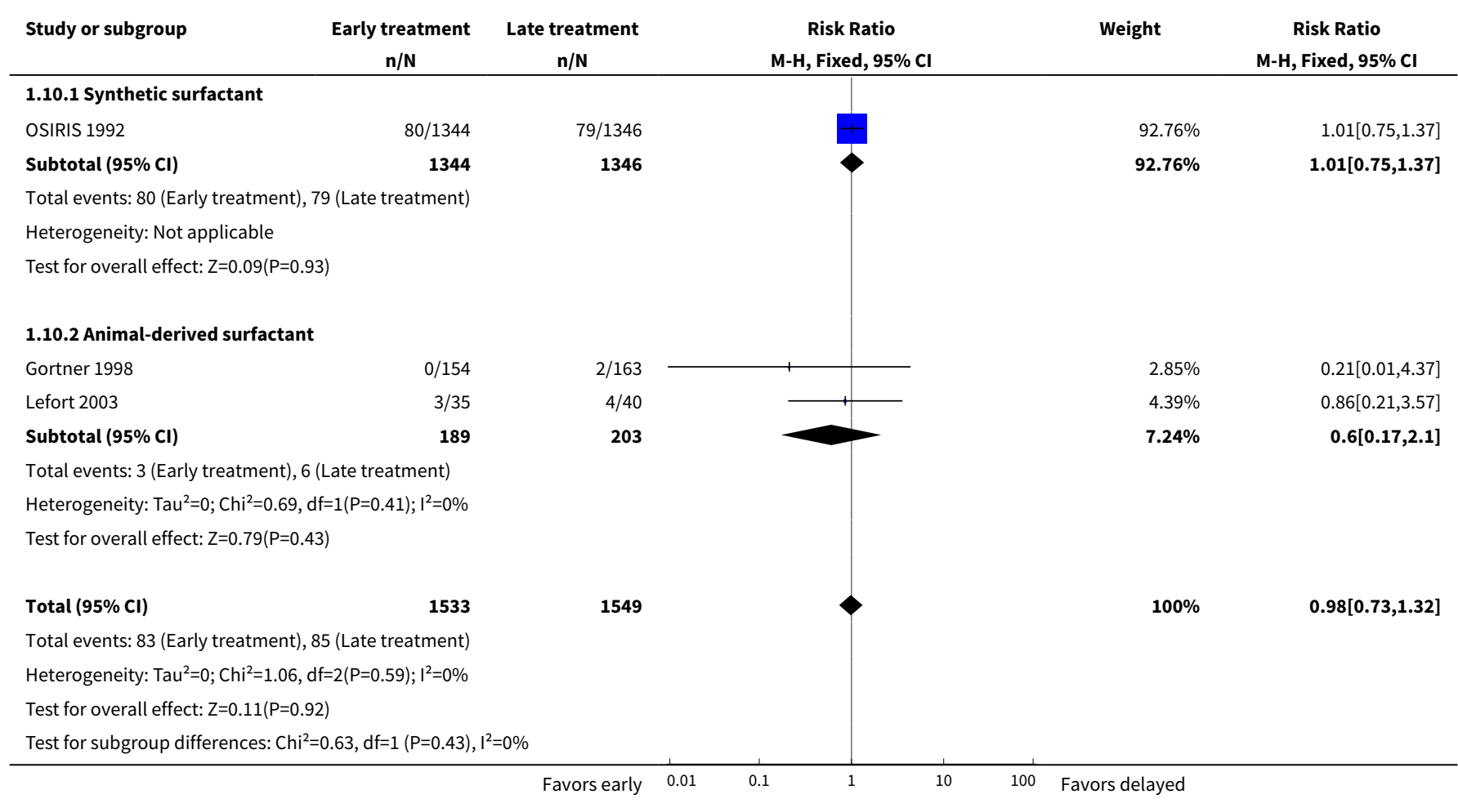


Analysis 1.11. Comparison 1 Early versus delayed selective surfactant treatment, Outcome 11 Patent ductus arteriosus.

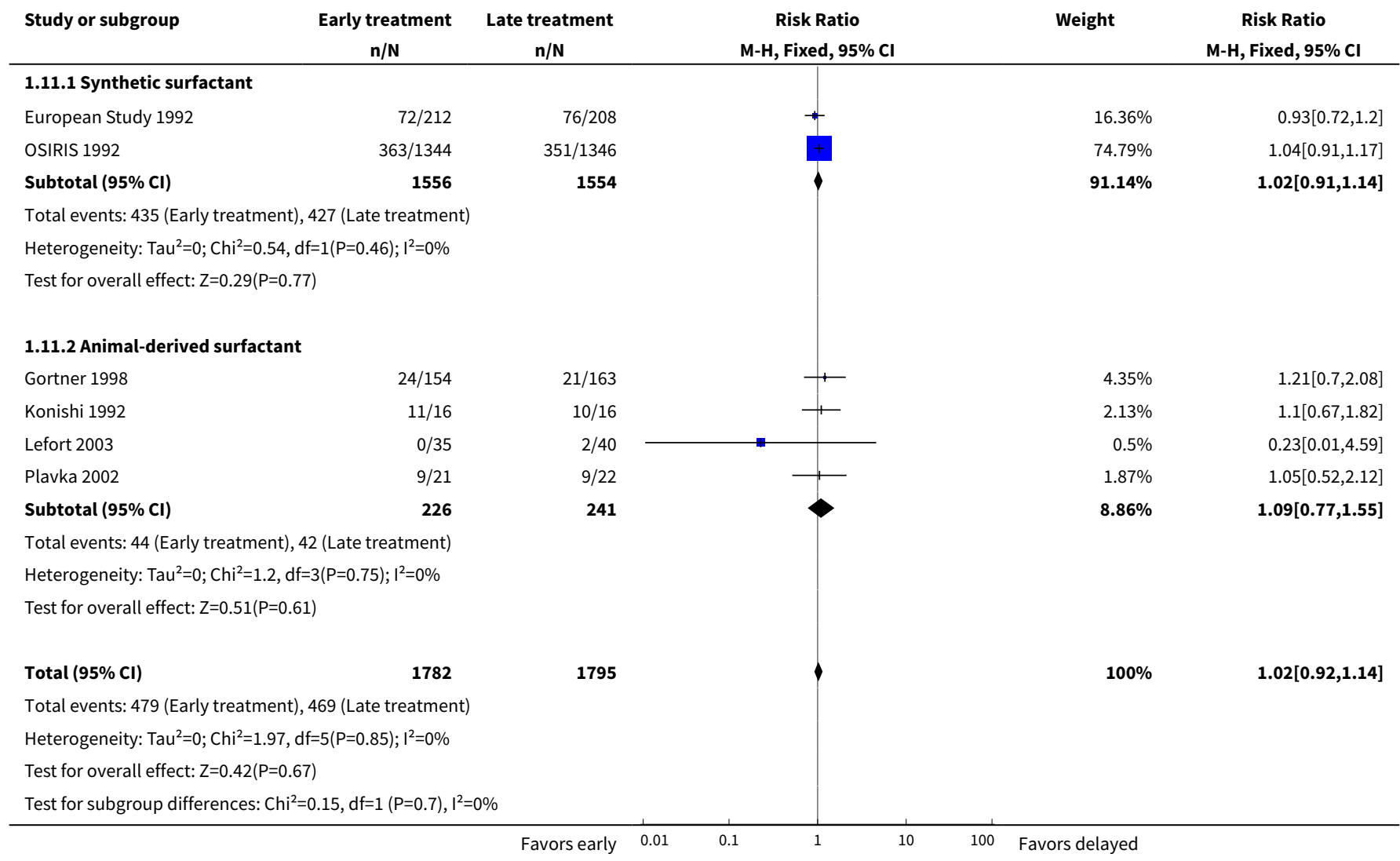

Analysis 1.12. Comparison 1 Early versus delayed selective surfactant treatment, Outcome 12 Confirmed bacterial sepsis.

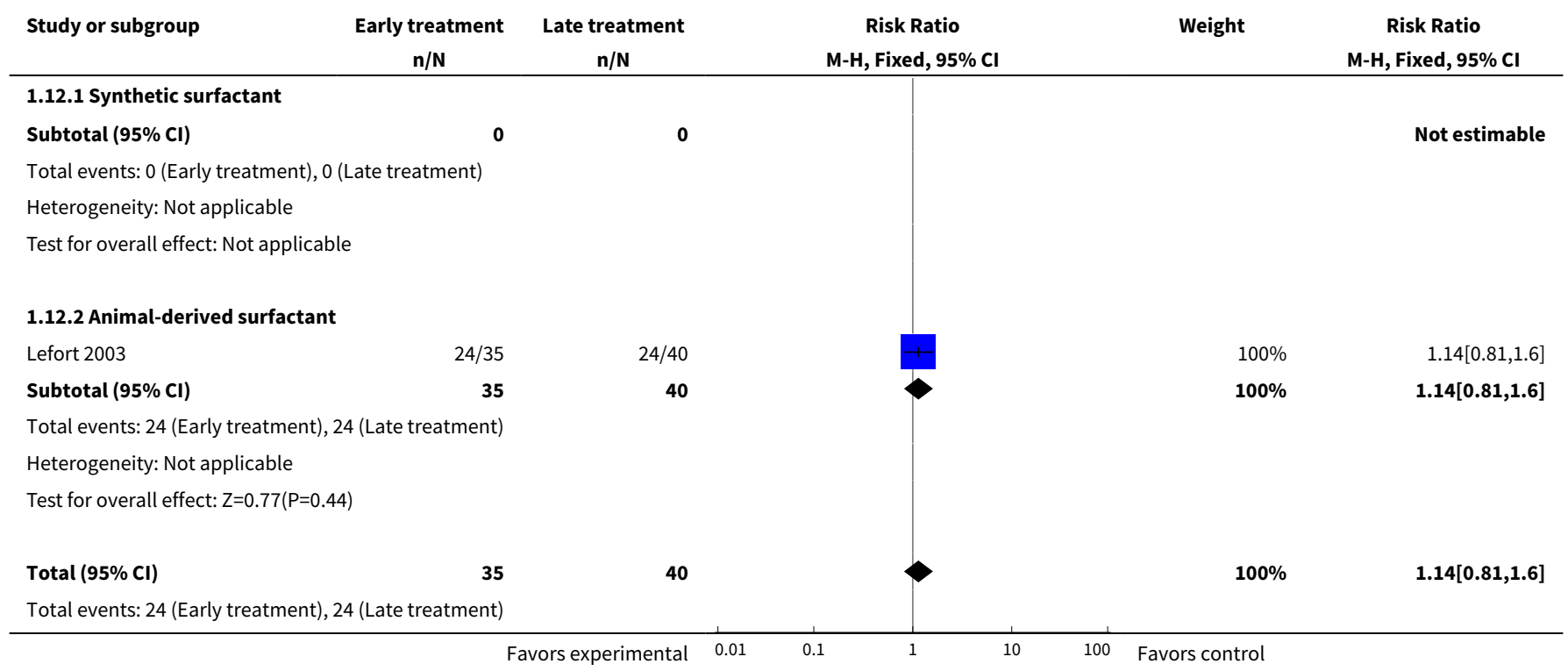




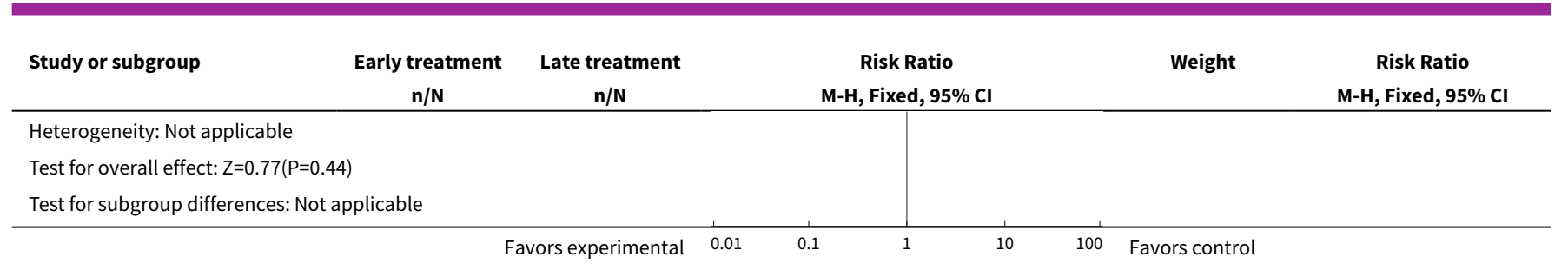

\section{Analysis 1.13. Comparison 1 Early versus delayed selective surfactant treatment, Outcome 13 Necrotizing enterocolitis.}

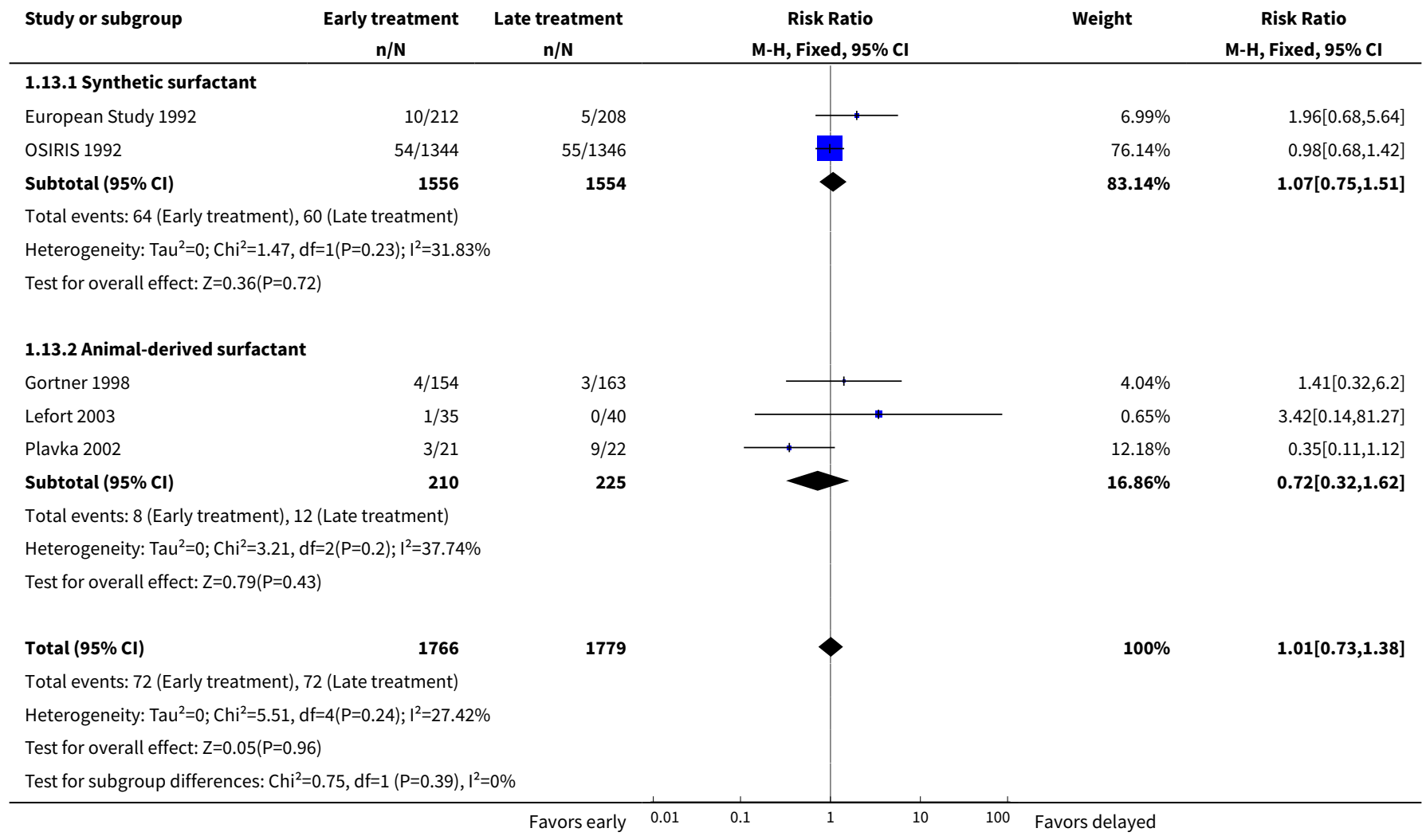

Analysis 1.14. Comparison 1 Early versus delayed selective surfactant treatment, Outcome 14 Intraventricular hemorrhage (any).

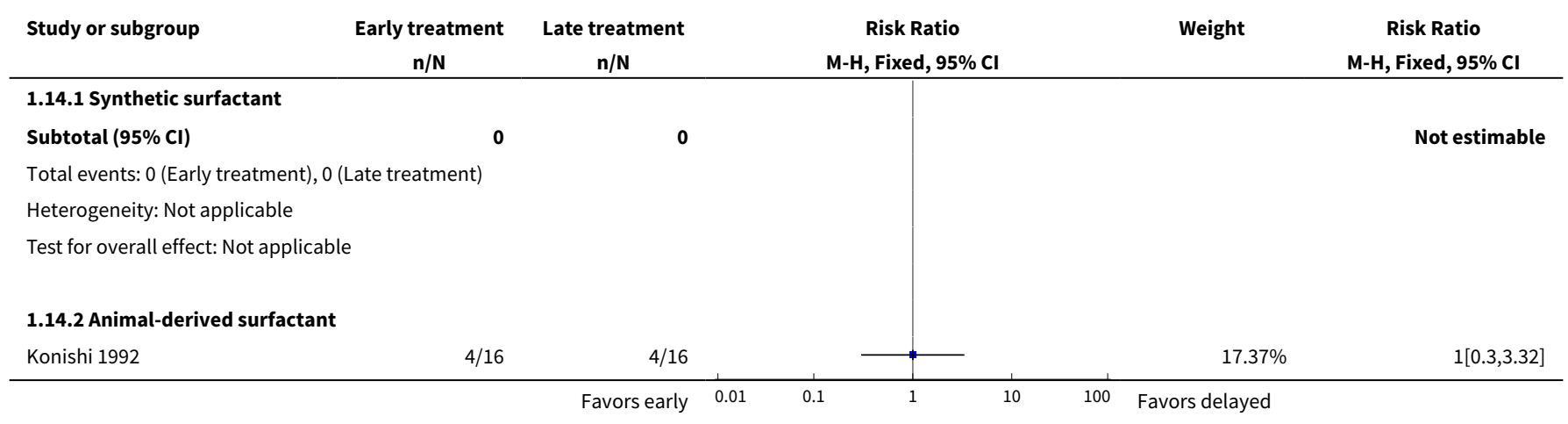




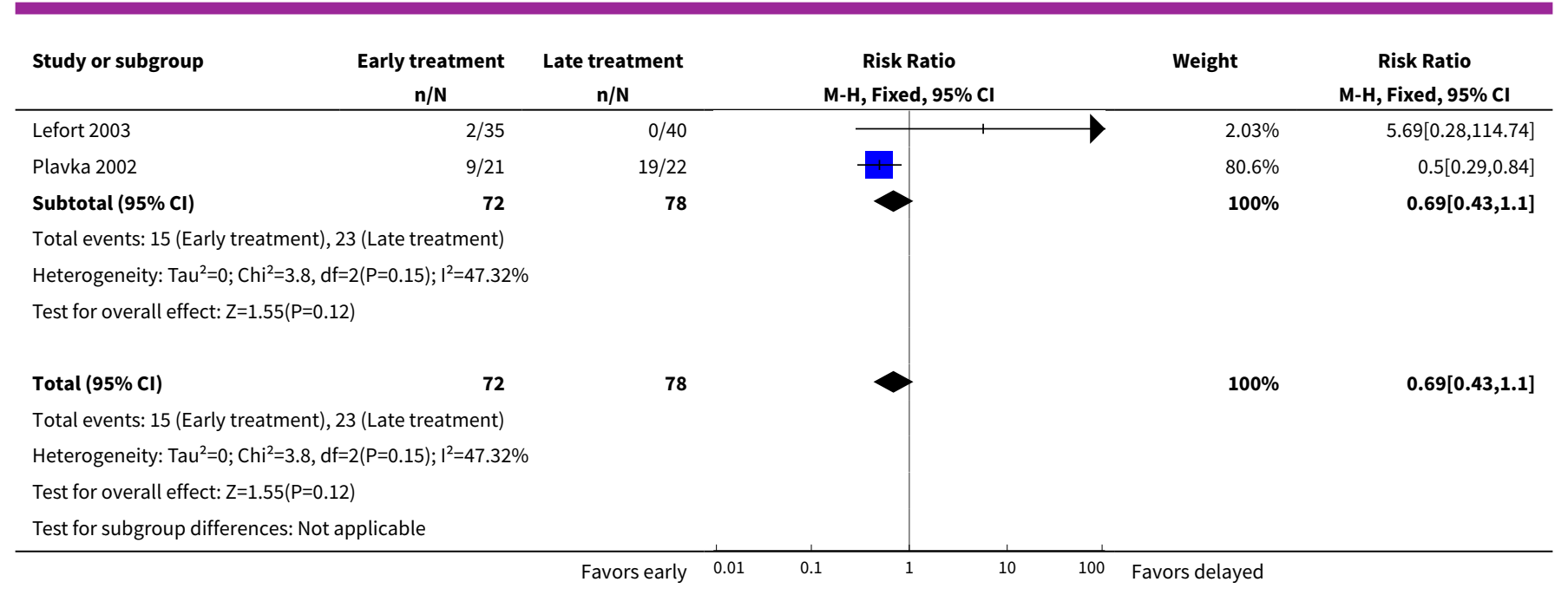

Analysis 1.15. Comparison 1 Early versus delayed selective surfactant treatment, Outcome 15 Intraventricular hemorrhage (severe).

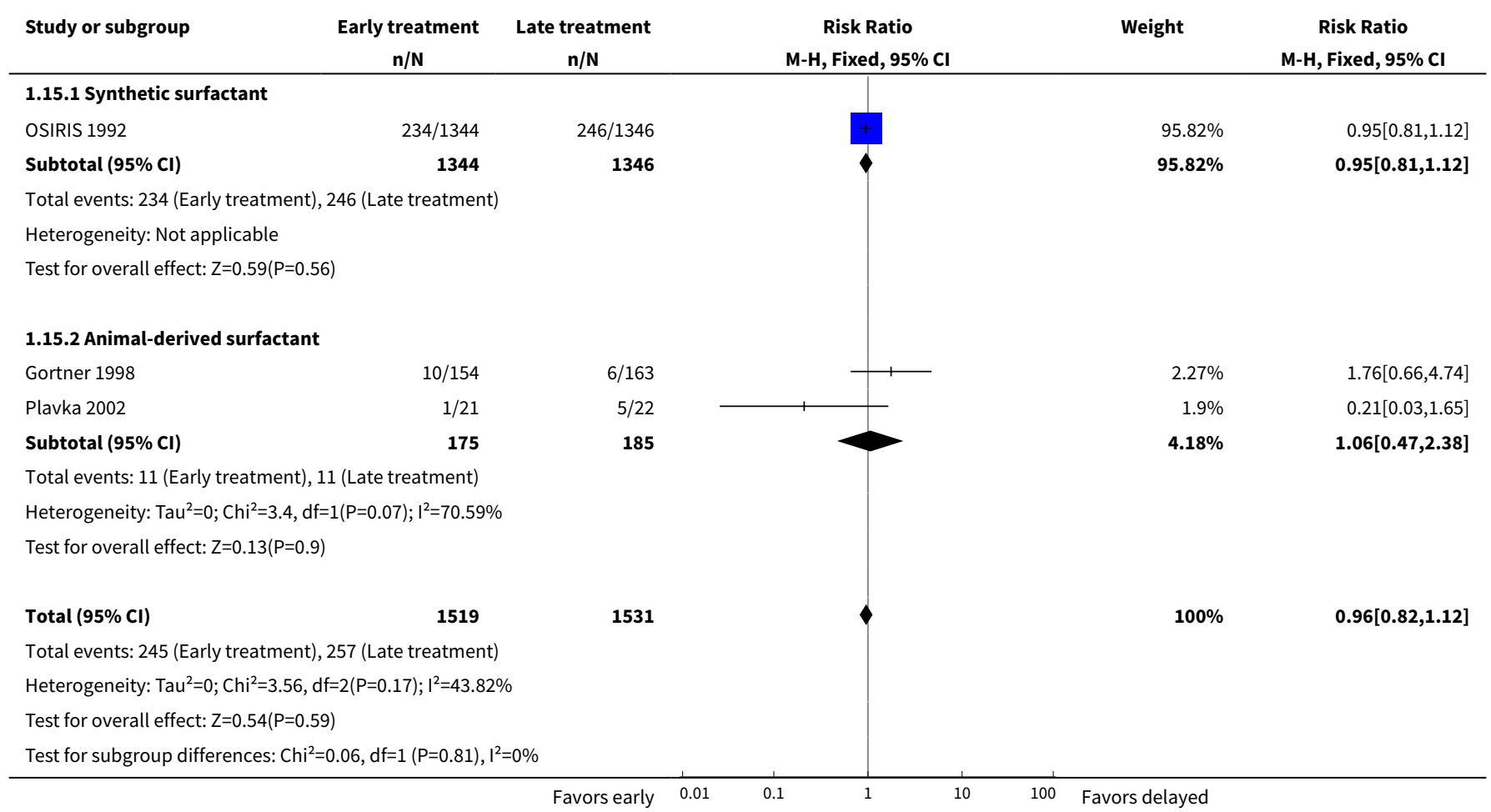

Analysis 1.16. Comparison 1 Early versus delayed selective surfactant treatment, Outcome 16 Periventricular leukomalacia.

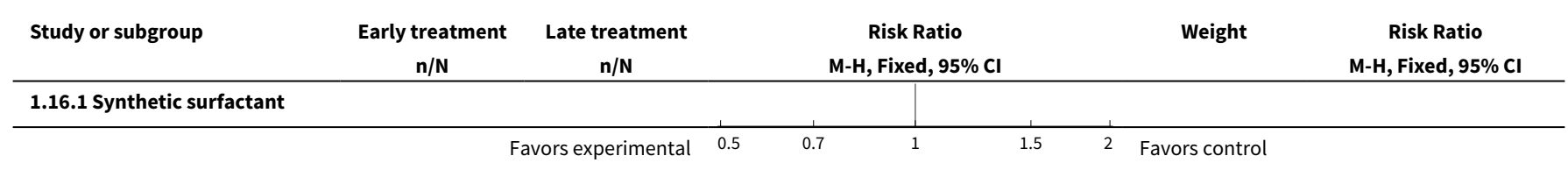




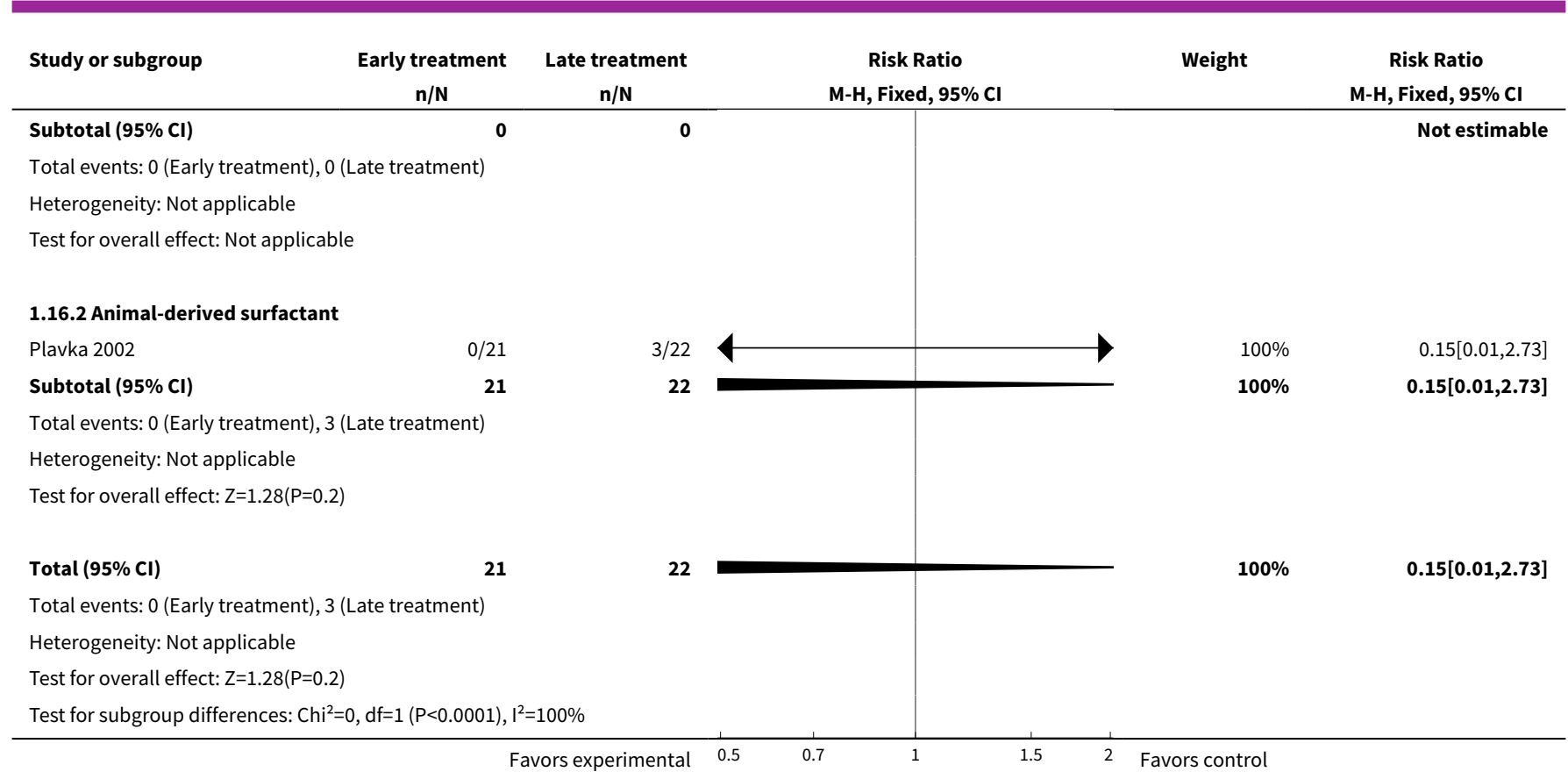

Analysis 1.17. Comparison 1 Early versus delayed selective surfactant treatment, Outcome 17 Retinopathy of prematurity (any).

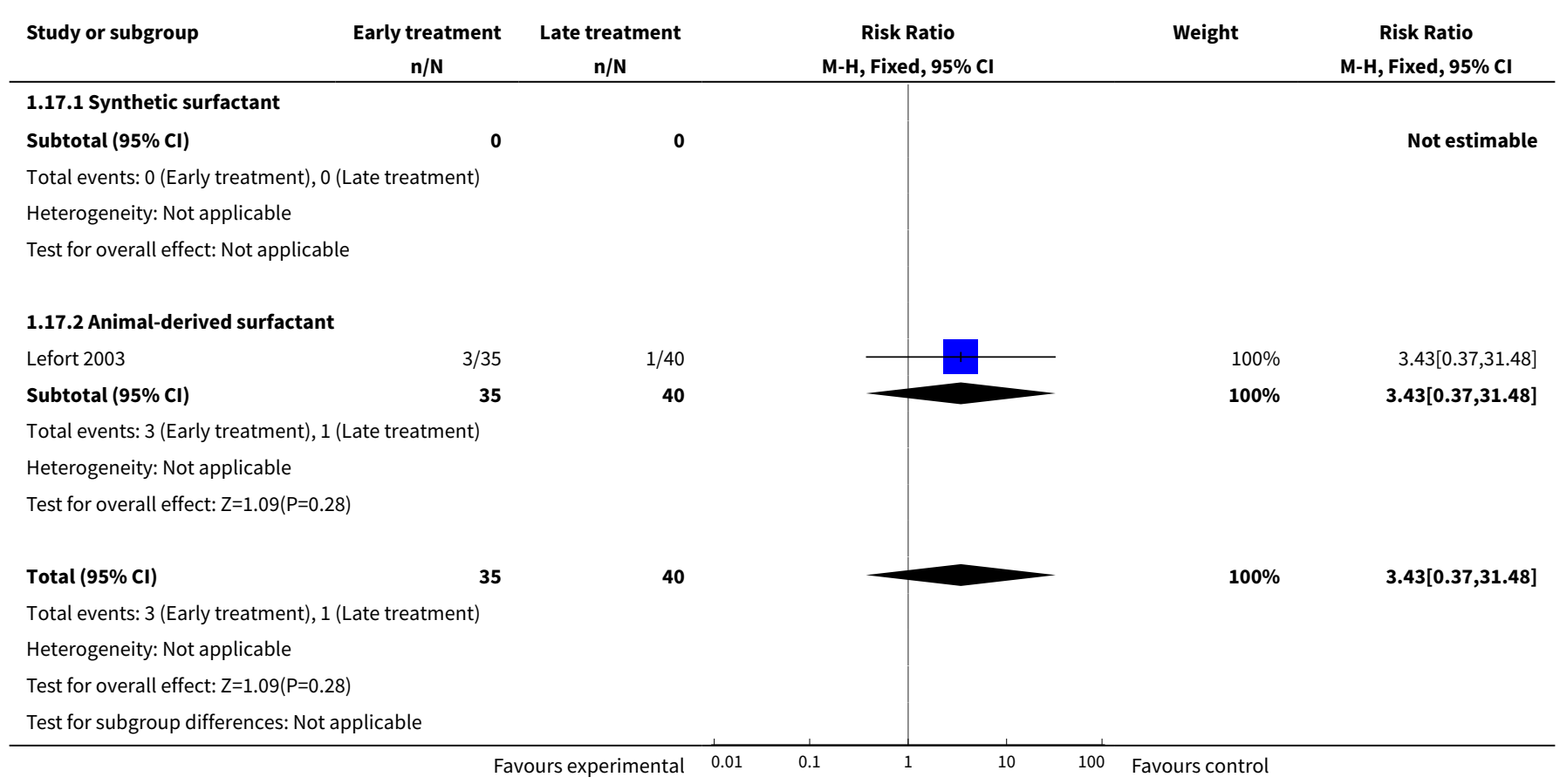


Analysis 1.18. Comparison 1 Early versus delayed selective surfactant treatment, Outcome 18 Retinopathy of prematurity stage 3 or greater.

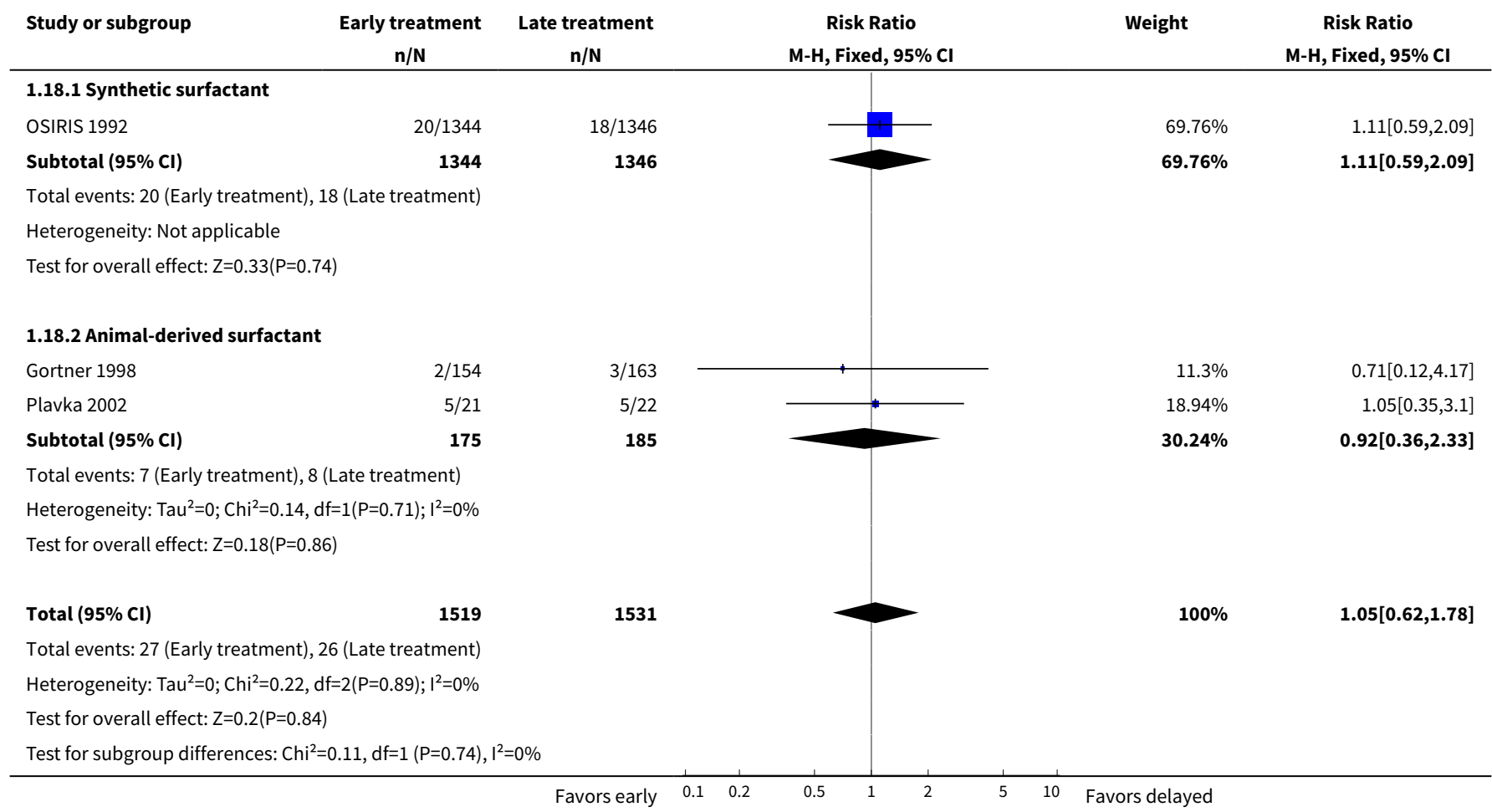

Analysis 1.19. Comparison 1 Early versus delayed selective surfactant treatment, Outcome 19 Long-term follow-up.

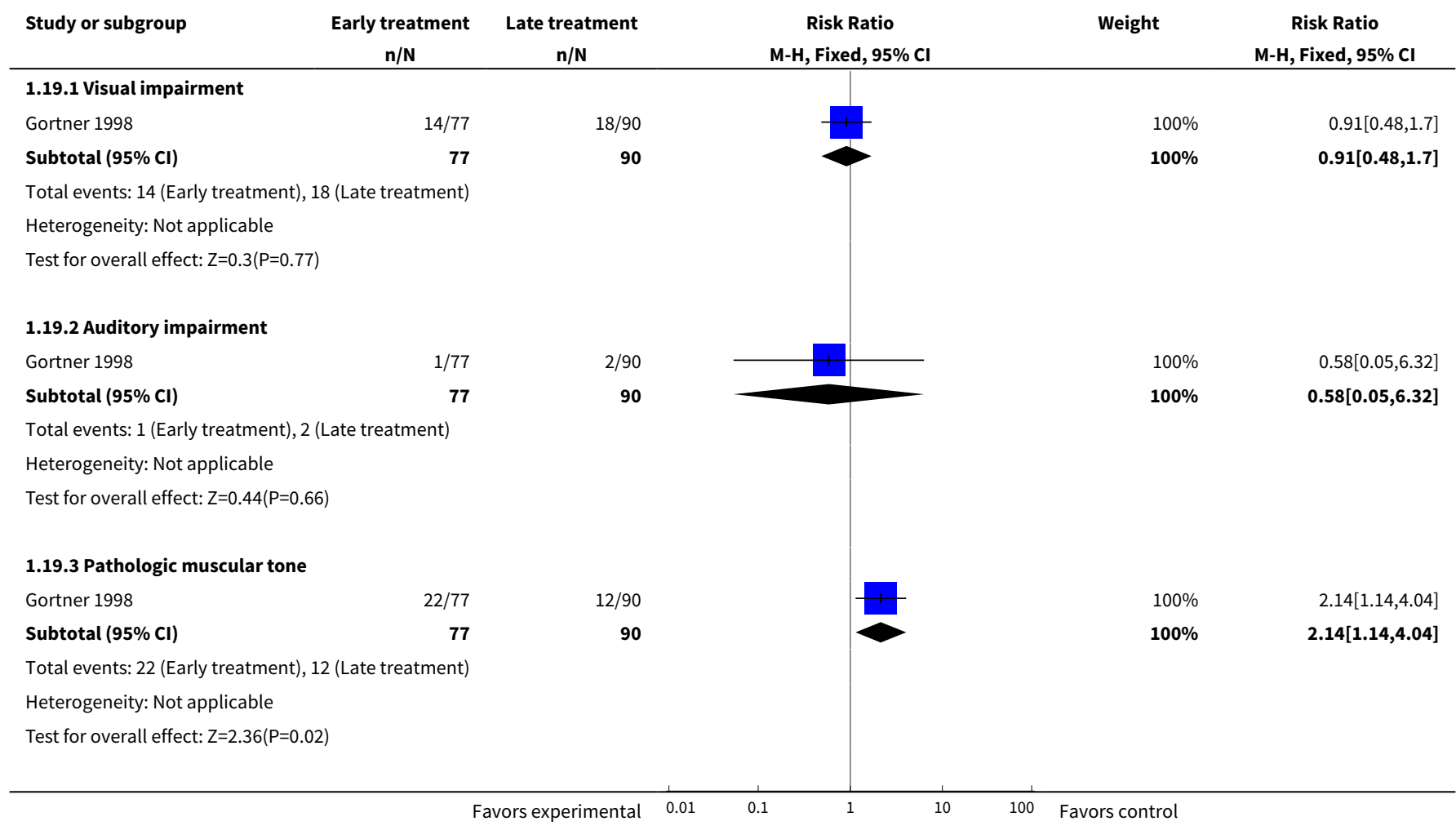




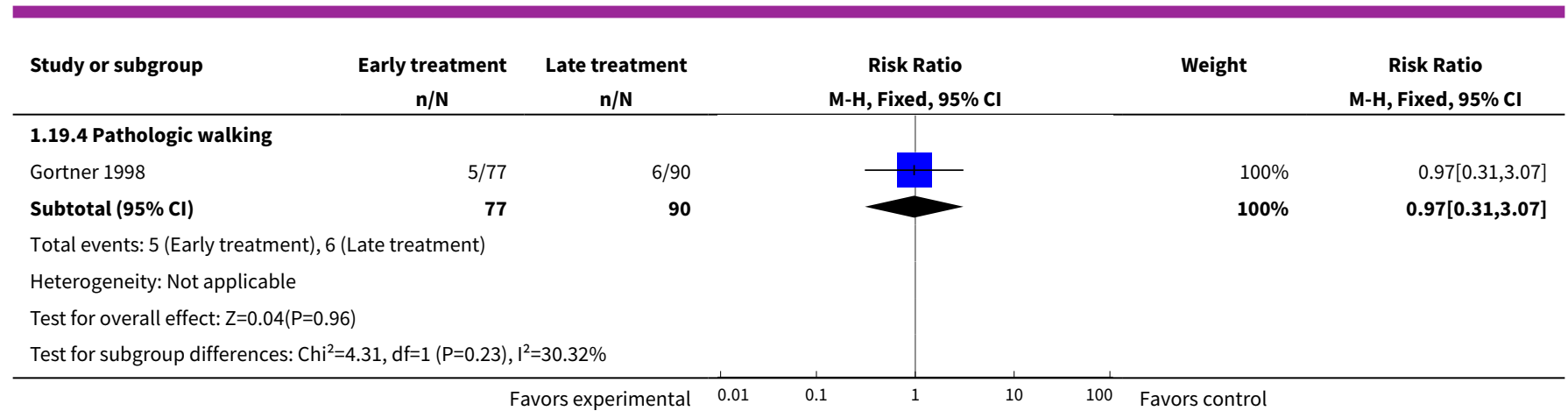

\section{Comparison 2. Early versus delayed selective surfactant treatment in infants less than $\mathbf{3 0}$ weeks' gestation}

\begin{tabular}{|c|c|c|c|c|}
\hline Outcome or subgroup title & $\begin{array}{l}\text { No. of } \\
\text { studies }\end{array}$ & $\begin{array}{l}\text { No. of } \\
\text { partici- } \\
\text { pants }\end{array}$ & Statistical method & Effect size \\
\hline 1 Neonatal mortality & 2 & 463 & Risk Ratio (M-H, Fixed, 95\% Cl) & $0.62[0.43,0.89]$ \\
\hline 1.1 Synthetic surfactant & 1 & 420 & Risk Ratio (M-H, Fixed, 95\% Cl) & $0.66[0.46,0.96]$ \\
\hline 1.2 Animal-derived surfactant & 1 & 43 & Risk Ratio (M-H, Fixed, 95\% Cl) & $0.30[0.07,1.28]$ \\
\hline 2 Mortality at discharge & 1 & 43 & Risk Ratio (M-H, Fixed, 95\% Cl) & $0.30[0.07,1.28]$ \\
\hline 2.1 Synthetic surfactant & 0 & 0 & Risk Ratio (M-H, Fixed, 95\% Cl) & $0.0[0.0,0.0]$ \\
\hline 2.2 Animal-derived surfactant & 1 & 43 & Risk Ratio (M-H, Fixed, 95\% Cl) & $0.30[0.07,1.28]$ \\
\hline 3 Chronic lung disease & 1 & 43 & Risk Ratio (M-H, Fixed, 95\% Cl) & $0.60[0.20,1.75]$ \\
\hline 3.1 Synthetic surfactant & 0 & 0 & Risk Ratio (M-H, Fixed, 95\% Cl) & $0.0[0.0,0.0]$ \\
\hline 3.2 Animal-derived surfactant & 1 & 43 & Risk Ratio (M-H, Fixed, 95\% Cl) & $0.60[0.20,1.75]$ \\
\hline 4 CLD or death at 36 weeks' PMA & 1 & 43 & Risk Ratio (M-H, Fixed, 95\% Cl) & $0.45[0.21,0.95]$ \\
\hline 4.1 Synthetic surfactant & 0 & 0 & Risk Ratio (M-H, Fixed, 95\% Cl) & $0.0[0.0,0.0]$ \\
\hline 4.2 Animal-derived surfactant & 1 & 43 & Risk Ratio (M-H, Fixed, 95\% Cl) & $0.45[0.21,0.95]$ \\
\hline
\end{tabular}

Analysis 2.1. Comparison 2 Early versus delayed selective surfactant treatment in infants less than 30 weeks' gestation, Outcome 1 Neonatal mortality.

\begin{tabular}{|c|c|c|c|c|c|}
\hline Study or subgroup & $\begin{array}{c}\text { Early treatment } \\
n / N\end{array}$ & $\begin{array}{l}\text { Late treatment } \\
\mathrm{n} / \mathrm{N} \\
\end{array}$ & $\begin{array}{c}\text { Risk Ratio } \\
\text { M-H, Fixed, 95\% Cl }\end{array}$ & Weight & $\begin{array}{c}\text { Risk Ratio } \\
\text { M-H, Fixed, 95\% Cl }\end{array}$ \\
\hline \multicolumn{6}{|c|}{ 2.1.1 Synthetic surfactant } \\
\hline European Study 1992 & $37 / 212$ & $55 / 208$ & & $89.04 \%$ & $0.66[0.46,0.96]$ \\
\hline Subtotal $(95 \% \mathrm{CI})$ & 212 & 208 & & $89.04 \%$ & $0.66[0.46,0.96]$ \\
\hline \multicolumn{6}{|c|}{ Total events: 37 (Early treatment), 55 (Late treatment) } \\
\hline
\end{tabular}




\begin{tabular}{|c|c|c|c|c|c|}
\hline Study or subgroup & $\begin{array}{l}\text { Early treatment } \\
\qquad \mathrm{n} / \mathrm{N}\end{array}$ & $\begin{array}{l}\text { Late treatment } \\
\qquad \mathrm{n} / \mathrm{N}\end{array}$ & $\begin{array}{c}\text { Risk Ratio } \\
\text { M-H, Fixed, 95\% Cl }\end{array}$ & Weight & $\begin{array}{c}\text { Risk Ratio } \\
\text { M-H, Fixed, } \mathbf{9 5 \% ~ C l}\end{array}$ \\
\hline \multicolumn{6}{|c|}{ Heterogeneity: Not applicable } \\
\hline \multicolumn{6}{|c|}{ Test for overall effect: $Z=2.2(P=0.03)$} \\
\hline \multicolumn{6}{|c|}{ 2.1.2 Animal-derived surfactant } \\
\hline Plavka 2002 & $2 / 21$ & $7 / 22$ & $\longrightarrow$ & $10.96 \%$ & $0.3[0.07,1.28]$ \\
\hline Subtotal $(95 \% \mathrm{Cl})$ & 21 & 22 & & $10.96 \%$ & $0.3[0.07,1.28]$ \\
\hline \multicolumn{6}{|c|}{ Total events: 2 (Early treatment), 7 (Late treatment) } \\
\hline \multicolumn{6}{|c|}{ Heterogeneity: Not applicable } \\
\hline \multicolumn{6}{|c|}{ Test for overall effect: $Z=1.63(P=0.1)$} \\
\hline Total $(95 \% \mathrm{Cl})$ & 233 & 230 & & $100 \%$ & $0.62[0.43,0.89]$ \\
\hline \multicolumn{6}{|c|}{ Total events: 39 (Early treatment), 62 (Late treatment) } \\
\hline \multicolumn{6}{|c|}{ Heterogeneity: $\mathrm{Tau}^{2}=0 ; \mathrm{Chi}^{2}=1.07, \mathrm{df}=1(\mathrm{P}=0.3) ; \mathrm{I}^{2}=6.86 \%$} \\
\hline \multicolumn{6}{|c|}{ Test for overall effect: $Z=2.62(P=0.01)$} \\
\hline \multicolumn{6}{|c|}{ Test for subgroup differences: $\mathrm{Chi}^{2}=1.07, \mathrm{df}=1(\mathrm{P}=0.3), \mathrm{I}^{2}=6.37 \%$} \\
\hline & & urs experimental & 0.1 & Favours control & \\
\hline
\end{tabular}

Analysis 2.2. Comparison 2 Early versus delayed selective surfactant treatment in infants less than $\mathbf{3 0}$ weeks' gestation, Outcome $\mathbf{2}$ Mortality at discharge.

\begin{tabular}{|c|c|c|c|c|c|}
\hline Study or subgroup & $\begin{array}{l}\text { Early treatment } \\
\qquad \mathrm{n} / \mathrm{N}\end{array}$ & $\begin{array}{l}\text { Late treatment } \\
\qquad \mathrm{n} / \mathrm{N}\end{array}$ & $\begin{array}{c}\text { Risk Ratio } \\
\text { M-H, Fixed, 95\% Cl }\end{array}$ & Weight & $\begin{array}{c}\text { Risk Ratio } \\
\text { M-H, Fixed, } 95 \% \mathrm{Cl}\end{array}$ \\
\hline \multicolumn{6}{|c|}{ 2.2.1 Synthetic surfactant } \\
\hline Subtotal $(95 \% \mathrm{CI})$ & 0 & 0 & & & Not estimable \\
\hline \multicolumn{6}{|c|}{ Total events: 0 (Early treatment), 0 (Late treatment) } \\
\hline \multicolumn{6}{|c|}{ Heterogeneity: Not applicable } \\
\hline \multicolumn{6}{|c|}{ Test for overall effect: Not applicable } \\
\hline \multicolumn{6}{|c|}{ 2.2.2 Animal-derived surfactant } \\
\hline Plavka 2002 & $2 / 21$ & $7 / 22$ & + & $100 \%$ & $0.3[0.07,1.28]$ \\
\hline Subtotal $(95 \% \mathrm{Cl})$ & 21 & 22 & & $100 \%$ & $0.3[0.07,1.28]$ \\
\hline \multicolumn{6}{|c|}{ Total events: 2 (Early treatment), 7 (Late treatment) } \\
\hline \multicolumn{6}{|c|}{ Heterogeneity: Not applicable } \\
\hline \multicolumn{6}{|c|}{ Test for overall effect: $Z=1.63(P=0.1)$} \\
\hline Total $(95 \% \mathrm{Cl})$ & 21 & 22 & & $100 \%$ & $0.3[0.07,1.28]$ \\
\hline \multicolumn{6}{|c|}{ Total events: 2 (Early treatment), 7 (Late treatment) } \\
\hline \multicolumn{6}{|c|}{ Heterogeneity: Not applicable } \\
\hline \multicolumn{6}{|c|}{ Test for overall effect: $Z=1.63(P=0.1)$} \\
\hline Test for subgroup dif & pplicable & & & & \\
\hline
\end{tabular}


Analysis 2.3. Comparison 2 Early versus delayed selective surfactant treatment in infants less than 30 weeks' gestation, Outcome 3 Chronic lung disease.

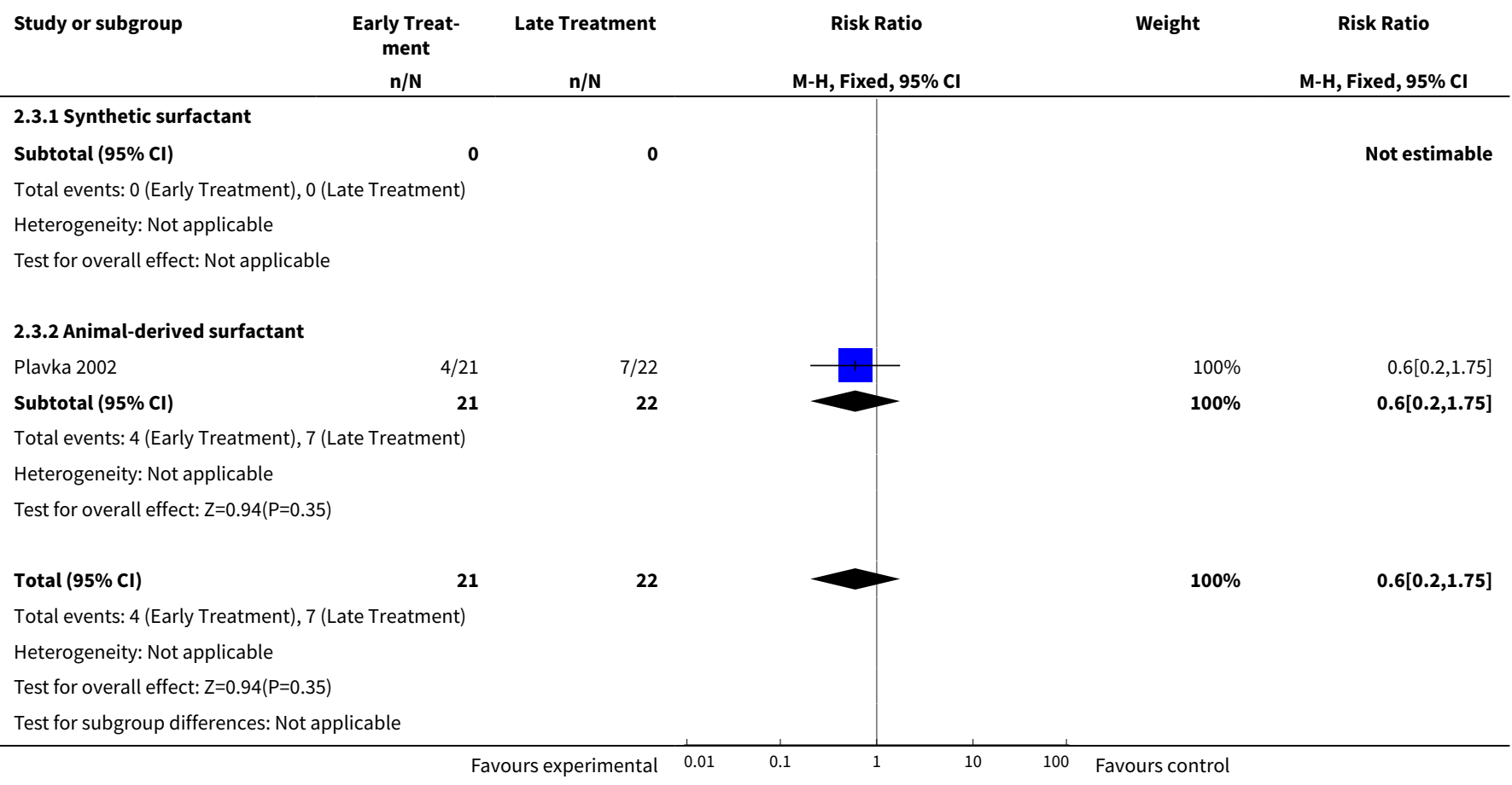

Analysis 2.4. Comparison 2 Early versus delayed selective surfactant treatment in infants less than 30 weeks' gestation, Outcome 4 CLD or death at 36 weeks' PMA.

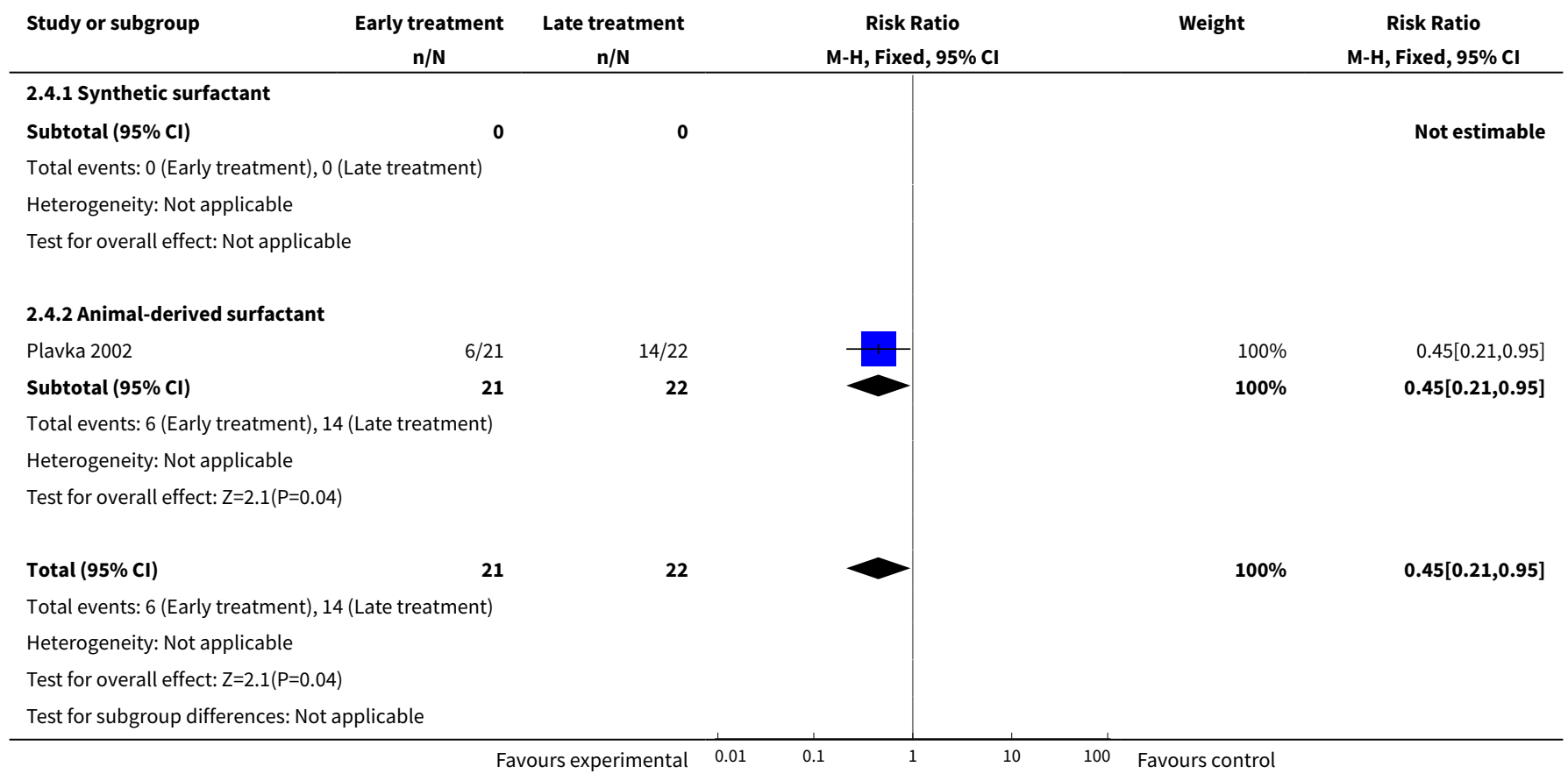


Comparison 3. Early versus delayed selective surfactant treatment by steroid exposure

\begin{tabular}{|c|c|c|c|c|}
\hline Outcome or subgroup title & $\begin{array}{l}\text { No. of } \\
\text { studies }\end{array}$ & $\begin{array}{l}\text { No. of } \\
\text { partici- } \\
\text { pants }\end{array}$ & Statistical method & Effect size \\
\hline 1 Neonatal mortality & 6 & 3577 & Risk Ratio (M-H, Fixed, 95\% Cl) & $0.84[0.74,0.95]$ \\
\hline 1.1 Steroid exposure < 50\% & 4 & 3185 & Risk Ratio (M-H, Fixed, 95\% Cl) & $0.84[0.74,0.95]$ \\
\hline 1.2 Steroid exposure $\geq 50 \%$ & 1 & 317 & Risk Ratio (M-H, Fixed, 95\% Cl) & $1.59[0.27,9.37]$ \\
\hline 1.3 Unknown steroid exposure & 1 & 75 & Risk Ratio (M-H, Fixed, 95\% Cl) & $0.76[0.46,1.26]$ \\
\hline 2 Mortality at discharge & 5 & 3157 & Risk Ratio (M-H, Fixed, 95\% Cl) & $0.88[0.78,0.99]$ \\
\hline 2.1 Steroid exposure < 50\% & 3 & 2765 & Risk Ratio (M-H, Fixed, 95\% Cl) & $0.88[0.78,0.99]$ \\
\hline 2.2 Steroid exposure $\geq 50 \%$ & 1 & 317 & Risk Ratio (M-H, Fixed, 95\% Cl) & $1.76[0.43,7.26]$ \\
\hline 2.3 Unknown steroid exposure & 1 & 75 & Risk Ratio (M-H, Fixed, 95\% Cl) & $0.76[0.46,1.26]$ \\
\hline 3 Bronchopulmonary dysplasia & 4 & 3114 & Risk Ratio (M-H, Fixed, 95\% Cl) & $0.97[0.88,1.07]$ \\
\hline 3.1 Steroid exposure < 50\% & 2 & 2722 & Risk Ratio (M-H, Fixed, 95\% Cl) & $0.96[0.87,1.06]$ \\
\hline 3.2 Steroid exposure $\geq 50 \%$ & 1 & 317 & Risk Ratio (M-H, Fixed, 95\% Cl) & $1.00[0.67,1.49]$ \\
\hline 3.3 Unknown steroid exposure & 1 & 75 & Risk Ratio (M-H, Fixed, 95\% Cl) & $1.37[0.46,4.11]$ \\
\hline 4 BPD or death at 28 to 30 days & 3 & 3039 & Risk Ratio (M-H, Fixed, 95\% Cl) & $0.94[0.88,1.00]$ \\
\hline 4.1 Steroid exposure < 50\% & 2 & 2722 & Risk Ratio (M-H, Fixed, 95\% Cl) & $0.93[0.87,0.99]$ \\
\hline 4.2 Steroid exposure $\geq 50 \%$ & 1 & 317 & Risk Ratio (M-H, Fixed, 95\% Cl) & $1.09[0.74,1.59]$ \\
\hline 4.3 Unknown steroid exposure & 0 & 0 & Risk Ratio (M-H, Fixed, 95\% Cl) & $0.0[0.0,0.0]$ \\
\hline 5 Chronic lung disease & 3 & 3050 & Risk Ratio (M-H, Fixed, 95\% Cl) & $0.69[0.55,0.87]$ \\
\hline 5.1 Steroid exposure $<50 \%$ & 2 & 2733 & Risk Ratio (M-H, Fixed, 95\% Cl) & $0.70[0.55,0.88]$ \\
\hline 5.2 Steroid exposure $\geq 50 \%$ & 1 & 317 & Risk Ratio (M-H, Fixed, 95\% Cl) & $0.62[0.25,1.53]$ \\
\hline 5.3 Unknown steroid exposure & 0 & 0 & Risk Ratio (M-H, Fixed, 95\% Cl) & $0.0[0.0,0.0]$ \\
\hline 6 CLD or death at 36 weeks' PMA & 3 & 3050 & Risk Ratio (M-H, Fixed, 95\% Cl) & $0.83[0.75,0.91]$ \\
\hline 6.1 Steroid exposure < 50\% & 2 & 2733 & Risk Ratio (M-H, Fixed, 95\% Cl) & $0.83[0.75,0.91]$ \\
\hline 6.2 Steroid exposure $\geq 50 \%$ & 1 & 317 & Risk Ratio (M-H, Fixed, 95\% Cl) & $0.85[0.41,1.75]$ \\
\hline 6.3 Unknown steroid exposure & 0 & 0 & Risk Ratio (M-H, Fixed, 95\% Cl) & $0.0[0.0,0.0]$ \\
\hline
\end{tabular}




\section{Analysis 3.1. Comparison 3 Early versus delayed selective surfactant} treatment by steroid exposure, Outcome 1 Neonatal mortality.

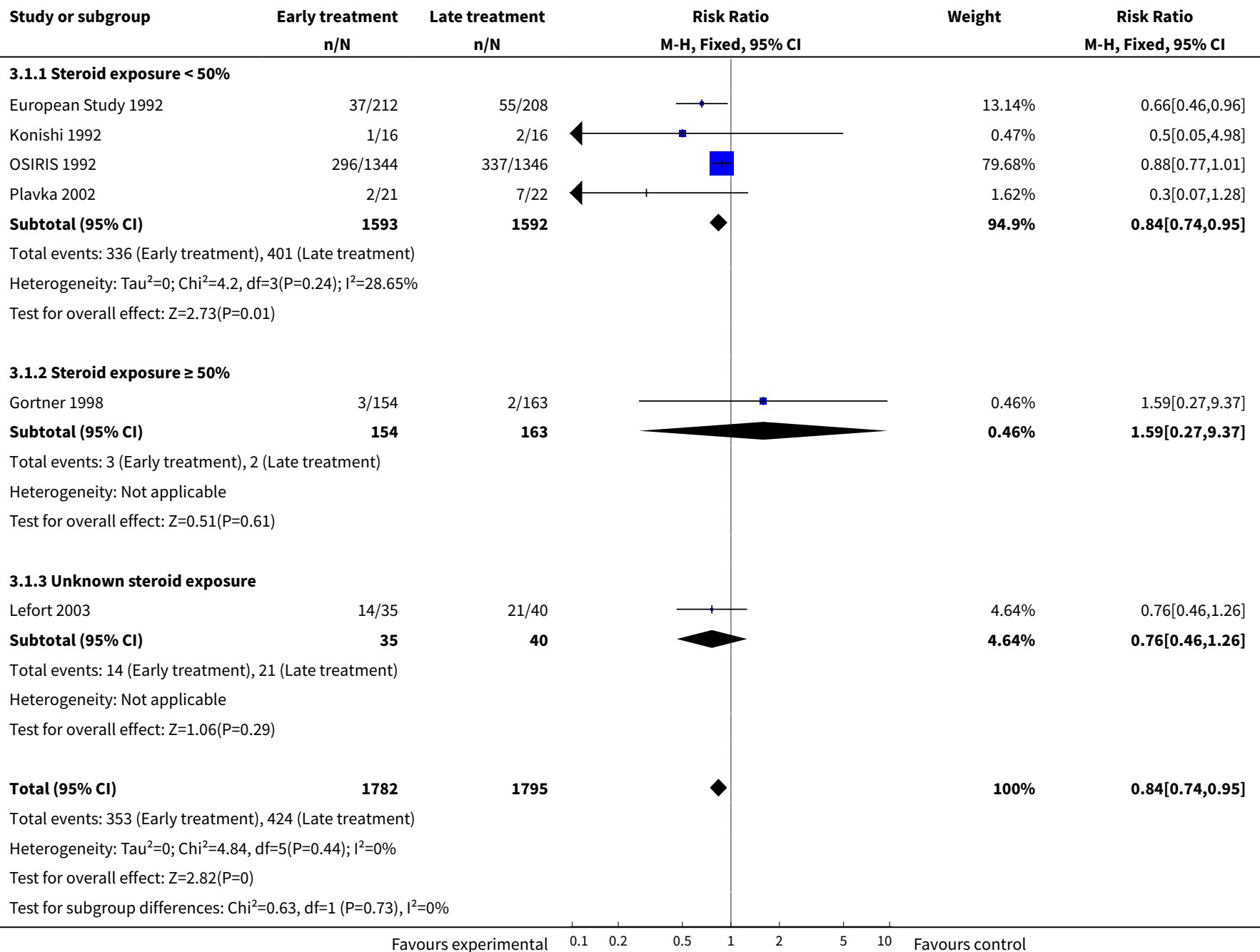

\section{Analysis 3.2. Comparison 3 Early versus delayed selective surfactant treatment by steroid exposure, Outcome 2 Mortality at discharge.}

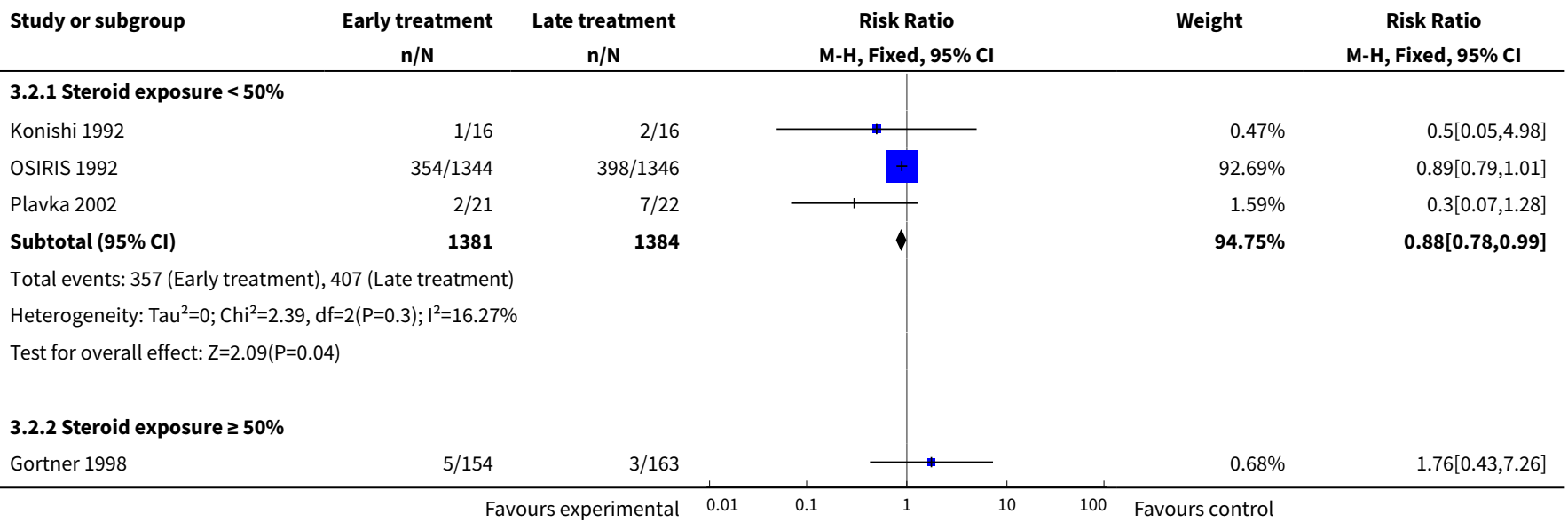




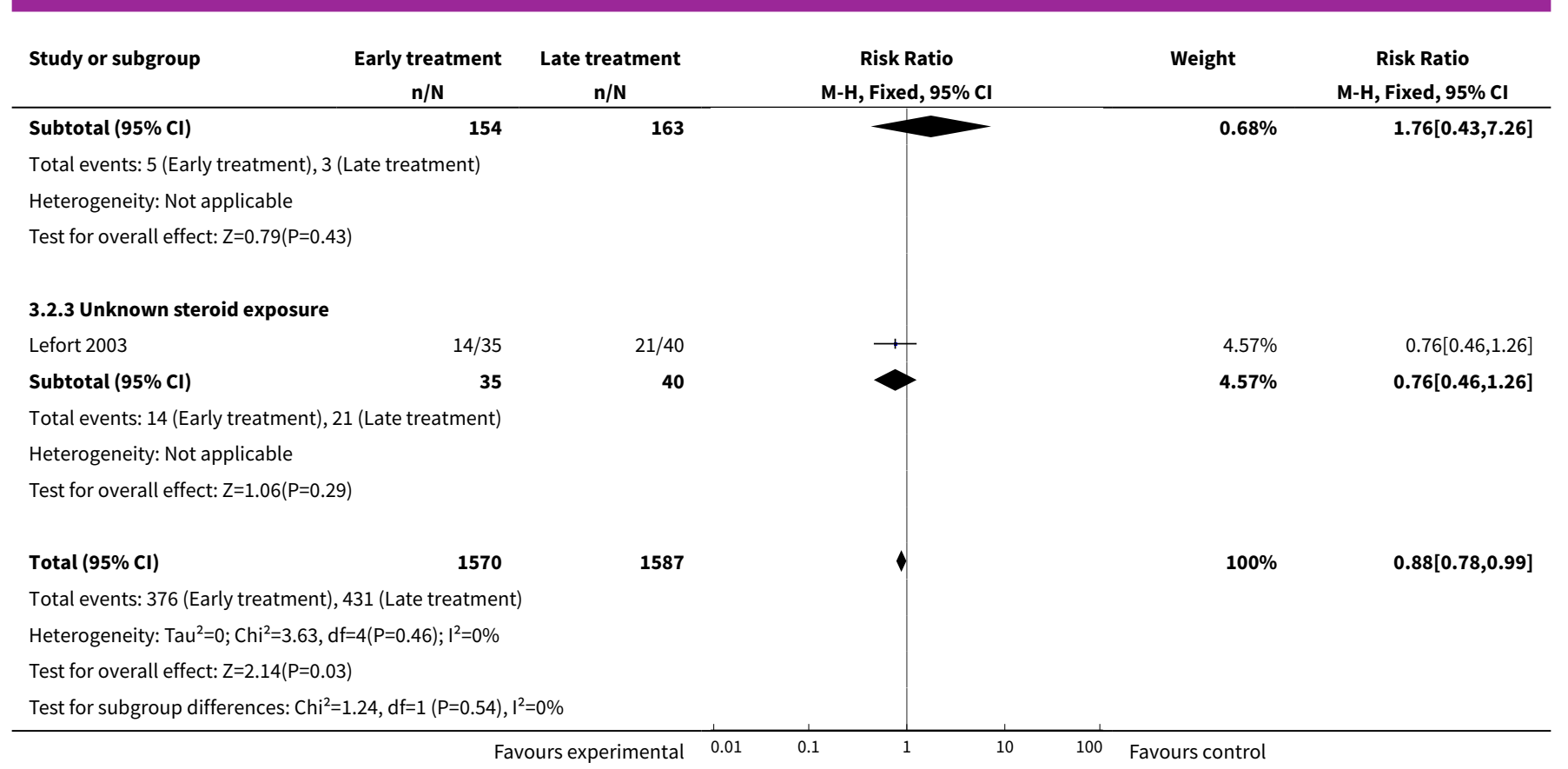

Analysis 3.3. Comparison 3 Early versus delayed selective surfactant treatment by steroid exposure, Outcome 3 Bronchopulmonary dysplasia.

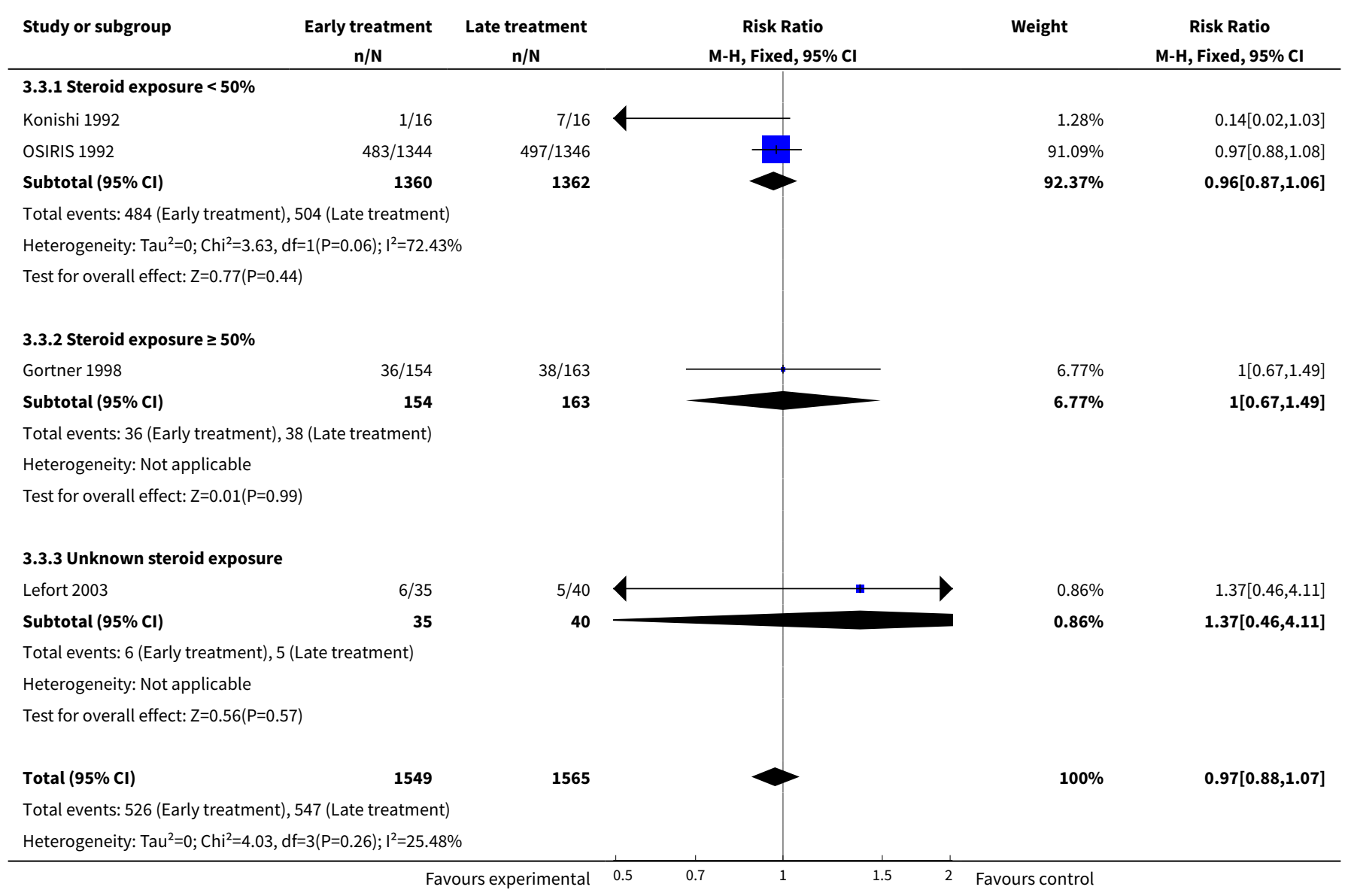




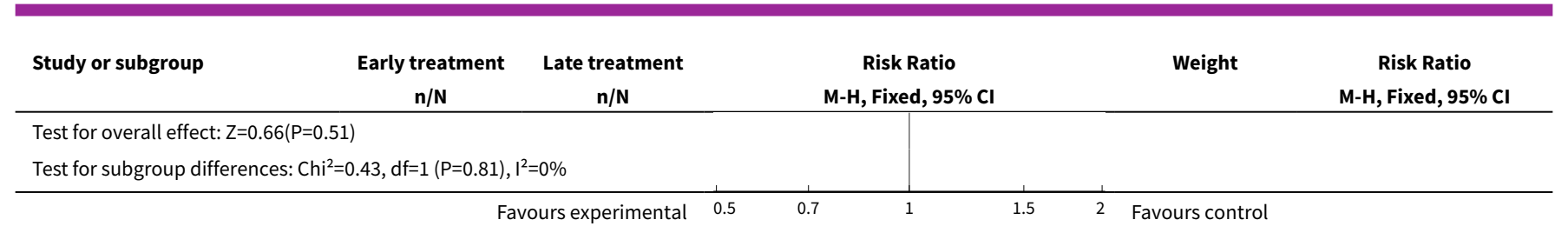

Analysis 3.4. Comparison 3 Early versus delayed selective surfactant treatment by steroid exposure, Outcome 4 BPD or death at 28 to 30 days.

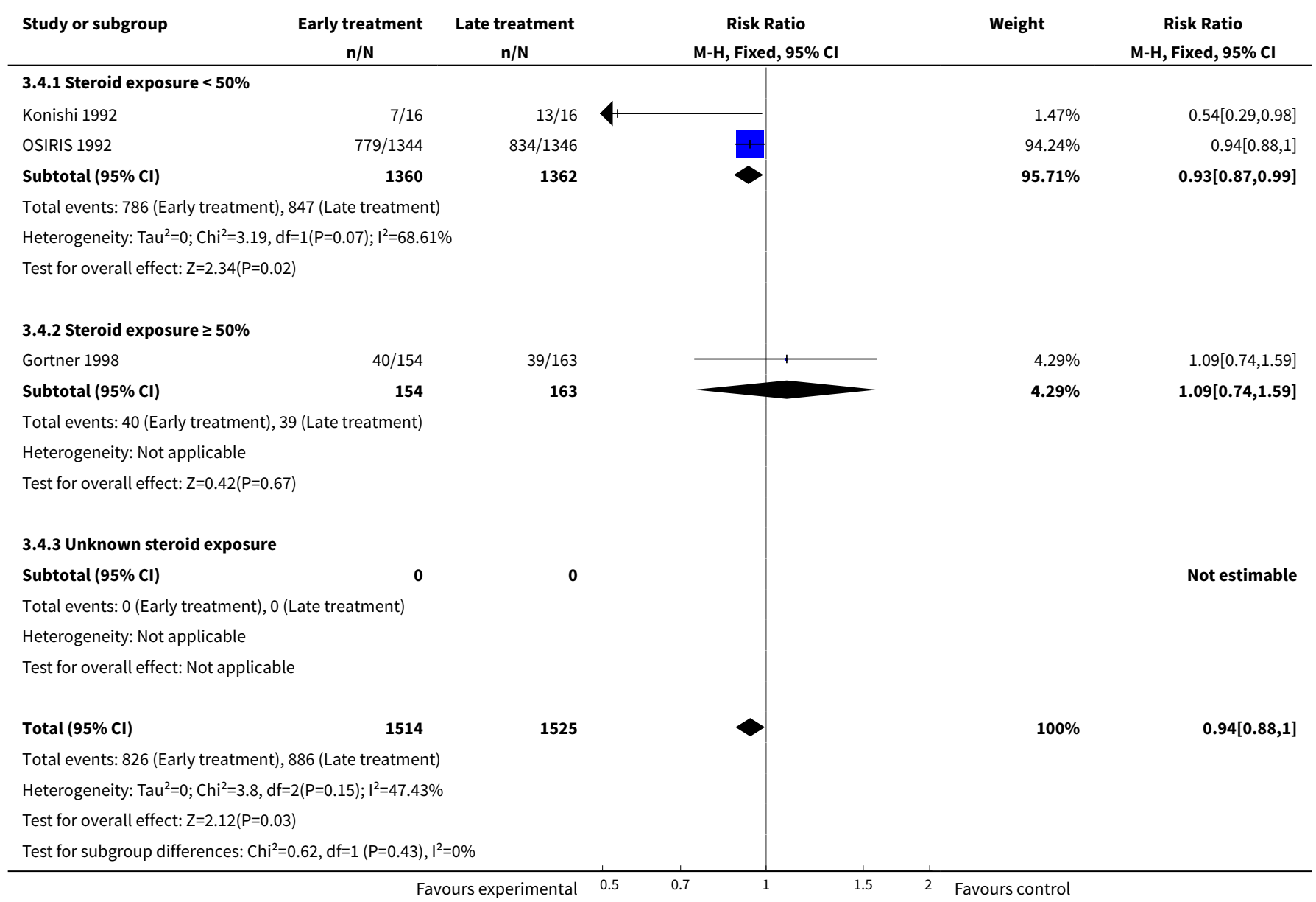

\section{Analysis 3.5. Comparison 3 Early versus delayed selective surfactant} treatment by steroid exposure, Outcome 5 Chronic lung disease.

\begin{tabular}{|c|c|c|c|c|c|}
\hline Study or subgroup & $\begin{array}{c}\text { Early Treat- } \\
\text { ment } \\
n / N\end{array}$ & Late Treatment & $\begin{array}{c}\text { Risk Ratio } \\
\text { M-H, Fixed, 95\% CI }\end{array}$ & Weight & $\begin{array}{c}\text { Risk Ratio } \\
\text { M-H, Fixed, 95\% Cl }\end{array}$ \\
\hline \multicolumn{6}{|c|}{ 3.5.1 Steroid exposure < $\mathbf{5 0 \%}$} \\
\hline OSIRIS 1992 & $106 / 1344$ & $151 / 1346$ & & $89.08 \%$ & $0.7[0.55,0.89]$ \\
\hline Plavka 2002 & $4 / 21$ & $7 / 22$ & & $4.04 \%$ & $0.6[0.2,1.75]$ \\
\hline Subtotal (95\% Cl) & 1365 & 1368 & & $93.12 \%$ & $0.7[0.55,0.88]$ \\
\hline
\end{tabular}




\begin{tabular}{|c|c|c|c|c|c|}
\hline Study or subgroup & $\begin{array}{c}\text { Early Treat- } \\
\text { ment } \\
n / N \\
\end{array}$ & $\mathrm{n} / \mathrm{N}$ & $\begin{array}{c}\text { Risk Ratio } \\
\text { M-H, Fixed, 95\% Cl }\end{array}$ & Weight & $\begin{array}{c}\text { Risk Ratio } \\
\text { M-H, Fixed, } 95 \% \mathrm{Cl}\end{array}$ \\
\hline $\begin{array}{l}\text { Total events: } 110 \text { (Ea } \\
\text { Heterogeneity: } \text { Tau }^{2}= \\
\text { Test for overall effect }\end{array}$ & $\begin{array}{l}58 \text { (Late Treatmer } \\
1(P=0.77) ; I^{2}=0 \%\end{array}$ & & & & \\
\hline \multicolumn{6}{|c|}{ 3.5.2 Steroid exposure $\geq \mathbf{5 0} \%$} \\
\hline Gortner 1998 & $7 / 154$ & $12 / 163$ & & $6.88 \%$ & $0.62[0.25,1.53]$ \\
\hline Subtotal $(95 \% \mathrm{Cl})$ & 154 & 163 & & $6.88 \%$ & $0.62[0.25,1.53]$ \\
\hline $\begin{array}{l}\text { Total events: } 7 \text { (Early } \\
\text { Heterogeneity: Not a } \\
\text { Test for overall effect }\end{array}$ & Late Treatment) & & & & \\
\hline \multicolumn{6}{|c|}{ 3.5.3 Unknown steroid exposure } \\
\hline Subtotal $(95 \% \mathrm{Cl})$ & 0 & 0 & & & Not estimable \\
\hline $\begin{array}{l}\text { Total events: } 0 \text { (Early } \\
\text { Heterogeneity: Not a } \\
\text { Test for overall effect }\end{array}$ & ate Treatment) & & & & \\
\hline Total $(95 \% \mathrm{Cl})$ & 1519 & 1531 & & $100 \%$ & $0.69[0.55,0.87]$ \\
\hline \multicolumn{6}{|c|}{ Total events: 117 (Early Treatment), 170 (Late Treatment) } \\
\hline \multicolumn{6}{|c|}{ Heterogeneity: $\mathrm{Tau}^{2}=0 ; \mathrm{Chi}^{2}=0.15, \mathrm{df}=2(\mathrm{P}=0.93) ; \mathrm{I}^{2}=0 \%$} \\
\hline \multicolumn{6}{|c|}{ Test for overall effect: $Z=3.21(P=0)$} \\
\hline Test for subgroup dif & $7, \mathrm{df}=1(\mathrm{P}=0.8), \mathrm{I}^{2}$ & & & & \\
\hline
\end{tabular}

\section{Analysis 3.6. Comparison 3 Early versus delayed selective surfactant} treatment by steroid exposure, Outcome 6 CLD or death at 36 weeks' PMA.

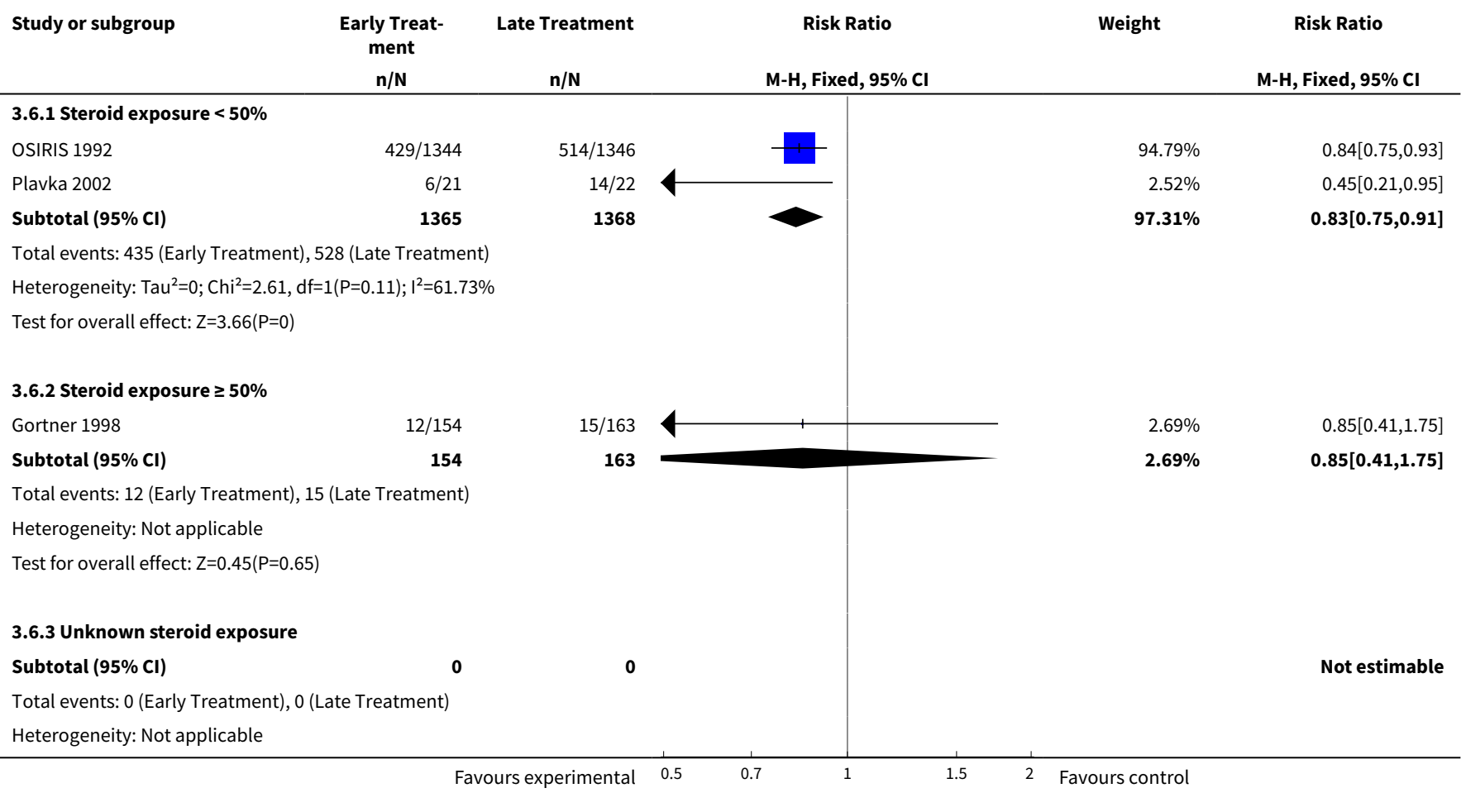




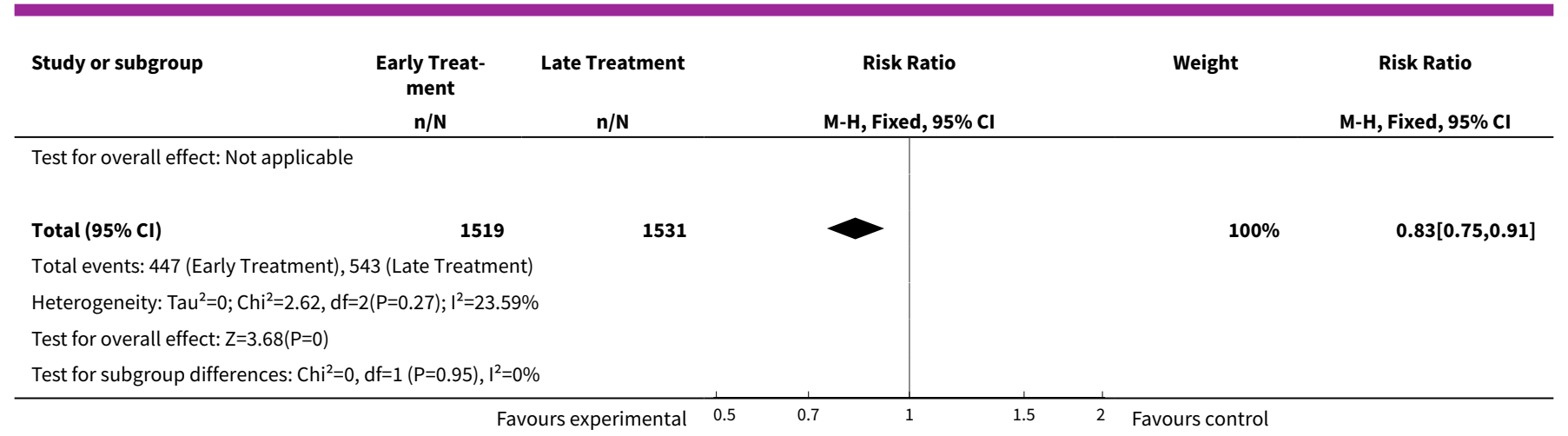

WHAT'S NEW

\begin{tabular}{lll}
\hline Date & Event & Description \\
\hline 18 September 2012 & $\begin{array}{l}\text { New citation required but conclusions } \\
\text { have not changed }\end{array}$ & $\begin{array}{l}\text { Search updated in April 2012. Two new studies were identified } \\
\text { for inclusion. }\end{array}$ \\
& $\begin{array}{l}\text { New subgroup analyses added to address gestational age groups } \\
\text { and the use of antenatal steroids. }\end{array}$ \\
& New authorship. \\
\hline 1 July 2012 & New search has been performed & $\begin{array}{l}\text { This updates the review "Early versus delayed selective surfac- } \\
\text { tant treatment for neonatal respiratory distress syndrome" (Soll } \\
\end{array}$ \\
& 1999). \\
\hline
\end{tabular}

\section{HISTORY}

Protocol first published: Issue 2, 1999

Review first published: Issue 4, 1999

\begin{tabular}{lll}
\hline Date & Event & Description \\
\hline 13 July 1999 & $\begin{array}{l}\text { New citation required and conclusions } \\
\text { have changed }\end{array}$ & Substantive amendment \\
\hline
\end{tabular}

\section{CONTRIBUTIONS OF AUTHORS}

Dr R. Soll wrote the original review. For the update in 2012, Dr. Soll reviewed the search output and helped select studies for inclusion, checked data entry, and edited the final version of the review.

For the update in 2012, F. Bahadue recreated the search, evaluated abstracts, obtained original studies, extracted and entered data, and wrote the first draft of the review.

\section{DECLARATIONS OF INTEREST}

Dr. R. Soll has previously acted as a paid consultant and invited speaker for several of the pharmaceutical companies that manufacture surfactant preparations (Abbott Laboratories, Ross Laboratories, Chiesi Pharmaceuticals, Dey Laboratories, Burroughs Wellcome).

Felicia L Bahadue has no conflicts of interest to declare. 


\section{SOURCES OF SUPPORT}

\section{Internal sources}

- No sources of support supplied

\section{External sources}

- Eunice Kennedy Shriver National Institute of Child Health and Human Development National Institutes of Health, Department of Health and Human Services, USA.

Editorial support of the Cochrane Neonatal Review Group has been funded with Federal funds from the Eunice Kennedy Shriver National Institute of Child Health and Human Development National Institutes of Health, Department of Health and Human Services, USA, under Contract No. HHSN275201100016C.

\section{INDEX TERMS}

\section{Medical Subject Headings (MeSH)}

Acute Disease; Acute Lung Injury [prevention \& control]; Chronic Disease; Drug Combinations; Fatty Alcohols [therapeutic use]; Lung Diseases [prevention \& control]; Phosphorylcholine [therapeutic use]; Polyethylene Glycols [therapeutic use]; Pulmonary Surfactants [*therapeutic use]; Randomized Controlled Trials as Topic; Respiratory Distress Syndrome, Newborn [ ${ }^{\star}$ drug therapy]; Time Factors

\section{MeSH check words}

Humans; Infant, Newborn 